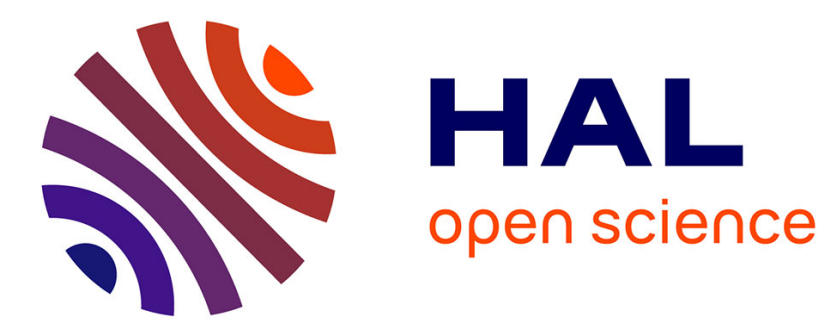

\title{
G Protein-Coupled Receptors: Dominant Players in Cell-Cell Communication
}

Joël Bockaert, Sylvie Claeysen, Carine Becamel, Sylvie Pinloche, Aline

Dumuis

\section{> To cite this version:}

Joël Bockaert, Sylvie Claeysen, Carine Becamel, Sylvie Pinloche, Aline Dumuis. G Protein-Coupled Receptors: Dominant Players in Cell-Cell Communication. International Review of Cytology, 2002, A Survey of Cell Biology, 212, pp.63-132. 10.1016/S0074-7696(01)12004-8 . lirmm-00268610

\section{HAL Id: lirmm-00268610 https://hal-lirmm.ccsd.cnrs.fr/lirmm-00268610}

Submitted on 5 Mar 2020

HAL is a multi-disciplinary open access archive for the deposit and dissemination of scientific research documents, whether they are published or not. The documents may come from teaching and research institutions in France or abroad, or from public or private research centers.
L'archive ouverte pluridisciplinaire HAL, est destinée au dépôt et à la diffusion de documents scientifiques de niveau recherche, publiés ou non, émanant des établissements d'enseignement et de recherche français ou étrangers, des laboratoires publics ou privés. 


\section{G-Protein-Coupled Receptors (GPCRs): \\ dominant players in cell-cell communication}

Joël Bockaert, Sylvie Claeysen, Carine Bécamel, Sylvie Pinloche* and Aline Dumuis

UPR CNRS 9023 - 141 Rue de la Cardonille - 34094 Montpellier Cedex 5, France

Tel: +33 467142930 - Fax: +33 467542432 - e.mail: bockaert@ ccipe.montp.inserm.fr

*LIRMM, 161 rue Ada, 34392 Montpellier Cedex 5, FRANCE 


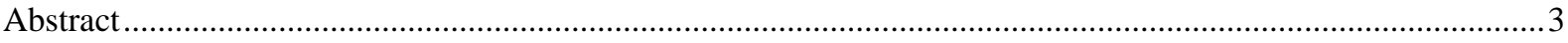

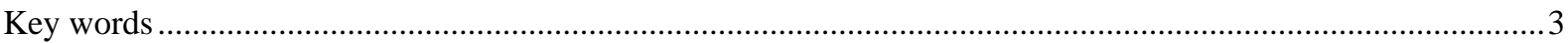

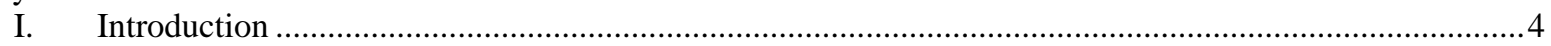

II. GPCR signal transduction: from a "ménage à trois" to a "ménage à quatre" .................................... 6

A. Rodbell's model: the receptor, the transducer (G-protein) and the effector ................................6

B. New partners in GPCR activation of G-proteins: the RGS ..................................................9

III. The different families of GPCRs and their binding sites........................................................ 14

IV. Homo- and hetero-dimerization of GPCRs, and interaction with other

TM proteins: a revolution in current concepts of GPCR structures and functions...........................24

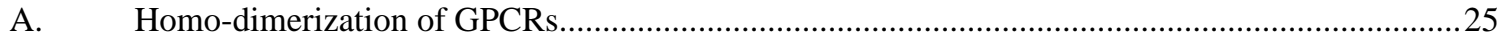

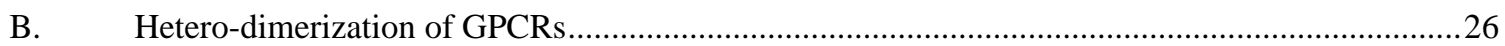

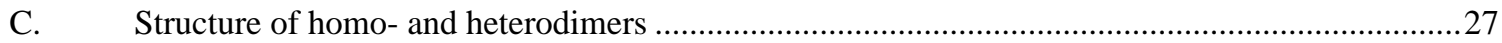

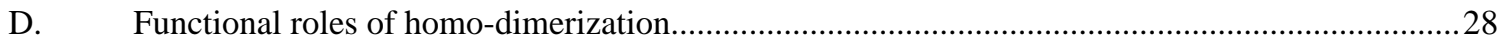

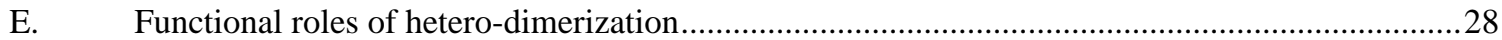

F. Hetero-dimerization of GPCRs with receptor channels .......................................................29

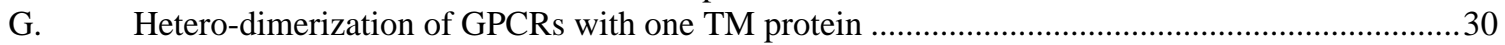

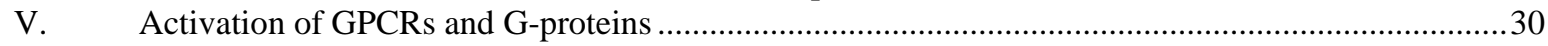

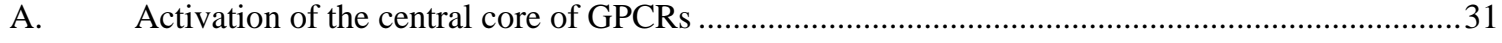

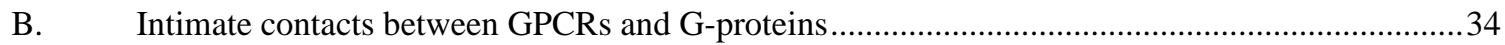

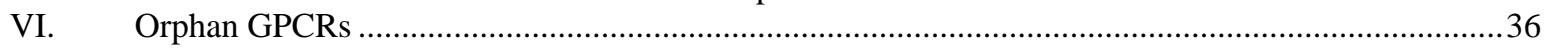

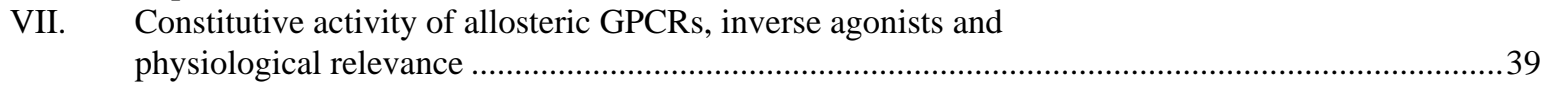

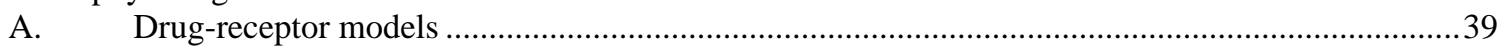

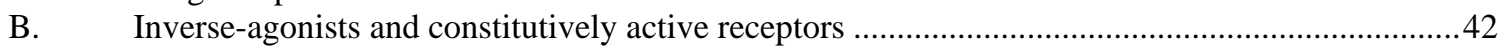

C. Constitutively active wild-type receptors in native tissues...............................................45

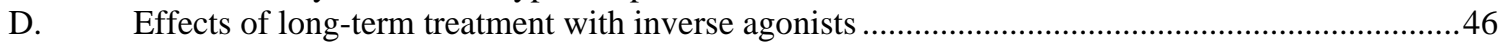

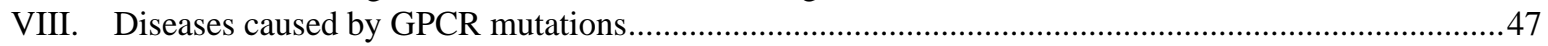

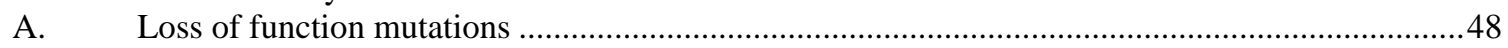

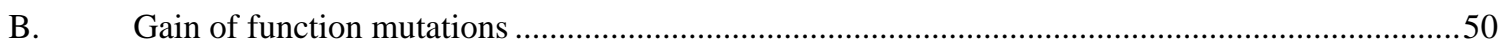

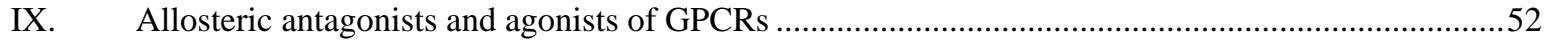

X. Post-trancriptional and post-translational modifications of GPCRs:

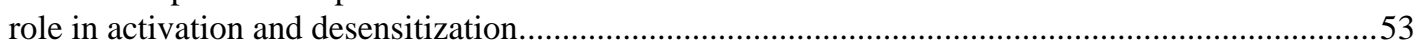

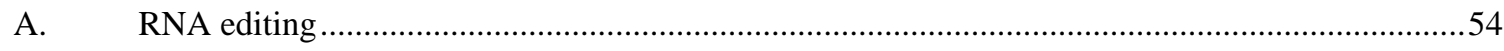

B. Phosphorylation associated with desensitization ............................................................5

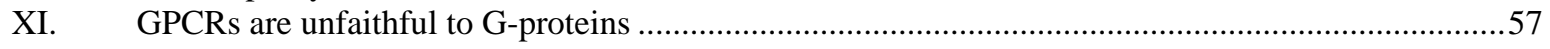

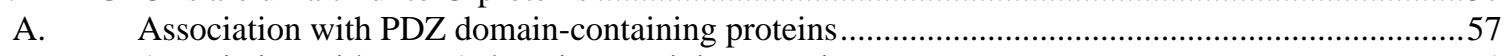

B. Association with EVH1-domain containing proteins ...........................................................61

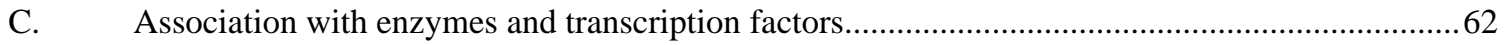

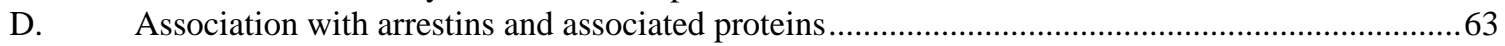

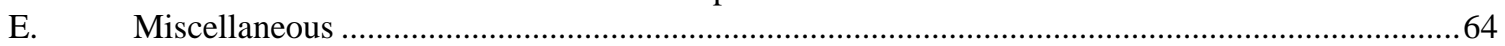

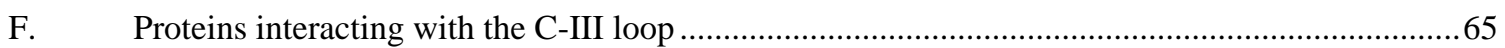

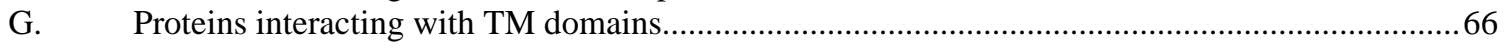

XII. Cross-talk between the GPCRs and the Tyrosine receptor kinase (TRK)

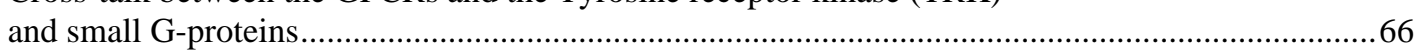

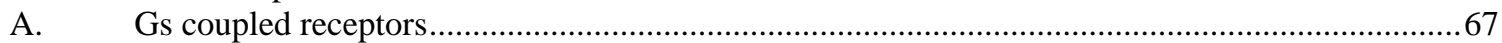

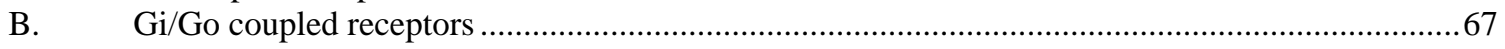

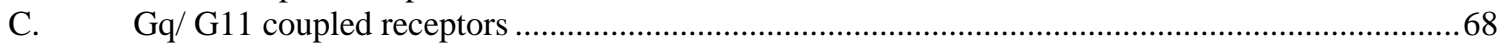

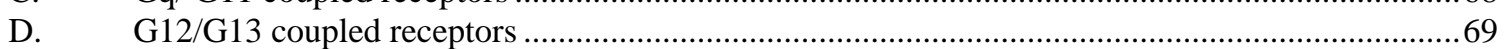

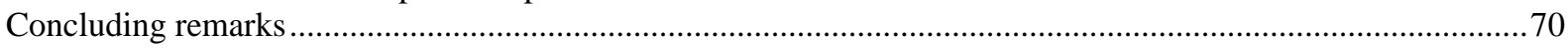

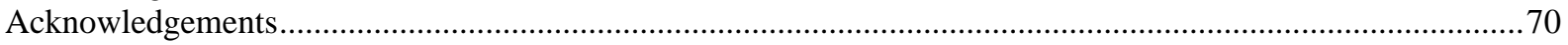

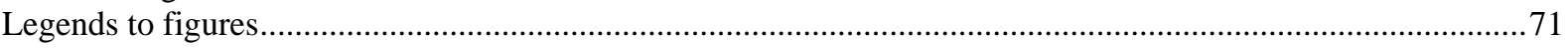

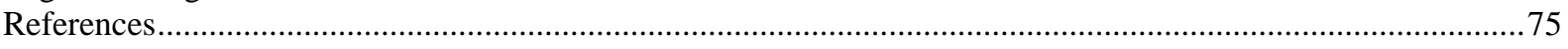

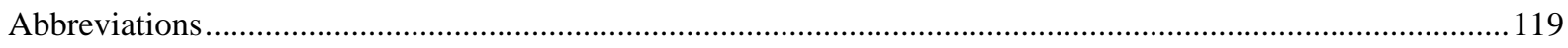




\begin{abstract}
The G-protein-coupled receptors (GPCRs) are the most numerous and the most diverse type of receptors ( 1 to $5 \%$ of the complete invertebrate and vertebrate genomes). They transduce messages as different as odorants, nucleotides, nucleosides, peptides, lipids and proteins. There are at least eight families of GPCRs showing no sequence similarities and using amazing different domains to bind ligands and activate a similar set of G-proteins. Homo- and hetero-dimerization of GPCRs seem to be the rule and in some cases, an absolute requirement for activation. There are about 100 orphan GPCRs in the human genome which will be used to find new message molecules. Mutations of GPCRs are responsible for a wide range of genetic diseases. The importance of GPCRs in physiological processes is illustrated by the fact that they are the target of the majority of therapeutical drugs and drugs of abuse.
\end{abstract}

\title{
Key words
}

G-protein-coupled receptors, G-proteins, orphan receptors, dimerization, constitutive activation, inverse agonism, genetic diseases, cellular signaling, desensitization. 


\section{Introduction}

In 1957, when most of the readers of this review were still at elementary school or perhaps not even born, Sutherland and Rall were busy describing the basic properties of an enzyme, the adenylate cyclase (now called adenylyl cyclase (AC)), its activation by hormones such as epinephrine and glucagon, and its well known product cAMP (Sutherland and Rall, 1958). Ten years later, AC was still believed to be a unique allosteric enzyme regulated by the binding of hormones on a regulatory site. In the late 60s, Rodbell and Birnbaumer demonstrated that fat cell AC is activated by multiple hormone receptors, in a non-additive manner, and they proposed that AC and hormonal receptors are distinct (Birnbaumer and Rodbell, 1969). A proposal which was subsequently demonstrated by Orly and Schramm (Orly and Schramm, 1976). Rodbell and Birnbaumer also demonstrated that receptors need a third partner to activate AC, the GTP-binding protein (G-protein). G-proteins plays the gobetween receptors and AC (Rodbell et al., 1971). In 1983, Gs (the G-protein which activates the AC) was the first G-protein to be purified by Gilman and co-workers (Northup et al., 1983). Purification of rhodopsin, the GPCR activated by light was achieved in 1967 (Shields et al., 1967) whereas the first purification of a hormonal GPCR (the $\beta$-adrenergic receptor, $\beta$ AR) was carried out by Lefkowitz's team in 1981 (Shorr et al., 1981).

Twenty years later, GPCRs constitute one of the largest known categories of proteins. Based on the fact that these receptors are all formed of seven transmembrane domains (TM-I to TMVII) and are believed to activate G-proteins, GPCRs are generally assumed to form a single super-family (Baldwin, 1993; Bockaert and Pin, 1998; Bockaert and Pin, 1999; Bourne, 1997b; Josefsson, 1999; Kolakowski, 1994; Wess, 1997). However, as we all know, the more data we accumulate, the more complex is the picture. Indeed, in this review, we will see that : (1) the comparison of primary amino-acid sequences leads to the multiplication of GPCR 
families (up to 8 families can be recognized to date) (Bockaert and Pin, 1999; Josefsson, 1999); (2) some GPCRs may signal by interacting with non G-proteins, in addition or not to their G-protein signaling (Hall et al., 1999). Calling some of them GPCRs may therefore be inaccurate. A large number of seven transmembrane proteins, (such as latrophilin, the receptor for the spider toxin $\alpha$-latrotoxin), EMR1 (human cell surface glycoprotein F4/80), BAI-1 (brain-specific angio-genesis inhibitor), or Methuselah, classified as LNB-TM7 (seven TM domains containing a long N-terminal extracellular region) have been described (Stacey et al., 2000). The long N-terminal domain of LNB-TM7 contains several repeats such as EGF repeats, thrombospondin type 1 repeats, olfactomedin homologous regions, galactose-binding lectin homologous region and laminin AG-type repeats. If the coupling of LNB-TM7 proteins to G-proteins exists, it has only been demonstrated for latrophilin (Stacey et al., 2000). More recently, another seven transmembrane protein having 20-25\% identity with the core domain of family 3 GPCRs, but devoid of the long and specific extracellular domain which is the characteristic of this family (see figure 4), has been cloned (Brauner-Osborne and Krogsgaard-Larsen, 2000). Whether or not it is a GPCR, remains to be demonstrated. GPCRs clearly represent some of the oldest devices devoted to signal transduction, present in protozoa and earliest diploblastic metazoa (New and Wong, 1998; Vernier et al., 1995), slime mold (Devreotes, 1994), yeast (Dohlman et al., 1991), plants (Josefsson and Rask, 1997; Plakidou-Dymock et al., 1998), invertebrates (Bargmann, 1998; Rubin et al., 2000) and vertebrates (Bockaert and Pin, 1999). GPCRs represent 5\% Caenorhabditis elegans (1100 genes) (Bargmann, 1998), 1\% Drosophila (160 genes) (Rubin et al., 2000) and certainly 1-3\% of vertebrate genomes (more than 1000 genes) (Bockaert and Pin, 1999).

During evolution, "molecular tinkering" of GPCR genes has been used to adapt their structure to recognize a wide range of environmental stimuli and regulatory molecules involved in cellcell communication. The success of this adaptation was tremendous (Bockaert and Pin, 1999; 
Yokoyama et al., 1999). GPCRs are implicated in recognizing messages as diverse as light

(Shichida and Imai, 1998), $\mathrm{Ca}^{2+}$, odorants of different chemical nature, amino acids, peptides, lipids, nucleotides, as well as proteins (figure 1A). They control the activity of effectors as diverse as enzymes (AC, phosphodiesterases, phospholipases...), ionic channels $\left(\mathrm{Ca}^{2+}, \mathrm{K}^{+}, \mathrm{Cl}^{-}\right.$ ...), transport vesicles, kinases and are key elements in physiological functions such as morphological movements during gastrulation and germ band extension, hormonal regulatory systems, synaptic transmission, and recognition of sensory stimuli (light, odorants, taste molecules, as well as pain stimuli). The odorant GPCRs are certainly the most abundant ones in most organisms representing roughly $50 \%$ of the total number of GPCRs in Drosophila and vertebrates and as much as $90 \%$ in Caenorhabditis elegans.

Such an important device for cell-cell communication in multi-cellular organisms, has been a key element during their evolution. In addition, GPCRs are direct or indirect targets of the vast majority of available therapeutics drugs, as well as drugs of abuse (Roush, 1996; Stadel et al., 1997). Somatic and genetic mutations of GPCRs generate various pathologies (Birnbaumer, 1995; Spiegel, 1996; Van Sande et al., 1995).

Since several recent reviews are available (Bockaert and Pin, 1999; Gether, 2000; Wess, 1997), we will summarize here most of the biochemical, pharmacological and physiological knowledge of this old (almost 50 years...), but still rapidly growing field.

\section{GPCR signal transduction: from a "ménage à trois" to a "ménage à quatre"}

A. Rodbell's model: the receptor, the transducer (G-protein) and the effector We have already recalled the crucial experiments Rodbell performed on fat cells during the late 60's (Birnbaumer and Rodbell, 1969). The non-additivity of several hormonal receptors 
on AC activity posed a problem for M. Rodbell who thought it inconceivable that several hormonal receptors could structurally anneal to the same enzyme (Rodbell, 1995). After long discussions with O. Hechter, M. Rodbell introduced the concept of hormone action as "a ménage à trois". This concept which is still valid today, was based on cybernetic theories of information introduced by N. Wiener (Weiner, 1961). The receptor was the equivalent of the discriminator, the $\mathrm{AC}$ was the amplifier and the notion of transducer was introduced. The transducer was a coupling device designed to allow communication between the discriminator and the amplifier. At that time, the nature of the transducer was unknown and Rodbell had no idea that it could be a GTP binding protein. This idea came a few months later after a series of experiments when the team observed that the binding of the hormone (the ${ }^{125}$ I-glucagon) was acutely modified (increase in $\mathrm{k}_{\mathrm{on}}$ and $\mathrm{k}_{\mathrm{off}}$, reduction of the "steady state" binding level) by some components used in the AC assay. After a clever search for the "culprit", they found that it was GTP. Not only GTP is modifying the hormonal binding characteristics, but they found that GTP was an absolute requirement to observe, in vitro, the stimulation of AC by receptors: the transducer was a GTP binding protein (G-protein) (Rodbell, 1992).

The purification of the G-protein by A. Gilman (Northup et al., 1983) revealed the trimeric nature of G-proteins. In their inactive form (state 1, figure 1B), the three subunits $(\mathrm{G} \alpha, \mathrm{G} \beta$,

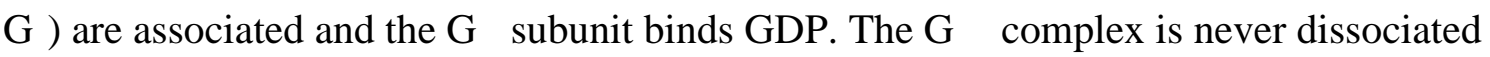
under biological conditions and can be considered as a single unity. GPCRs can be considered as releasing exchange factors, functions homologous to those of monomeric small G-proteins GRF/GEF (GRF: GDP releasing factors or GEF: guanine nucleotide exchange factor). Their role is to catalyze the GDP release from G $\alpha$. State 2 is then obtained (figure 1B) and is characterized as an empty nucleotide site. The G $\alpha$ and GPCR have different structures than in states 1 and 3; they are tightly associated (Chabre and Deterre, 1989). The GPCR affinity for agonists is generally higher than under states 1 and 3. It corresponds to the high agonist 
affinity state obtained in binding experiments when performed in vitro in the absence of GTP. State 2 is a short-life transition state. In vivo, GTP rapidly associates with the Go empty state; dissociation then occurs. The G $\alpha-G T P$ and G $\beta \gamma$ are split and dissociated from the activating GPCR (state 3, figure 1B). G $\alpha$ and G $\beta \gamma$ can activate their respective effectors (figure 1B) (Bockaert and Pin, 1998; Clapham and Neer, 1993; Hamm, 1998). In some cases, both G $\alpha$ and G $\beta \gamma$ are needed to activate their effector. This is the case for the activation of type II, IV and presumably type VII AC (Defer et al., 2000; Tang and A.G., 1991) and some L-type Ca ${ }^{2+}$ channels (figure 1B). GTP hydrolysis is the only event that stops the activation of both G $\alpha$ -

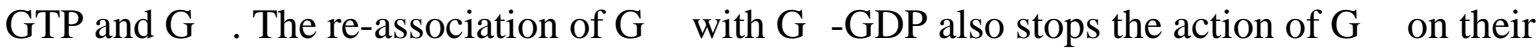
effectors. GTP hydrolysis is certainly tightly controlled, especially by proteins like RGS (regulators of G-protein signaling) as discussed in section II-B (de Vries et al., 2000). There are 17 genes (leading to at least 23 proteins) coding for $\mathrm{G} \alpha, 5$ for $\mathrm{G} \beta$ and 12 for $\mathrm{G} \gamma$ (Hamm, 1998). Not all the conceivable heterotrimeric G $\alpha \beta \gamma$ complexes are indeed formed in

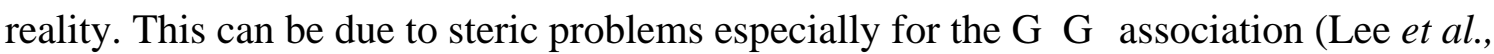
1995). The G $\alpha$ proteins are divided into 4 families based on sequence similarities (figure 1B): - the Gos family which also comprises Goolf (localized in olfactory neurons but also in striatum);

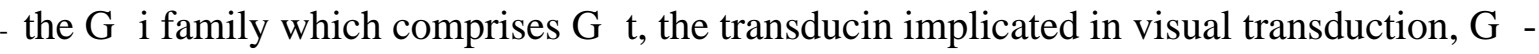

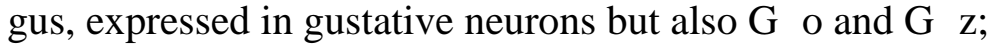

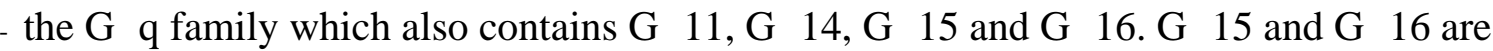
homologous proteins expressed in hematopoïtic cells of rodents and human respectively (Gomeza et al., 1996b; Offermanns and Simon, 1995; Parmentier et al., 1998). They have the remarkable property of being stimulated by most GPCRs, those which are naturally coupled to Gq but also those coupled to Gi/Go and even Gs; the $\mathrm{G} \alpha 12, \mathrm{G} \alpha 13$. family. 
The crystal structures of $\mathrm{G} \alpha(\mathrm{G} \alpha \mathrm{t}$ and $\mathrm{G} \alpha \mathrm{i})$, as well as $\mathrm{G} \alpha \beta \gamma$, have been obtained at a resolution of 2-3Å, in (a) an inactive form (GDP form) (Lambright et al., 1994; Lambright et al., 1996; Mixon et al., 1995; Wall et al., 1995) (state 1, figure 1B); (b) under a transition mimicking state (GDP-AlF4-) associated (Tesmer et al., 1997a), or not (Sondek et al., 1994)

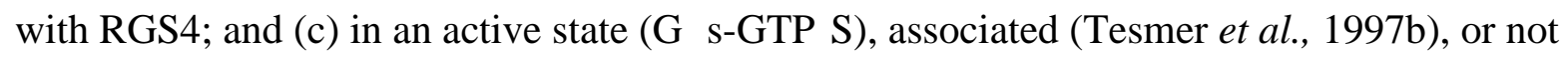
(Coleman et al., 1994; Noel et al., 1993) with the catalytic domains of AC. G $\alpha$ subunits contain two domains, a domain involved in binding and GTP hydrolysis (the G domain) which is structurally similar to the super-family of GTPases, including small G-proteins and elongation factors (called the "ras"-like domain), and a unique helical domain (ho) that is inserted within the ras domain, which buries GTP in a pocket (figure 2A, B). The G $\beta$ subunits have a 7-membered $\beta$-propeller structure based on 7 WD-40 repeats. G $\gamma$ subunits interact with G $\beta$ through their N-terminal coiled-coil and all along G $\beta$. G $\alpha$ subunits are myristoylated and/or palmitoylated at their N-terminus, and $\mathrm{G} \gamma$ is farnesylated or geranyl-geranylated at its C-terminal. These acyl and prenyl groups are the only devices controlling the association between the heterotrimeric G $\alpha \beta \gamma$ complex with the membrane. In section V, we will discuss the mechanism by which GPCRs interact and activate G-proteins.

Reversible palmitoylation may possibly play a regulatory role in GPCR action (Wedegaertner and Bourne, 1994). Long-term modulation of G-protein mRNA levels has been reported (Milligan, 1993), but at protein levels, G-proteins are generally stable molecules with long lives (Brabet et al., 1991).

B. New partners in GPCR activation of G-proteins: the RGS For many years now, it has been known that Ras-type, monomeric, small G-proteins have a very low GTPase activity. Specific proteins called GAP (GTPase activating proteins) are an absolute requirement for the deactivation of these proteins (Boguski and McCormick, 1993). 
Any reduction in the capacity of GAP to activate Ras GTPase activity is a common cause of malignancies. The mechanism of activation of Ras GTPase activity by GAP involves the coordination between a Gln $\left(\mathrm{Q}^{61}\right.$ often mutated in oncogenic Ras) and a $\operatorname{Thr}\left(\mathrm{T}^{35}\right)$ of Ras, a glutamic acid residue of GAP protein and a water molecule. The GAP protein puts its glutamic "finger" inside the Ras protein (Bourne, 1997a). Interestingly, in heterotrimeric Gproteins, which have an intrinsic GTPase activity 1000-fold higher than the small G-proteins,

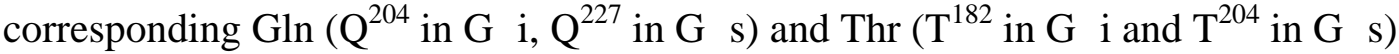
coordinate a glutamic acid "finger" localized within the molecule itself $\left(\mathrm{R}^{178}\right.$ in Goi and $\mathrm{R}^{201}$ in Gos localized in linker 2) and a water molecule to hydrolyze the GTP molecule. Note that mutations of the corresponding Gln and Arg in Gi or Gs have been found in tumors, and pathologies such as McCune-Albright and pseudo-hypoparathyroidism. In addition, ADPribosylation of the $\mathrm{R}^{201}$ of Gs by cholera-toxin reduces its GTPase activity leaving the protein to be constitutively active. Overproduction of cAMP within the intestinal epithelial cells is responsible for diarrheas (Spiegel, 1996; Spiegel et al., 1993).

For a long time, GTPase activity of purified heterotrimeric G-proteins was recognized to be still too slow to explain the deactivation of cellular processes under the regulation of Gproteins. The $\mathrm{t} 1 / 2$ of hydrolysis of GTP by most G $\alpha$ proteins is in the $10-20$ s range (Gilman,

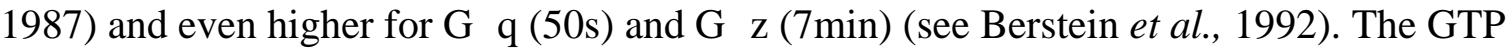

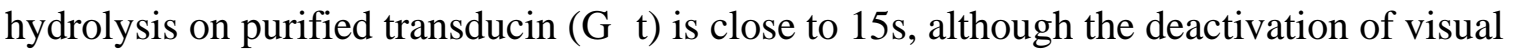
signals is close to 0.2s (Navon and Fung, 1984; Vuong and Chabre, 1990). The Gat effector, GMPc phosphodiesterase, has been proposed to be the GAP which accelerates GTP hydrolysis, but this is still a matter of controversy (Antonny et al., 1993; Arshavsky and Bownds, 1992). The idea that the effector can serve as GAP came from the fact that the effector of Gaq, the phospholipase C $\beta 1$, is a GAP (Berstein et al., 1992). The effector, and in particular the phosphodiesterase (PDE) of rods, clearly act in synergy with the real GAP of 
Gat, the RGS9 both in vitro and in vivo (He et al., 1998; Tsang et al., 1998). The discovery of RGS came simultaneously from genetic studies and double hybrid studies using Gai3 as bait. In the latter, de Vries et al. were able to "fish" for a protein that they called GAIP (G $\alpha$ interacting protein) (De Vries et al., 1995; de Vries et al., 2000; Dohlman and Thorner, 1997). In Caenorhabditis elegans, and Sacchromyces cerevisiae, mutations within two genes, EGL10 and SST2, respectively, were responsible for a delay in egg laying and reduced desensitization to pheromones respectively (de Vries et al., 2000; Dohlman and Thorner, 1997). In fact, the three proteins, GAIP, EGL-10 and SST2 were homologous within a 130 residue domain, now called the RGS domain (de Vries et al., 2000; Wieland and Chen, 1999). This domain is responsible for the binding to G $\alpha$ proteins. RGS accelerate 50 to 100 times GTP hydrolysis of G $\alpha$ proteins which reduces the t1/2 of GTP hydrolysis to a value compatible with the "physiology" (Berman et al., 1996).

There are now 30 mammalian RGS proteins (de Vries et al., 2000), which differ considerably in size (17 to $160 \mathrm{kDa}$ ). The mechanism of action of RGS is certainly still in its infancy. The known role of RGS is of course to have a GAP function. This is confirmed in vitro but also in vivo although mainly in recombinant systems. RGS clearly attenuate the action of GPCRs as shown with RGS4 and GAIP which inhibit the transduction of bradykinin (Goq-mediated) and somatostatin (Goi-mediated) receptors (de Vries et al., 2000). In addition, the binding of RGS to G $\alpha$, results in an inhibition of the effectors-G $\alpha$ associations. RGS4 is able to inhibit GTP $\gamma$ S-activated PLC- $\beta 1$. Similarly, PLC- $\beta 1$ can displace RGS4 bound to G $\alpha q-G D P-A l F 4$ (de Vries et al., 2000). Finally, as already discussed, the increase in G $\alpha$ GTP hydrolysis and therefore accumulation of G $\alpha$-GDP levels, accelerates the deactivation of GPCR transducing effects mediated via $\beta \gamma$. Over-expression of RGS1, RGS2, RGS4, and RGS8, accelerates the turning off of G-protein-coupled inward rectifying $\mathrm{K}^{+}$channels (GIRKs), known to be activated by $\beta \gamma$ (Doupnik et al., 1997). More surprisingly, RGS also result in an increase in 
the $\mathrm{k}_{\text {on }}$ of GIRK activation by $\beta \gamma$ (Doupnik et al., 1997). Rod photo-response recovery is slowed in mice lacking RGS9-1 (Chen et al., 2000). RGS is made of $9 \alpha$-helical structures that form two lobes, one made of helical structures $\alpha 1, \alpha 2, \alpha 3, \alpha 8, \alpha 9$, and the other made of helical structures $\alpha 4, \alpha 5, \alpha 6, \alpha 7$ (Tesmer et al., 1997a). The base of $\alpha 3-\alpha 4, \alpha 5-\alpha 6$ and the $\alpha 7-\alpha 8$ loops, constitutes the contacting surface with the $G \alpha$ subunit. The latter is made by the $\mathrm{N}$-terminal domain of $\mathrm{G} \alpha$, switches I and II, and to a lesser extent switch III (switch regions are the domains where there is a dramatic conformational change during the GTP cycle (see figure 2) (Sprang, 1997). Switch II is also part of the interacting surface of $G \alpha$ with $\beta \gamma$ and the effector AC as revealed in the co-crystal Gas-GTP $\gamma \mathrm{S}-\mathrm{AC}$ (Tesmer et al., 1997b). However, crystallographic data indicate that Goi can accommodate RGS4 and AC at the same time (Sunahara et al., 1997). Similarly, the synergism between the effect of RGS9 and PDE $\gamma$ on the GTPase activity of Gat, suggests that both the effector and RGS can interact simultaneously with some $\mathrm{G} \alpha$ (He et al., 1998). This is a priori somehow contradictory with the idea that RGS can antagonize the $\mathrm{G} \alpha$-effector association. The stabilization of the switch regions, and in particular switch II, in which the important Arg residue implicated in GTP hydrolysis is localized (see early discussion), is certainly the basis of RGS action (Natochin et al., 1998). Several residues of RGS4 $\left(S^{85}, E^{87}, N^{88}, L^{159}, D^{163}, S^{164}, R^{167}\right)$ encircle the Thr $\left(T^{182}\right.$ in Goi1) engaged in GTP hydrolysis. $\mathrm{N}^{88}, \mathrm{~L}^{159}$ and $\mathrm{R}^{167}$ seem to be the most important for the formation of the $\mathrm{Thr}^{182}$ pocket (Druey and Kehrl, 1997). However, more work has to be done to understand the structural basis of RGS mechanisms of action.

One major question is whether there is specificity in the RGS-G $\alpha$ interaction. To make things simple, most of the RGS proteins tested so far are GAP for Gi/Go and Gq. p115Rho GEF (and perhaps PDZ-rhoGEF) (PDZ: a 90-residue domain first recognized in the post-synaptic

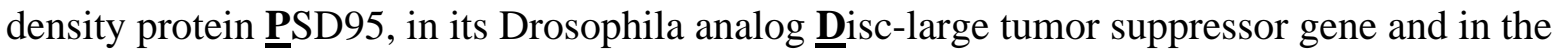

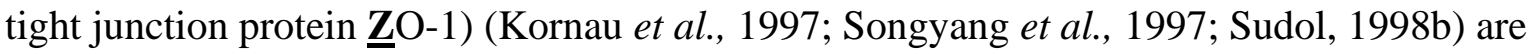


specific GAP for G12/G13. No RGS have been found for Gas (de Vries et al., 2000). This

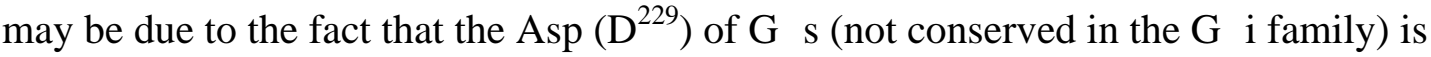
localized in switch II, and may constitute a barrier for its interaction with RGS. However, some sub-domains of AC-V have been found to be able to accelerate both activation and deactivation of Gs (Siderovski et al., 1999).

Most RGS are present in the cytosolic pool, in plasma membrane (PM) and in intracellular membrane pools (especially membrane vesicles for GAIP). They can be recruited by G $\alpha$ at the PM but can also have an intrinsic TM domain (RET-RGS1) and be palmitoylated (GAIP, RGS4). RGS 12 has a PDZ domain which binds the C-terminus of IL-8B and CXCR2 receptors (Snow et al., 1998). RGS 12 also binds and inhibits $\mathrm{N}$-type $\mathrm{Ca}^{2+}$ channels (Schiff et al., 2000).

In addition to the RGS domain, RGS contain other structural domains, at the N-terminal and the C-terminal positions. These structural domains connect RGS to other interacting proteins (de Vries et al., 2000).

In conclusion, the "ménage à quatre" in the GPCR transduction is already well established. The implication of RGS in cancer, seizures, and drug tolerance is just starting to be investigated but is certainly promising (de Vries et al., 2000). The regulation of RGS7 by TNF and the endotoxin LPS is also particularly interesting. Indeed, these pro-inflammatory and sleep-inducing compounds inhibit the degradation of RGS7 by the proteasome system in the brain. This effect may certainly lead to a decrease in the Gai/o-mediated antiinflammatory GPCR action and an increase in the secondary anti-inflammatory effects of TNF mediated via Gs-associated GPCRs (Benzing et al., 1999). Another intriguing finding is that newly discovered proteins, such as AGS (activator of Gprotein signaling) stimulate the GDP/GTP exchange on G $\alpha$ proteins (Cismowski et al., 2000). The AGS1 is a ras-related protein possibly making a new link between small $\mathrm{G}$ and 
heterotrimeric G. Rapsynoid, a Drosophila protein, shares 43\% identity with AGS (Parmentier et al., 2000b). RGS14 has been proposed to be a Rap effector (Bidot et al., 2000). As such, the "ménage à quatre" may already be old-fashioned.

\section{The different families of GPCRs and their binding sites}

Sequence comparison between the different GPCRs has revealed the existence of different receptor families sharing no sequence similarities (Bockaert and Pin, 1998; Bockaert and Pin, 1999; Josefsson, 1999; Kolakowski, 1994). However, all these receptors seem to share a central core domain made up of seven transmembrane domains (TM-I to -VII) which are helical tubes connected by three extracellular loops (E-I to E-III) and 3 cytoplasmic loops (C-I to $\mathrm{C}$-III). Within the C-terminus, a C-IV loop has been proposed to be formed between the TM-VII and the cysteine residues that are palmitoylated (figures 1 and 2). The crystal structure of rhodopsin revealed that this loop is an $\alpha$-helical structure (helice VIII, figure 2D). We have constructed a phylogenic tree of 56 GPCRs taken from diverse eucaryotes including yeast, slime mold (Dictyostelium discoideum), and the only GPCR cloned so far in plant is from Arabidopsis thaliana. Protein sequences (excluding N-terminal and C-terminal domains) were multi-aligned and a tree was calculated using Clustal W. No further functional driven hypotheses were taken into consideration to adjust the alignment. Using this simple method we were able to classify these receptors into 8 distinct families (figure 3). Only a few receptors were not included in these families, the pheromone yeast GPCRs (STE2 and STE3 and pheromone P), the Arabidopsis thaliana putative GPCR (Josefsson and Rask, 1997; Plakidou-Dymock et al., 1998), the Methuselah protein (an LNB-7TM protein of Drosophila) (Lin et al., 1998), the mutation of which extended life-span and stress resistance, and the Drosophila putative taste receptors (GR = gustatory receptor (Clyne et al., 2000) family). In 
addition, these receptors did not group together. In this section, we will not describe the receptor for trehalose, recently cloned in Drosophila which may represent a new subclass or family, (Clyne et al., 2000).

We (Bockaert and Pin, 1998; Bockaert and Pin, 1999) and others have previously described 6 families of GPCRs, using generally more polished alignments (for example; without the intraand extracellular loops). These families are again found in the present study: Family 1: the rhodopsin receptor family, family 2: the PTH, PACAP, VIP receptor family, family 3: the glutamate metabotropic receptor (mGluR) family, family 4: one vomeronasal pheromone receptor family $(\mathrm{VN})$, family 5: the frizzled receptor family, and family 6 , the cAMP receptor family. There are now two other families, family 7: the vertebrate T2R gustative receptor family which responds to bitter tastants (Adler et al., 2000; Chandrashekar et al., 2000) and family 8 which corresponds to a new family of putative odorant receptors in Drosophila (Clyne et al., 1999; Gao and Chess, 1999; Vosshall et al., 1999).

Receptors from different families share no sequence similarity, suggesting that we are in the presence of a remarkable example of molecular convergence.

Family 1: contains most of the GPCRs including receptors for odorants (more than one thousand). One important recent event concerning this family was published in 2000. This is the crystal structure (2.8 $\AA$ ) of rhodopsin (figure 2D) (Palczewski et al., 2000). As expected from previous electron diffraction structures of rhodopsin (Unger et al., 1997), the TM-I, IV, VI and VII are bent at Pro $(\mathrm{P})$ residues, although in TM-I it is not significant and in TM-IV it is present at the extracellular end. Prolines are conserved in all members and play a crucial role in activation. TM-V with a proline in its middle is almost straight, while TM-II has a kink in the middle at the Gly-Gly doublet. TM-IV and VII are shorter than the other TMs.

The following residues and sequences are considered to represent the signature of this family: 
(a) an Asp (D) of TM-II which is essential for the coupling to G-proteins and which can form a hydrogen bond with the side chain of a conserved Asn (N) in TM-I and an Ala (A) in TMVII in rhodopsin (Palczewski et al., 2000). In other receptors, the Asp in TM-II may have a possible contact with an Asn in TM-VII. Complementing mutations in many receptors argue for such a direct interaction. In any case, TM-I, TM-II and TM-VII are in close contact (figure 2D) (Zhou et al., 1994; Zhou and Fishman, 1991);

(b) the Asp-Arg-Tyr (DRY) or Glu-Arg-Tyr (ERY) or Glu-Arg-Tryp (ERW) sequences found at the N-terminus of C-I are highly conserved and are directly involved in G-protein activation (Oliviera et al., 1994; Scheer et al., 1996). Mutation of Arg in this sequence suppresses G-protein activation. This sequence is surrounded by hydrophobic residues from H-II (Pro ${ }^{71}$ and Leu ${ }^{72}$ in rhodopsin), C-II (V136V137V138 and Phe ${ }^{148}$ in rhodopsin), H-V ( $\mathrm{Leu}^{226}$ and $\mathrm{Val}^{230}$ in rhodopsin) and $\mathrm{H}-\mathrm{VI}\left(\mathrm{Val}^{250}, \mathrm{Met}^{253}\right.$ in rhodopsin). This region is likely to be a surface contact with G-proteins (Palczewski et al., 2000);

(c) basic residues at the end of C-III ( $\mathrm{Lys}^{245}, \mathrm{Lys}^{248}, \mathrm{Arg}^{252}$ in rhodopsin) are currently found at that position crucial for specific activation of G-proteins (Bockaert and Pin, 1999; Bourne, 1997b);

(d) other intra-domain constraints are likely to be important to keep the receptor under an inactive " $\mathrm{R}$ " state. This includes a bridge constraint made by Lys ${ }^{296}$ of TM-VII which is covalently attached (Schiff base) to the retinal. The retinal protonated Schiff base also makes a salt bridge with Glu ${ }^{113}$ in TM-III (figure 5). Mutation of Lys ${ }^{296}$ generates a constitutively active receptor and causes retinitis pigmentosa (Robinson et al., 1992). In $\alpha_{2}$-adrenergic receptors, this salt bridge is likely to be between an Asp of TM-III and a Lys in TM-VII. Mutations of these residues resulted in constitutive activation of the receptors and complementing mutations reverse this phenotype (Porter and Perez, 1999). Interestingly, the binding of the protonated amine of adrenaline probably disturbs the salt bridge due to its 
binding to the Asp of TM-III. However, a Lys in TM-VII is not conserved in all biogenic amine receptors. Other constraints include hydrophobic interactions between a conserved IleLeu doublet of TM-III and a Phe of TM-VI (mutations of these residues constitutively activate the C5a-receptors) (Baranski et al., 1999), and a bridge between a highly conserved Tyr in TM-VII and Asn in TM-II (Palczewski et al., 2000).

A cysteine-cysteine bridge is very well conserved between E-I and E-2 in all GPCRs of this family. In rhodopsin, the $\mathrm{N}$-terminal domain contains two anti-parallel $\beta$-sheets which are located just below the E-II loop, which also contains two anti-parallel $\beta$-sheets. All four $\beta$ sheets, as well as most parts of E-II, make an extracellular plug blocking the exit from the pocket (Palczewski et al., 2000). The E-II loop is almost inserted within the TM core, whereas the $\mathrm{Asn}^{2}$ is above the E-III loop in contact with $\mathrm{Asp}^{282}$. The role of the plug in rhodopsin is not clear, however, it may prevent the all-trans retinal from projecting out of the pocket during activation. It remains to be seen if such plugs are found in other GPCRs of this family. Depending on the size and the location of the binding site, we have proposed to divide this family into three subfamily groups (Bockaert and Pin, 1999).

Subfamily 1a contains GPCRs for small ligands such as rhodopsin, catecholamines, odorants, small peptides, ATP etc.... the binding site of agonists is localized inside the 7 TMs at a

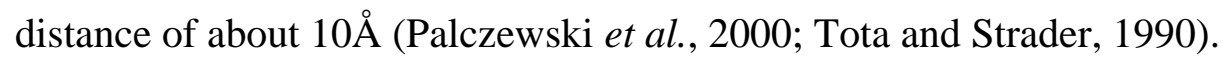

The sub-family $1 \mathrm{~b}$ includes most GPCRs for peptides in which the binding site is localized at the external face of the receptors, including the N-terminal, the extracellular loops and the TM domains at the frontier of the extracellular surface (Bockaert and Pin, 1999).

Family 1c includes GPCRs for glycoproteins such as TSH, LH etc... The binding site is essentially extracellular, within the $\mathrm{N}$-terminal domain and made by a structure containing a series of leucine-rich repeats forming a crescent with the concave inner surface, consisting of $\beta$-sheets which may bind ligands (Kajava et al., 1995; Phang et al., 1998). 
The intracellular loops contain the classical three loops and at least in rhodopsin, but likely in many other GPCRs, a fourth loop (C-IV) (figures 1A and 2D) made of an $\alpha$-helical structure after TM-VII and before the cysteines of the C-terminal which are palmitoylated. The corresponding peptides are reported to prevent rhodopsin from activating the G-protein, transducin (Gt) (Palczewski et al., 2000). Such an $\alpha$-helical structure in this C-IV region has been demonstrated in turkey $\beta$-adrenergic receptors by solution NMR spectroscopy (Jung et al., 1996). This $\alpha$-helical structure is amphiphilic, as is the C-terminal domain of C-III. Both regions are likely to be very important for the specificity and the potency of GPCRs to activate G-proteins. The C-II and C-IV project laterally from either side of the receptor creating a platform of $43 \AA$ that may be broad enough to allow rhodopsin to interact simultaneously with the $\alpha$ and $\gamma$ subunits of G-proteins (Bourne and Meng, 2000) (figure 2C). Several GPCRs from this family have particularly interesting structural or functional properties:

Protease activated GPCRs (PARs) are activated when thrombin (PAR1, PAR3, PAR4 receptors) or trypsin and tryptase (PAR2 and PAR4) binds to and cleaves its amino-terminal exo-domain to unmask a new receptor amino-terminus. This new amino terminus then serves as a tethered peptide agonist ligand, binding intra-molecularly to the body of the receptor (Coughlin, 1999).

In a number of herpes and pox viruses, genes coding for homologues of chemokines, as well as chemokine GPCRs (Wells and Schwartz, 1997) have been described. The virus chemokine ligands are antagonists used to prevent the local recruitment of leukocytes. The function of virus GPCRs is less clear, some of them are constitutively active (see section VII) and may be implicated in malignancies such as Kaposi's sarcoma or acceleration of vascular diseases (Geras-Raaka et al., 1998). 
The entry of the human immuno-deficiency virus (HIV) into human CD4-positive cells depend on the presence of both CD4 receptors and a GPCR which is generally CXCR4 (natural ligand, SDF-1 - stromal derived factor 1) in T-tropic HIV-1 strains and CCR5 (natural ligands RANTES, MIP-1 $\alpha$, MIP-1 $\beta$ - macrophage inflammatory protein 1 alpha) in M-tropic strains. T-tropic strains infect primary $\mathrm{T}$ lymphocytes and appear at the late stage of the disease, whereas M-tropic strains infect monocytes / macrophages and have been shown to be responsible for viral transmission (Berger et al., 1999). The mechanism of HIV entry involves the interaction of the envelope protein gp160 (cleaved to gp120 and gp41 by the cell) with CD4, the association of gp120 with GPCR and finally the dissociation of gp41 from gp120 and its participation in the virus fusion. A mutant allele of the CCR5 gene, $\Delta 32$ ccr5 found in Caucasian populations was shown to provide homozygotes with a strong resistance to infection by HIV (Samson et al., 1996). A north to south gradient was found with the highest allele frequency in Finland and Mordvinia (16\%) and the lowest in Sardinia (4\%). Data indicates that most ccr5 alleles originate from a single mutation event that took place a few thousand years ago in Northeastern Europe. The high frequency suggests that a selection advantage is associated with this mutation (Libert et al., 1998). Note that the CCR5 variants account for a small proportion of individuals with apparent HIV resistance. In addition, a structural variant of the chemokine receptors CX3CR1 appears to confer a more rapid progression of the pathology (Faure et al., 2000). Drugs interfering with CCR5 and CXCR4 are actively researched and constitute a hope in the treatment of this infection.

Family 2: this family includes the smallest number of GPCRs (figure 3) including those for secretin, calcitonin, CRF (corticotropin releasing factor), VIP (vasoactive intestinal peptide), PACAP (pituitary adenylate cyclase activating polypeptide) and glucagon. The binding site is mostly extracellular, but E loops and part of the TMs exposed to extracellular domains are likely to be involved. Calcitonin and PACAP receptor N-terminal splice variants have been 
described to have a modified pharmacology (Houssami et al., 1994; Pantaloni et al., 1996). Note that we have included a series of receptors within this family (although figure 3 indicates that they are structurally closed, but distinct from the classical list of hormonal receptors quoted above) which belong to LNB-TM7 (see introduction). This is the case for the latrotoxin receptor, a receptor for the toxin of the spider called "Black widow" known to strongly stimulate neurotransmitter release in $\mathrm{C} \mathrm{Ca}^{2+}$-independent manner (Davletov et al., 1998; Krasnoperov et al., 1997). Also included in this subgroup is EMR1, a LNB-TM7 protein localized in macrophages, BAI-1 and also BAI-2 and BAI-3 are LNB-TM7 proteins exclusively expressed in brain (Stacey et al., 2000).

Family 3: the prototype of this family are the metabotropic glutamate receptors (mGluRs). The first one to be described was coupled to phosphoplipase C (Nicoletti et al., 1986; Sladeczek et al., 1985). Now eight mGluRs have been cloned and classified into three groups, group I (mGluR1 and 5) coupled to PLC, group II (mGluR2 and 3 and a Drosophila receptor DmGluRA - Parmentier et al., 1996) and group III (mGluR4, -6, -8). An N-terminal truncated mGluR is proposed to be a putative glutamate taste receptor (Chaudhari et al., 2000) negatively coupled to adenylyl cyclase (Pin et al., 1999; Pin and Duvoisin, 1995). The signaling properties of mGluRs are far more complex (Fagni et al., 2000). Family 3 now includes: calcium-sensing receptors (CASR), a specific family of pheromones (VR) (reviewed in Bargmann, 1997), putative vertebrate taste receptors (TR) (Hoon et al., 1999), $\mathrm{GABA}_{\mathrm{B}} \mathrm{R} 1$ (Kaupmann et al., 1997) and $\mathrm{GABA}_{\mathrm{B}} \mathrm{R} 2$ receptors (Jones et al., 1998a; Kaupmann et al., 1998; Kuner et al., 1999; Ng et al., 1999; White et al., 1998), and goldfish basic amino-acids receptor (Speca et al., 1999). Closed, but slightly distinct, is the bride of seven-less (BOSS), which is a ligand of seven-less tyrosine kinases involved in eye differentiation in Drosophila (Hart et al., 1990). However, the fact that a G-protein is required for its action has not yet been demonstrated. 
Family 3 GPCRs possess a typical but unique feature, being that they have a large extracellular domain that shares some sequence similarities with bacterial periplasmic amino acid-binding proteins (PBPs), such as the leucine / isoleucine / valine-binding protein (LIVBP) (O'Hara et al., 1993) and acetamide-binding protein (Amic-C) (Bessis et al., 2000). These proteins are characterized by a bilobate structure with ligand binding in a cleft which can open or close like a Venus flytrap. The extracellular domain of mGluR1, 4 and $\mathrm{GABA}_{\mathrm{B}} 1$ in isolation, is enough to bind their ligands (Malitschek et al., 1999; Okamoto et al., 1998), a conclusion supported by the possibility of exchanging the extracellular domains of some of them keeping the entire pharmacology associated (Parmentier et al., 2000a; Pin et al., 1999) and by the recent crystallization of extracellular domains of mGluR1 associated or not with glutamate (Kunishima et al., 2000).

Mutagenesis of both mGluRs (Pin et al., 1999), GABA 1 (Galvez et al., 2000a; Galvez et al., 2000b), and CASR as well as crystal structures of mGluR1 (Kunishima et al., 2000), modelization of mGluRs (Bessis et al., 2000) and GABA $\mathrm{B}$ (Galvez et al., 2000a), give a clear picture of the binding sites.

Kunishima et al. (Kunishima et al., 2000) determined the structure of two mGluR1 unliganded forms and a complex form with glutamate (figure 4). All crystals contain two protomers (dimer) connected via a disulfide bridge between Cys ${ }^{140}$. The dimerization of GPCRs will be the subject of section IV. The N-terminal binding domain is made of two lobes each made of two domains separated by three linkers (L 1-3) in the following order on the primary sequence and starting from the N-terminus: LB1a, L1, LB2a, L2, LB1b, L3, LB2b, followed by a cysteine-rich $(\mathrm{CR})$ domain not present in $\mathrm{GABA}_{\mathrm{B}} \mathrm{Rs}$. The binding site is indeed localized within the cleft at the surface of lobe 1a (LB1a) in the open state and the bound ligand also contacts with lobe 2 (LB2a) in the closed state. Each domain can adopt an open or closed state and in addition, the two protomers in the dimer can adopt two positions called 
"active $=\mathrm{A}$ " and "resting $=\mathrm{R}$ ", differing in the orientation of an $\alpha$-helical interface. The two un-liganded crystallized forms correspond to a closed-open /A and an open-open / $\mathrm{R}$ form respectively, whereas the liganded form corresponded to only one of them, the closed-open/A. There was no difference in the latter due to the presence of glutamate. This confirms previous thoughts proposing that agonists stabilize rather than induce active forms. The feasibility of other putative conformers has been demonstrated such as closed-open/R, closed-closed/R, open-open/A and closed-closed/A (Kunishima et al., 2000). In the open state, glutamate binds to two residues conserved in the entire mGluR family including Drosophila and Caenorhabditis elegans. These residues are $\operatorname{Ser}^{165}$ and $\mathrm{Thr}^{188}$ in mGluR1 which form hydrogen bonds with the $\alpha$-carboxyl and the $\alpha$-amino-group, respectively. The $\gamma$-carboxyl is linked to a conserved $\mathrm{Arg}$ residue $\left(\mathrm{Arg}^{78}\right.$ in mGluR1) via a $\mathrm{H}_{2} \mathrm{O}$ molecule and to $\mathrm{Tyr}^{74}$ via a hydrogen bond (Kunishima et al., 2000). Additional contacts exist in the open, as well as in the closed state (Kunishima et al., 2000).

Mutagenesis and modeling of $\mathrm{GABA}_{\mathrm{B}} \mathrm{R} 1$ binding sites indicate that the carboxyl of GABA (equivalent of the $\gamma$-carboxyl of glutamate) binds to $\operatorname{Ser}^{246}$ (homologue of $\operatorname{Ser}^{165}$ of mGluR1 which by the $\alpha$-carboxyl) in LB1a, whereas its amino group binds Asp $^{471}$ in LB1b (Galvez et al., 2000a). $\operatorname{Ser}^{269}$ (homologue of Thre ${ }^{188}$ in mGluR1) is necessary for the potentiation of $\mathrm{GABA}_{\mathrm{B}} \mathrm{R} 1$ activation by $\mathrm{Ca}^{2+}$, suggesting that $\mathrm{Ca}^{2+}$ can compensate the lack of the $\alpha$-amino group of GABA (Galvez et al., 2000b).

Family 4: this is another family of putative pheromone receptors (VN1,-6) cloned from

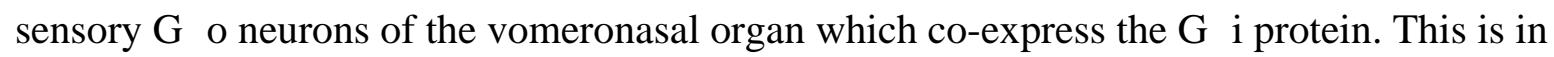
contrast to the observation that VRs from family three are expressed in vomeronasal neurons, which also express Goo (Bargmann, 1997).

Family 5: the frizzled receptor family (11 members identified in mice) which are either activated or inhibited by Wnt proteins (the name is derived from mouse Int- 1 and Drosophila 
Wingless) and control embryonic development, cell proliferation and determination (Patapoutian and Reichardt, 2000; Perrimon, 1996). These receptors activate two downstream signaling pathways; one controls gene transcription and the other G-protein mediated $\mathrm{Ca}^{2+}$ influx. The immediate proteins activated by frizzled receptors are unknown, but the important APC (adenomatous polyposis coli) protein, often mutated in colorectal cancer, lies in its pathway. This family also contains receptors for "smooth" which are interesting because they appear to be under a permanent negative control of "patched", a 10 TMs receptor for the morpho-genetic factor "hedgehog". The binding of hedgehog to patched releases this inhibition (Perrimon, 1996; Ruiz i Altaba, 1997). MOM-5 and LIN-17, are Caenorhabditis elegans GPCRs, the latter required for certain asymmetric cell divisions.

Family 6: this family of cAMP receptors has only been described in the slime mold called Dictyostelium discoideum and are implicated in chemo-attraction (Kim et al., 1998; Klein et al., 1988).

Family 7: this family are taste receptors (T2R) of vertebrates and mediate bitter taste via activation of gustducin, a G-protein which activates cGMP phosphodiesterase and homologue to transducin (Adler et al., 2000; Chandrashekar et al., 2000).

Family 8: this is the family for odorant Drosophila olfactory receptors (DOR) localized in antenna and maxillary palp (Clyne et al., 1999; Gao and Chess, 1999; Vosshall et al., 1999). In conclusion to this section on the diversity of GPCRs and to follow the idea that evolution has "tinkered" GPCRs to adapt their structure to a wide range of ligands having very different structures (Bockaert and Pin, 1999), we can notice that genes coding for 7 TM proteins may have fused with genes coding for binding domains of other proteins to generate genes coding for new families of GPCRs. The same binding domains may also have fused with one TM protein to generate other receptors. Such a situation is found in glycoprotein hormone GPCRs in which the extracellular binding site is composed of several leucine repeats, similar to those 
found in Toll receptors (one TM receptor) implicated in inflammation (see Hsu et al., 1998; Kajava et al., 1995). Secretin and frizzled receptors both share a cysteine-rich extracellular amino terminus that is thought to be involved in ligand binding and which is conserved in diverse proteins including several one TM receptor tyrosine kinases such as those of the Ror family or the MusSK family (Xu and Nusse, 1998). Furthermore, as already discussed, the binding site of family 3 is homologous to the binding site of ionotropic glutamate receptors (Armstrong et al., 1998) Ami-C (Bessis et al., 2000) and atrial natriuretic peptide/guanylate cyclase receptors and procaryote proteins such as PBPs (see http://www.pharmsci.org/, volume 1, issue 2).

\section{Homo- and hetero-dimerization of GPCRs, and interaction with other TM proteins: a revolution in current concepts of GPCR structures and functions}

For many years, the classical view of GPCR / G-protein coupling stoichiometry was thought to be one receptor for one G-protein. However, there was some evidence in favor of the formation of dimers and even oligomers. Experimental evidence was provided in the early 80 's by several groups, with the use of radiation inactivation, which indicated that GPCRs, Gproteins and $\mathrm{AC}$ acted as functional units that were larger than predicted for simple monomeric structures (Fraser and Venter, 1982; Salahpour et al., 2000; Schlegel et al., 1979). This was modeled by M. Rodbell in the early 90's (Rodbell, 1995). In addition, it was not conceivable that binding of ligands on the extracellular domain, like the one present in family 3 GPCRs, could modify the structure of the TM domains and intracellular loops without using dimerization or oligomerization, in order to induce an allosteric change in the whole structure. This situation is similar to that demonstrated in tyrosine kinase receptors (Changeux and Edelstein, 1998). 


\section{A. Homo-dimerization of GPCRs}

The recent interest in dimerization of GPCRs arose from functional studies in which inactive point-mutated (angiotensin AT1) (Monnot et al., 1996) or chimeric receptors ( $\alpha 2-\mathrm{AR}-\mathrm{m} 3$ muscarinic composed of the first five TM domains of one receptor and the last two TM domains of the other receptor), were not functional and did not bind ligands, but recovered these properties when co-expressed (Maggio et al., 1993). In the case of the chimeric receptors, both $\alpha 2-\mathrm{AR}$ binding and $\mathrm{m} 3$ binding as well as coupling were restored which indicates that the inter-dimerization restored two "correct" binding pockets. Similarly, coexpression of CASRs that harbor inactivating mutations in distinct domains, could also partially rescue $\mathrm{Ca}^{2+}$ responses (Bai et al., 1999). In contrast, some mutated and truncated GPCRs have been shown to behave as dominant negatives. This constitutes another indication of dimerization. In the case of truncated V2-vasopressin and CCR5 chemokine receptors, the dominant negative effect was due to intracellular retention (Benkirane et al., 1997; Vila-Coro et al., 2000; Zhu and Wess, 1998). This may indicate that dimerization is, at least for some GPCRs, required for trafficking to the membrane. This role of dimers for trafficking to the membrane has also been demonstrated for the $\mathrm{GABA}_{\mathrm{B}}$ heterodimer (Margeta-Mitrovic et al., 2000). In addition, the dominant negative effect of CCR5 32 has been proposed to be the reason for the slow onset of the disease observed in AIDS patients who are heterozygotes for this mutation (Benkirane et al., 1997; Vila-Coro et al., 2000). In addition to functional studies, co-immunoprecipitation of differentially epitope-tagged receptors has allowed a great number of studies to demonstrate the reality of the dimerization. More interesting, dimerization has been demonstrated in vivo (in cellulo) using FRET (fluorescence resonance energy transfer) in the case of alpha-mating factor receptor in living yeast (Overton and Blumer, 2000), or somatostatin receptors (Rocheville et al., 2000b) and 
BRET (bioluminescence resonance energy transfer) in the case of $\beta 2$-AR (Angers et al., 2000).

In total, dimerization has been found so far in the following receptors:

- family 1 GPCRs: $\beta 2$-adrenergic (Herbert et al., 1996), angiotensin AT1 (Monnot et al., 1996), $\delta$-opioid (Cvejic and Devi, 1997), m3 muscarinic, somatostatin (Rocheville et al., 2000b), vasopressin V2 (Schulz et al., 2000), dopamine D1 (George et al., 1998), bradykinin-B2 (Quitterer et al., 1999);

- family 3 GPCRs: mGluR1 and mGluR 5 (Kunishima et al., 2000; Okamoto et al., 1998;

Romano et al., 1996; Tadokoro et al., 1999; Tsuji et al., 2000), and CASR (Bai et al., 1998;

Goldsmith et al., 1999);

- $\alpha$-mating factor GPCR (Overton and Blumer, 2000).

This is not an exhaustive list.

B. Hetero-dimerization of GPCRs

The first surprising observation that GPCRs can form heterodimers came from family 3 . Cloning of $\mathrm{GABA}_{\mathrm{B}}$ receptors revealed that they are composed of two non-functional subunits $\left(\mathrm{GABA}_{B} \mathrm{R} 1\right.$ and $\left.\mathrm{GABA}_{\mathrm{B}} \mathrm{R} 2\right)$ sharing sequence similarity. Co-expression of $\mathrm{GABA}_{\mathrm{B}} \mathrm{R} 1$ and $\mathrm{GABA}_{\mathrm{B}} \mathrm{R} 2$ gave rise to a functional receptor, efficiently coupled to G-proteins (Jones et al., 1998a; Kaupmann et al., 1998; Kuner et al., 1999; White et al., 1998). Recently, more surprises came from the observations that somatostatin and dopamine D2 GPCRs (Rocheville et al., 2000a), $\kappa$ and $\delta$ (Jordan and Devi, 1999), as well as $\mu$ and $\delta$ opioid receptors (George $e t$ al., 2000), angiotensin AT1 and bradykinin-B2 (AbdAlla et al., 2000) can heterodimerize. 
C. Structure of homo- and heterodimers

The diversity of solutions selected during evolution to form homo- and heterodimers is quite surprising, but may indicate that formation of such dimers is crucial for generating diversity of coupling and pharmacology.

Homo-dimerization via the $\mathrm{N}$-terminal domain is found in the following receptors:

bradykinin-B2 receptors (AbdAlla et al., 1999), mGluR1,5 (Kunishima et al., 2000; Okamoto et al., 1998; Romano et al., 1996) and CASR (Goldsmith et al., 1999). In the case of CASR and mGluRs, dimerization occurs via one conserved Cys residue localized on lobe I of the LIVBP binding site (Goldsmith et al., 1999; Kunishima et al., 2000; Romano et al., 1996; Tsuji et al., 2000). The S-S bond is not the only mechanism of dimerization (Robbins et al., 1999). This bond certainly functions as an inter-promoter linker to increase the concentration of dimers (Kunishima et al., 2000). Dimerization has also been proposed to occur via the highly conserved Cys residues of E2 and E3 was found in m3 muscarinic receptors (Zeng and Wess, 1999).

Dimerization via TM regions has been suggested, following observations that peptides corresponding to sequences present in these regions and especially those from TM-VI and TM-VII, disturb dimerization and sometimes functions of $\beta 2$-adrenergic (Hebert et al., 1996), D2 dopaminergic (Ng et al., 1996), vasopressin V2 (Schulz et al., 2000) and CXCR4 receptors (Tarasova et al., 1999).

Homo and hetero-dimerization via the $\mathrm{C}$-terminal tail has been reported for $\delta$-opioid receptors (Cvejic and Devi, 1997) and $\mathrm{GABA}_{B} \mathrm{R} 1$ and $\mathrm{GABA}_{\mathrm{B}} \mathrm{R} 2$ receptors. In the latter, the interaction occurs via a coiled-coil $\alpha$-helical structure (Kammerer et al., 1999; Kuner et al., 1999). 
D. Functional roles of homo-dimerization

The first question is to find out whether agonists induce or increase dimerization. The answer is not clear, agonists either do not modify dimerization ( $\alpha$-mating receptors - Overton and Blumer, 2000), slightly induce dimerization ( $\beta 2-A R$ - Angers et al., 2000), potently induce dimerization (bradykinin B2 receptors - AbdAlla et al., 1999); somatostatin receptors Rocheville et al., 2000b) or even disrupt pre-existing dimerization ( $\delta$-opioid receptors - Cvejic and Devi, 1997). The necessity for homo-dimerization for a correct trafficking to the plasma membrane has already been discussed and is likely (Benkirane et al., 1997; Vila-Coro et al., 2000; Zhu and Wess, 1998). The absolute necessity for homo-dimerization for coupling to Gproteins has not been clearly demonstrated (Rocheville et al., 2000b) (see however $\delta$-opioid receptors - Cvejic and Devi, 1997).

E. Functional roles of hetero-dimerization

Before discussing the functional role of hetero-dimerization, evidence for such associations in naturally-existing tissues has to be discussed imperatively. In the case of $\mathrm{GABA}_{\mathrm{B}}$ receptors, extensive co-localization of $\mathrm{GABA}_{\mathrm{B}} \mathrm{R} 1$ and $\mathrm{GABA}_{\mathrm{B}} \mathrm{R} 2$ subunits (except in striatum) favors such naturally-occurring dimers (Kaupmann et al., 1998). Similarly, somatostatin and dopamine D2 receptors are co-localized in brain cortex and striatum (Rocheville et al., 2000a). An elegant experiment performed in smooth muscle cells indicates that antisense knock-out of bradykinin B2 receptors inhibit the angiotensin AT1 response (AbdAlla et al., 2000). The role of $G A B A_{B} R 1$ hetero-dimerization is now quite clear. Alone, the $G A B A_{B} R 2$ subunit, which is inactive, is required for cell surface expression of the $\mathrm{GABA}_{B} \mathrm{R} 1$ subunit (Jones et al., 1998b; Kaupmann et al., 1998; Kuner et al., 1999; Margeta-Mitrovic et al., 2000; White et al., 1998). Indeed, $\mathrm{GABA}_{\mathrm{B}} \mathrm{R} 1$ is retained in the endoplasmic reticulum through a C-terminal retention / retrieval motif Arg-Lys-Arg (RKR), reminiscent of a similar 
sequence in ATP-sensitive $\mathrm{K}^{+}$channels. Interaction of $\mathrm{GABA}_{\mathrm{B}} \mathrm{R} 1$ and $\mathrm{GABA}_{\mathrm{B}} \mathrm{R} 2$ through their C-terminal coiled-coil $\alpha$ helical structure, masks the retention signal in GABA $A_{B} R$ (Margeta-Mitrovic et al., 2000). Moreover, Galvez et al. have recently shown that the central core and intracellular domains of $\mathrm{GABA}_{\mathrm{B}} \mathrm{R} 2$ contain the molecular determinants required for recognition and activation of the proteins. The central core and intracellular domains of $\mathrm{GABA}_{\mathrm{B}} \mathrm{R} 1$ improved coupling efficacy (Galvez et al., 2001). In terms of pharmacology, hetero-dimerization may be a fine-tuning mechanism to increase the pharmacological diversity and coupling efficiency. In the AT1-bradykinin B2 dimer, the coupling of AT1 to messenger production is greatly increased by the presence of a functional or even a nonfunctional bradykinin-B2 receptor (AbdAlla et al., 2000). The pharmacology of the $\kappa-\delta$ opioid receptor dimers and $\mu-\delta$ receptor dimers are obviously different from those of the corresponding homo-dimeric corresponding receptors (George et al., 2000; Jordan and Devi, 1999). This is, of course, interesting for drug development, but at the same time, quite puzzling.

F. Hetero-dimerization of GPCRs with receptor channels The curiosity of some researchers for, strange and up to now, unbelievable associations, led Liu et al. to look for a direct protein-protein coupling between dopamine D5 (a Gs coupled GPCR) and $\mathrm{GABA}_{\mathrm{A}}$ ionotropic receptors (Liu et al., 2000). Indeed, both receptors are colocalized in dendritic shafts and the cell soma/axon hillock area where inhibitory GABAergic neurons form major post-synaptic contacts. These authors showed that the C-terminus of D5 receptors (but not D1 receptors), selectively binds the second intracellular loop of the GABA $\gamma 2$ receptor subunit. This physical association enables a mutually inhibitory functional interaction between these receptors. The physiological and therapeutic consequences of such an a priori bizarre marriage, remain to be demonstrated. 
G. Hetero-dimerization of GPCRs with one TM protein

Nina A from Drosophila melanogaster and its vertebrate homologue RanBP2, two

cyclophilin-related proteins, have been known for some years to bind opsins for folding and transport (Baker et al., 1994; Ferreira et al., 1996). In Caenorhabditis elegans, odr-4 and odr8 are required to localize a subset of odorant GPCRs to cilia of olfactory neurons (Dwyer et al., 1998). More surprising and disturbing for pharmacologists, is the report that the CRLR (calcitonin receptor-like receptor) is a virtual receptor which generates the CGRP (calcitonin gene-related peptide) receptor when associated with RAMP1 (receptor activity-modifying protein) and the adreno-medullin receptor when associated with RAMP2. RAMP1 and 2 are also required for a correct glycosylation and transport of CRLR to plasma membranes. A yeast two-hybrid screen with the C-terminal 81 residues of the D1 receptor used as bait, allowed Lezcano et al. (Lezcano et al., 2000) to fish out a one-TM protein coding clone of the P19/21 calcyon family. Calcyon and dopamine D1 GPCRs are co-expressed in macaque brain within the spines of the CA3 region of hippocampus and caudate nucleus. Interestingly, D1 coupling to Gs is shifted to Gq when co-expressed with calcyon. In brain and kidney, D1 agonists have also be found to increase 1,4,5-trisphosphate turnover (see refs in Lezcano et al., 2000).

\section{Activation of GPCRs and G-proteins}

The structures of the different families of GPCRs are so diverse, that their mechanisms of activation are also likely to be quite different, although a common fundamental mechanism may exist at the final step. 
A. Activation of the central core of GPCRs

The crucial observations that single mutations localized in intracellular loops, but also within the TMs or even in the extracellular loops or domains, may lead to constitutively active receptors, will be discussed in more detail in section VII. These data are in favor of an allosteric model in which constrained receptors $\mathrm{R}$ loses some intra-molecular constraints and undergo a conversion to an active state $\mathrm{R}^{*}$. We have already described some of these constraints in section III (figure 5). In rhodopsin, a salt bridge exists between Lys ${ }^{296}$ of TMVII (the retinal attachment site) and $\mathrm{E}^{113}$ in TM-III (the Schiff base counterion) (Palczewski et al., 2000; Robinson et al., 1992) as well as: (1) an interaction between Asn ${ }^{73}$ of TM-I and Tyr of the conserved motif NPXXY in TM-VII; (2) interactions between $\mathrm{Asn}^{55}$ in TM-I, Asp ${ }^{83}$ in TM-II and $\mathrm{Ala}^{299}$ in TM-VII, as well as $\mathrm{Asn}^{302}$ (of NPXXY) via a water molecule (the socalled "polar pocket", also described in $\alpha 1-\mathrm{AR}$ (Scheer et al., 1996) as described by (Palczewski et al., 2000). This "polar pocket" is well conserved in family 1 . In $\alpha 1$ b-AR, a salt bridge between $\mathrm{Asp}^{125}$ of TM-III, and Lys of TM-VII, constrains the receptor in the R state (Porter and Perez, 1999). Similarly, in AT-1 receptor stabilization of TM-III and TM-VII, via $\mathrm{Asn}^{111}$ of TM-III and Tyr ${ }^{292}$ of TM-VII, has been described (Groblewski et al., 1997). In C5a$\mathrm{R}$, many mutations of TM-III and TM-VI lead to constitutive activation. Some of them suggest that hydrophobic constrains occur for example between Ile $\mathrm{e}^{124} / \mathrm{Leu}^{127}$ of TM-III and Phe ${ }^{251}$ in TM-VI (figure 5) (Baranski et al., 1999). Other constraints are evident in the rhodopsin crystal (Palczewski et al., 2000) and it is likely that each receptor has its own. How these constraints are released and how agonists stabilize the active forms, remain to be elucidated. One key event is certainly a change in the environmental situation of the DRY (or ERY) sequence and the resulting protonation of the aspartic / glutamic acid (Arnis et al., 1994; Oliviera et al., 1994; Scheer et al., 1996; Scheer et al., 1997). This protonation has been directly measured in rhodopsin (Arnis et al., 1994). An indirect argument in favor of this 
hypothesis is the fact that charged-neutralizing mutations which mimic the non-protonated state of the aspartic acid, cause dramatic constitutive activation of $\alpha 1 \mathrm{~b}$, vasopressin and rhodopsin GPCRs (Cohen et al., 1993; Morin et al., 1998; Scheer et al., 1996). The role of the arginine of the DRY sequence is crucial. Its mutation impairs the response mediated by GPCRs linked to different signaling pathways ((Scheer et al., 2000) and discussion within). Two hypotheses have been proposed to define the specific role of aspartate / arginine of DRY. In the first one, arginine is constrained in the R state, in the "polar pocket", causing an ionic interaction with the conserved aspartate in TM-II (Scheer et al., 1996). Following activation and protonation of the aspartate of DRY, molecular modeling indicates that the arginine breaks its interaction with the aspartate of TM-II and shifts out of the pocket. In the second hypothesis, based on computational simulations in $\mathrm{GnRH}$ receptors, it has been suggested that, in the "inactive state", the ionic counterpart of the arginine of DRY is the adjacent aspartate (or glutamate) (Ballesteros et al., 1998). Upon activation, this ionic interaction is broken and the arginine of DRY now induces ionic interaction with the aspartate of TM-II. In favor of the latter hypothesis is the fact that mutation of the aspartate of TM-II disturbs functional coupling (see (Gether, 2000) and that in rhodopsin, the aspartate of TM-II is more strongly hydrogen-bound upon activation (Rath et al., 1993).

The physical modifications of the central core of family 1 and 2 GPCRs are far from being understood, but some data have proven to be interesting. The main message is that the intramolecular constraints between the TMs, described above, are released. This is generally associated with thermal instability (Claeysen et al., 2001; Gether et al., 1997a; Rasmussen et al., 1999) of the receptor and a separation of the TMs, leading to an increase in the crevice surface of the receptor forming contacts with G-proteins (figure 5). Displacements have been observed between TM-III and TM-VI. Using the cysteine accessibility method, Javitch et al. described that a cysteine in TM-VI $\left(\mathrm{Cys}^{285}\right)$, inaccessible to a hydrophilic sulfhydryl-reactive 
reagent in the $\mathrm{R}$ state, becomes accessible in constitutively active $\beta 2$-AR (Javitch et al., 1997). This indicates a clock-wise rotation (looking at the receptor from the cytoplasmic surface) of TM-VI. Using tryptophan UV-absorbance spectroscopy, Lin and Sakman obtained direct evidence that rhodopsin activation involves relative movements of TM-III and TM-VI (Lin and Sakmar, 1996). Site-directed labeling of single cysteines, inserted at the cytoplasmic side of the transmembrane helical structures $\left(\mathrm{Cys}^{139}\right.$ in TM-III and $\mathrm{Cys}^{285}, \mathrm{Cys}^{248}$ in TM-VI) with sulfhydryl-specific nitroxide spin labels, provides evidence for clock-wise $\left(30^{\circ}\right)$ and separation movements of TM-III and TM-VI (Farrens et al., 1996). A recent cross-linking experiment indicates that the retinal ionone is attached to $\operatorname{Trp}^{265}$ in TM-VI, just as predicted in the crystal structure in the $\mathrm{R}$ state (Borhan et al., 2000). In the $\mathrm{R}^{*}$ state, the ionone ring is cross-linked to $\mathrm{Ala}^{169}$ of TM-IV. Bourne and Meng have pointed out that if the trans-retinal interacts in such a way, this implies considerable movement of TM-III, but also movement of TM-IV and VII (Bourne and Meng, 2000). Similarly, in $\beta 2-A R$, fluorescent labeling of cysteines in TM-III and TM-VI has provided a way of measuring an increase in fluorescence (accessibility to a more polar environment), upon agonist activation (Gether et al., 1997b). Favoring the importance of the TM-III and TM-VI movements upon activation, is the fact that binding of $\mathrm{Zn}^{2+}$ to the bis-His metal ion binding site, constructed between these TMs, blocks rhodopsin, $\beta 2-\mathrm{AR}$ and PTH receptor activation (Sheikh et al., 1999; Sheikh et al., 1996). There is certainly some variability in the mechanisms by which the different families activate the central core. In family 1c, glycoprotein binding to the N-terminal part is likely to generate a special way of activation. G. Vassart's group (unpublished data) has recently proposed that the $\mathrm{N}$-terminal domain constrains the central core. This constraint would be released by the glycoprotein hormones. In the case of family 3, the twist between the two protomers of the dimer (see section III), has been proposed to be associated with a relative movement of their central cores leading to activation. 
In the section IV dealing with the dimerization of GPCRs, we have clearly shown that homoor hetero-dimerization of family 3 GPCRs is required for their activation. In family 1 GPCRs, the role of dimerization in activation is not quite as clear.

The platform formed by the intracellular loops, including intracellular loop C-IV (43A), is sufficient for simultaneous interaction with the carboxyl terminal of $\mathrm{G} \alpha$ and $\mathrm{G} \gamma$ (Bourne and Meng, 2000).

B. Intimate contacts between GPCRs and G-proteins Numerous studies have been dedicated to the research of GPCR domains that may confer specificity of interaction with particular G-proteins. The general idea is that most intracellular domains, including the C-IV loop and the C-terminal domain, are implicated, whereas no consensus sequences have been recognized. It is possible that each receptor has designed its own solution. For two very close receptors like vasopressin V2 (coupling to Gs) and V1a (coupling to $\mathrm{Gq}$ ), the specificity of interaction is localized in C-I and C-III loops, respectively (Liu and Wess, 1996). In many family 1 GPCRs, the C-terminal part of the C-III loop determines the specificity. When four VTIL residues of the VTRTIL sequence, localized in the $\mathrm{C}$-terminal of $\mathrm{C}$-III of muscarinic $\mathrm{m} 2$ receptors (coupled to $\mathrm{Gi}$ ), are introduced in the homologous positions of the muscarinic $\mathrm{m} 3$ receptor (coupled to $\mathrm{Gq}$ ), the chimera is now able to activate Gi (Liu et al., 1995). These four residues are likely to be on the same face of an $\alpha$ helix. There are six splice variants of PACAP receptors differing within the C-terminal part of the C-III loop, by introduction of "hip" and "hop" cassettes. PACAP receptors can be coupled to both AC and PLC. The presence of the hip cassette suppresses the PLC coupling (Spengler et al., 1993). Mutations of the key residue in the C-III intracellular loop often results in constitutive activation (Claeysen et al., 2000; Kjelsberg et al., 1992) (see section VII). In mGluRs, the C-II loop and the putative C-IV intracellular loop, determine the specificity of 
coupling to G-proteins (Gomeza et al., 1996a; Gomeza et al., 1996b; Mary et al., 1998; Parmentier et al., 1998; Prézeau et al., 1996). Editing the 5-HT $2 \mathrm{C}$ mRNA within the sequence coding for the C-II loop, leads to proteins with different coupling signaling characteristics (Burns et al., 1997). Finally, phosphorylation of different intracellular domains induces a finetuning of the coupling to G-proteins, including desensitization and change from Gs to Gi coupling (Daaka et al., 1997) (section VIII). The capacity of mGluR5 to produce an oscillatory intracellular $\mathrm{Ca}^{2+}$ release, depends on $\mathrm{PKC}$ phosphorylation of a specific threonine residue of the C-terminal domain (Kawabata et al., 1996).

An important domain of G $\alpha$, implicated in the interaction and the specificity of a given GPCR to a given G-protein, concerns the last few residues of their C-terminus (figure 2). The residue

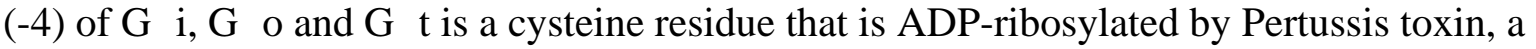
covalent modification that prevents the interaction of G-proteins with receptors (Hamm, 1998). In the $\mathrm{Gq}$ family, residue -4 is a tyrosine that has to be phosphorylated for an efficient coupling to PLC-activating receptors (Umemori et al., 1997). Goq chimeras, in which the last

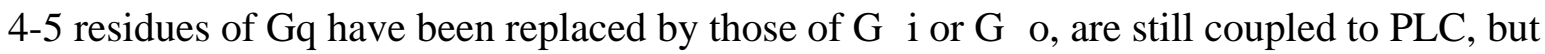

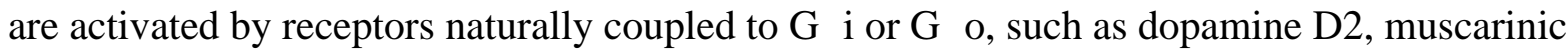
$\mathrm{m} 2$, mGluR2, 3, 4 and 8. Interestingly, there are no sequence similarities at all between receptors from different families (Blahos et al., 1998; Conklin et al., 1993). The most

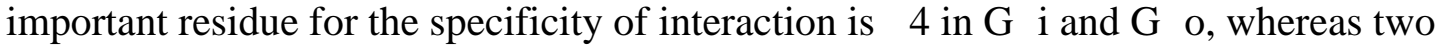

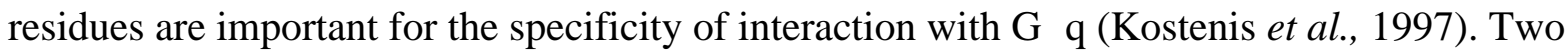
other domains of $\mathrm{G} \alpha$ are important for the coupling, as well as for its specificity (figure 2). These are the $\alpha 4$ and $\alpha 5$ helices, plus the L9 and $\beta 6$ on the one hand (Mazzoni and Hamm, 1996; Noel et al., 1993) and a short region between the N-terminal $\alpha$-helix and $\beta 1$ strand, on the other (Blahos II et al., 2001). A photoactivated peptide derived from the C-III loop of $\alpha 2-$ 
$\mathrm{AR}$, is cross-linked with the $\mathrm{N}$ terminal domain of $\mathrm{G} \alpha \mathrm{O}$, and also with the C-terminal part of G $\beta$. Rhodopsin, as well as $\beta 2-A R$, bind to G $\beta$ (Taylor et al., 1994; Taylor et al., 1996).

The scenario leading from these interactions to the change in the conformation of $\mathrm{G} \alpha$, especially at the level of switches I, II and III, followed by the release of GTP (figure 2) is not known. H. Bourne has proposed two routes; one via $\alpha 5-\beta 6$, a region in which a mutation

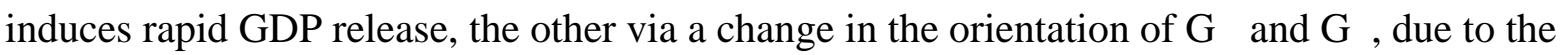
interaction of receptor intracellular loops, with the cavity separating these two subunits (Bourne, 1997b).

\section{Orphan GPCRs}

The current explosion of genomic sequence data provides a way to identify many more GPCR members in human and other species, genomes. Most, if not all newly identified GPCRs, falls into the category of orphan receptors for which the endogenous ligand remains to be identified. Typically, these GPCRs show only low levels of similarity (less than 35\% sequence similarity) with known GPCRs. For family 1, more than 80 orphan GPCRs are known (Lee et al., 2001).

The rationale for investing resources in characterizing orphan GPCRs is certainly to increase our fundamental knowledge, although this is no longer a pertinent driving force. A stronger motivation is the fact that GPCRs have a proven history of being excellent, directly or indirectly (anti-depressant drugs for example), targets of the majority of drugs (Wilson et al., 1998). Another reason is that there is an increasing number of diseases associated with GPCR mutations (see section IX). GPCR mutations and polymorphism are likely to be associated with pathologies and/or susceptibility to pathologies. The overall strategy has been called "reverse pharmacology". The research starts with extensive bio-informatical analysis of 
expressed sequence tags (EST) databases. ESTs are short sequences representing transcribed genes and continuous protein coding regions. They can be used to localize the GPCR tissue expression by in situ hybridization. Full-length clones can be obtained and chromosomal localizations determined. A possible association with genetic diseases can be analyzed. Once the full-length clone is obtained, the receptor can be expressed in heterologous cells and functional assays can begin using a wide range of coupling mechanisms. The most popular assays are the measurement of changes in intracellular cAMP or $\mathrm{Ca}^{2+}$ levels either directly or through the use of reporter genes. The possibility of using promiscuous G-proteins, such as G15/G16 or chimeric Gqi, Gqo, Gqz, is widely used (Conklin et al., 1993; Gomeza et al., 1996b; Offermanns and Simon, 1995; Parmentier et al., 1998). Once a functional assay is found, the search for the ligand can begin. Sometimes, a weak homology or a consensus sequence can be used to guess if the ligand for the orphan receptor is a peptide or a small ligand. Existing banks of compounds or biological extracts can be screened.

Every year, the natural ligands for several orphan receptors are discovered (Lee et al., 2001). The following ligands have been discovered:

- nociceptin (orphanin) (Meunier et al., 1995; Reinscheid et al., 1995);

- orexin (hypocretin) (Sakurai et al., 1998);

- prolactin releasing hormone (Hinuma et al., 1998);

- apelin (Tatemoto et al., 1998);

- melanin-concentrating hormone (Chambers et al., 1999; Saito et al., 1999);

- urotensin (Ames et al., 1999).

We are not going to provide an exhaustive review of all six, but we will take two recent examples.

Prolactin secretion is very closely controlled by many neurotransmitters. Only dopamine inhibits prolactin secretion, whereas many others, such as TSH and VIP, can stimulate 
prolactin secretion. However, they were not really thought to be the most important physiological stimulators of prolactin receptors. Hinuma et al. (Hinuma et al., 1999) first cloned an orphan GPCR called hGR3 which was largely expressed in the pituitary gland. Expression of this GPCR in cells and stimulation with hypothalamus bovine extracts led to the release of arachidonic acid. The use of this functional assay in combination with chromatographic fractionation of the extracts, led to the discovery of two peptides (PrP31 and PrP20) which stimulate the release of prolactin (Hinuma et al., 1998). Hyperprolactinemia is a serious condition because this pathology inhibits reproduction. One can consider that mutations turning the hGR3 receptor to permanently active (see section VII), even in the absence of the PrP peptide, may be involved in the sterility of women suffering from hyperprolactinemia, especially those resistant to bromocryptine, a dopaminergic agonist which is the only drug available for this pathology. If this is the case, an inverse agonist may provide the solution.

The search for the ligand for an orphan receptor called HFGAN72, identified as an expressed sequence tag from human brain, was carried out in HPLC fractions of rat brain extract. The receptor was expressed in HEK cells and intracellular $\mathrm{Ca}^{2+}$ release was measured. This led to the discovery of two peptides termed "orexins -A and-B" after the Greek word "orexis" which means appetite (Sakurai et al., 1998). Both peptides are produced from a single precursor, the prepro-orexin. Precursor and orexia peptides are localized in neurons of the lateral and posterior hypothalamus. The projections of these neurons are directed to the olfactory bulb, cerebral cortex, thalamus, and the midbrain region, including the locus coeruleus, raphe nucleus, and reticular formation. When administered centrally to rats, these peptides stimulate food consumption. Additionally, prepro-orexin mRNA level is up-regulated upon fasting, suggesting a physiological role for the peptides as central feedback mechanisms that regulate 
feeding behavior. The dream story went on and the role of orexin receptors in narcolepsy was recently described (Lin et al., 1999).

Narcolepsy is a disabling sleep disorder affecting humans and animals, characterized by daytime sleepiness, cataplexy, and striking transitions from wakefulness into rapid eye movement (REM) sleep. Lin et al. determined that canine Doberman (canarc-1 dogs) narcolepsy is caused by disruption of the orexin receptor 2 gene (Hcrtr2). In parallel, Chemelli et al. (Chemelli et al., 1999) reported that, by behavioral and electroencephalographic criteria, orexin knockout mice exhibit a phenotype strikingly similar to human narcolepsy patients, as well as canarc-1 mutant dogs. Besides, Modafinil, an antinarcoleptic drug with ill-defined mechanisms of action, was reported to activate orexincontaining neurons. Two recent reports indicate that in human narcolepsy, a reduction of orexin synthesis, rather than a mutation in its receptor, is involved (Peyron et al., 2000; Thannickal et al., 2000). Thus the pathway to therapy is now clear. In two years, the orphan receptor has led to the discovery of peptides implicated in appetite and sleep physiology and pathology... not too bad. There is no doubt that orphan receptors will lead to new and exciting discoveries over the next few years.

\section{Constitutive activity of allosteric GPCRs, inverse agonists and}

\section{physiological relevance}

\section{A. Drug-receptor models}

Until the 90's, pharmacologists working on GPCRs were still using the traditional "receptor occupation" theory that was the foundation of pharmacology for decades (Clark, 1933). The receptor was supposed to be "quiescent" under a $\mathrm{R}$ form in the absence of agonists (A). The agonist, when present, binds to $\mathrm{R}$, inducing the formation of an $\mathrm{AR}$ complex $(\mathrm{A}+\mathrm{R} \leftrightarrows \mathrm{AR})$ 
which triggers a cascade of events leading to physiological functions. The "ternary complex model" was introduced to account for the fact that GPCRs were found to bind agonists (not antagonists) with high and low affinity (De Lean et al., 1980). This is because AR, but not R, is coupled with heterotrimeric G-proteins and induces the GDP-GTP exchange (figure 1B). The ternary complex AR-G (state 2 in figure 1B, G-protein empty) generally has a high affinity for the agonist, whereas AR and R generally have a lower affinity for the agonist. The antagonist has a unique affinity for $\mathrm{R}$. The antagonist-R complex does not bind the G-protein. In 1965, Monod, Wyman and Changeux wrote a famous article entitled "On the nature of allosteric transitions: a plausible model" (Changeux and Edelstein, 1998; Monod et al., 1965). The allosteric model proposed was based on observations made on bacterial enzymes that catalyze reactions of important biosynthetic pathways. They found that the catalytic activity of these enzymes can be regulated by the end product of the synthetic pathway which has no structural similarity to the substrate, and acts on a specific regulatory binding site, which is different from the catalytic site. The regulatory site induces a reversible alteration of the conformation of the protein: an allosteric transition. The observation that cooperative interactions exist for both the substrate and the ligand further extends the properties of allosteric proteins. The cooperativity of oxygen binding on the symmetrical tetramer hemes of hemoglobin distant by at least $25 \AA$, further establishes the model. Several key features of allosteric proteins were first established for receptor channels, such as ionotropic receptors, nicotinic receptors and then GABA-benzodiazepine receptors (Changeux and Edelstein, 1998):

- the protein is an oligomer composed of several subunits and possesses one axis of rotation. As we have seen, GPCRs are probably associated as a dimer and possibly as oligomers, although the exact role of dimerization is not always clear except for $\mathrm{GABA}_{\mathrm{B}}$ receptors and mGluRs (Galvez et al., 2001; Kunishima et al., 2000) ; 
- the oligomer can spontaneously exist in a minimum of two freely inter-convertible and discrete conformational states;

- the ligand binding stabilizes the particular state for which they exhibit a higher affinity;

- in the absence of agonists, the preexisting equilibrium between the inactive $(\mathrm{R})$ and the active $\left(R^{*}\right)$ states is characterized by an isomerization constant $\mathrm{J}$. Therefore, in the case of GPCRs we can write:

$\mathrm{R} \stackrel{\mathrm{J}}{\leftrightarrows} \mathrm{R}^{*}$ with $\mathrm{J}=\mathrm{R} / \mathrm{R}^{*}$

This isomerization step is the foundation for the "extended ternary complex" (Samama et al., 1993). Indeed, this explains the increased affinity of agonists and partial agonists for the constitutively active mutant receptors, in proportion to their efficacy, even in the absence of G-proteins (Samama et al., 1993). In the "ternary extended model”, only $\mathrm{R}^{*}$ and $\mathrm{R}^{*} \mathrm{~A}$ can couple to G-proteins.

Several consequences were to be expected from such a model:

- depending on the value of J, GPCRs can exhibit constitutive activity, i.e. an activity in the absence of agonists, meaning that there is enough $\mathrm{R}^{*}$ coupled to $\mathrm{G}$ to activate a detectable amount of effector activity;

- an antagonist is a drug which does not modify the equilibrium and therefore has an equal affinity for $\mathrm{R}$ and $\mathrm{R}^{*}$;

- an agonist is a drug with a higher affinity for $\mathrm{R}^{*}$ than for $\mathrm{R}$ and which therefore shifts the equilibrium towards the $\mathrm{R} *$ form. The latter being the only one coupled to G-proteins in the extended ternary complex model which is the model we are presently examining and which was first proposed by Lefkowitz and his colleagues; 
- ligands having a higher affinity for $\mathrm{R}$ than for $\mathrm{R}^{*}$ should exist. In this case, they would displace the equilibrium towards $\mathrm{R}$ and reduce the constitutive activity, if any. These ligands are called "inverse agonists";

- depending on the relative affinity for $\mathrm{R}$ and $\mathrm{R}^{*}$, an agonist will be a full agonist or more or less partial.

Recently, Kenakin introduced the cubic model which differs from the ternary extended model by conveying the notion that $\mathrm{R}$ and $\mathrm{R}^{*}$ can couple to $\mathrm{G}$ (and of course $\mathrm{RA}$ and $\mathrm{R}^{*} \mathrm{~A}$ ) (even though they have with different affinities). Thermodynamically, this is the most complete model (Kenakin and Weiss, 1996).

B. Inverse-agonists and constitutively active receptors The existence of inverse agonists were first proposed by Braestrup et al. when they reported that DMCM (methyl 6,7-dimethoxy-4-ethyl- $\beta$-carboline-e-carboxylate), in contrast to benzodiazepines, was a potent convulsant in vivo. DMCM seemed to favor binding on a closed conformational state of the $\mathrm{GABA}_{\mathrm{A}}$ channel (Braestrup et al., 1982). Shortly after, Costa and Hertz were pioneers in demonstrating that some, but not all $\delta$-opioid receptor antagonists, had a "negative" intrinsic activity in membranes prepared from NG108-15, i.e. they reduce basal adenylyl cyclase activity (Costa and Hertz, 1989). Therefore, they proposed that the receptor could be under two states, only one in association with G-proteins, in the absence of the ligand. In a pharmacological model, Wreggett and De Lean predicted that "antagonists" may be active in hindering the ability of receptors to spontaneously associate with G-proteins (Wreggett and De Lean, 1984).

The existence of "inverse" agonists was a seminal observation that was pivotal for the existence of isomerization between $\mathrm{R}$ and $\mathrm{R}^{*}$ (Chidiac et al., 1994; de Ligt et al., 2000). 
However, it was not until mutated GPCRs were discovered, which were able to adopt active conformations in the absence of ligands and it was demonstrated that over-expression of native wild-type receptors generates enough active receptors to elicit a response, that the concept was fully accepted.

The first description of a mutated constitutively active receptor was made by Lefkowitz and collaborators (Cotecchia et al., 1990; Kjelsberg et al., 1992). They reported that mutations of a key residue $\left(\mathrm{A}^{293}\right)$ in the C-III loop, a region critically involved in the activation of Gproteins, are spontaneously active. The substitution of $\mathrm{A}^{293}$ for each of the other 19 aminoacid residues led to receptors having a variable, but always observable constitutive activity. This may indicate that in critical GPCRs domains, evolution has selected the residue which allows constraint upon the receptor under the R form (Samama et al., 1993).

In certain human diseases, mutations of GPCRs are often the causal agents as we will discuss in section VIII (Spiegel, 1996).

In theory, mutated receptors have a less constrained form and therefore a higher potency to isomerize from $\mathrm{R}$ to $\mathrm{R}^{*}$. This is what we found by measuring the isomerization $\mathrm{J}$ constant in COS-cells for wild-type and constitutively active mutated 5-HT 4 receptors (Claeysen et al., 2000). However, Claeysen et al. have also found that mutated receptors have different $\mathrm{R}^{*}$ structures (Claeysen et al., 2001).

The existence of an equilibrium between an inactive form $\mathrm{R}$ and an active form $\mathrm{R}^{*}$, governed by the equilibrium constant $\mathrm{J}$, also explains that over-expression of wild-type GPCRs, by the virtue of increasing the absolute amount of $\mathrm{R}^{*}$ (keeping the $\mathrm{J}$ constant unchanged), generates measurable constitutive activity, both in cell lines, but also in vivo (Chidiac et al., 1994; Lefkowitz et al., 1993). Bond et al. described transgenic mice over-expressing the wild $32-\mathrm{AR}$ at various receptor levels in atrial cells (Bond et al., 1995). Baseline, left atrial tension in these transgenic mice was increased 3-fold over control mice and ICI-118,551 acts as an 
inverse agonist, decreasing basal tension. The degree of ICI-118,551 inhibition was correlated with receptor density, suggesting that the event was receptor-mediated.

In fact, some receptors are more or less constrained under the R form. In COS-7 cells, at a density of $300 \mathrm{fmol} / \mathrm{mg}$ (a density close to that found in wild-type tissues), the $\beta 2$-AR had no constitutive activity, whereas the $5-\mathrm{HT}_{4 \mathrm{a}} \mathrm{R}$ increased cAMP production by 4 -fold. Further increasing the density of $\beta 2$-AR generates constitutive activity (Claeysen et al., 1999). In contrast, the wild-type PACAP receptor will not generate a constitutive activity event at high density (unpublished results from our laboratory).

Interestingly, splice variants of GPCRs and especially those showing splicing within the Cterminal domain, have variable constitutive activities. There is increasing evidence that specific sequences of the C-terminal region of GPCRs modulate the isomerization between $\mathrm{R}$ and R* (Claeysen et al., 1999; Joly et al., 1995; Prézeau et al., 1996). A cluster of basic residues present in the $\mathrm{C}$-terminal of the short $\mathrm{C}$-terminal forms of mGluR splice variants (mGluR1b, mGluR1c and mGluR1d) impair their ability to isomerize from R to R* (Mary et al., 1998). Removing this cluster by mutation reveals their constitutive activity. In addition, the effect of this inhibitory cluster is suppressed by the long C-terminal domain of the other splice variant mGluR1a which has, in fact, a high constitutive activity (Mary et al., 1998). Considering the splice variants of $5-\mathrm{HT}_{4}$ receptors differing in the length of their $\mathrm{C}$-terminal domain; the shorter the tail, the higher the constitutive activity. Artificial truncations revealed a domain of the tail, rich in Ser and Thr, which is largely engaged in constraining the receptor under the R form (Claeysen et al., 1999).

Truncating or splicing out the last residues of thyrotropin-releasing hormone receptors and prostaglandin E receptors induces constitutive activity. The last 12 residues of bovine rhodopsin have also been proposed to be involved as negative regulators of the GTP 
exchange. Removing the C-terminus of avian $\beta$-AR increases its activity (Hasegawa et al., 1996; Matus-Leibovitch et al., 1995; Parker and Ross, 1991; Weiss et al., 1994).

Either C-terminal-associated proteins, or post-translational modifications in the C-terminal domain, are likely to be involved in the turning-off of constitutive GPCR activity. This remains to be demonstrated. However, the existence of such interacting proteins, able to reduce the isomerization from $\mathrm{R}$ to $\mathrm{R}^{*}$, is possible. Their presence in tissues, in which these receptors are naturally expressed, and not in cell lines, would also explain why it is easy to obtain constitutive activity of GPCRs transfected in the latter. Recently, we found that the Homer proteins which interact with the C-terminus of mGluR1,5 (see section XI and figure 7) are able to modulate the constitutive activity of these receptors (Ango et al., 2001).

\section{Constitutively active wild-type receptors in native tissues}

Demonstrating the existence of constitutively active wild-type receptors in native tissues has in fact proved to be difficult (not speaking here of cell lines, naturally expressing some GPCRs). There are several reasons for this difficulty. The first is that due to the reasons discussed above, constitutive activity is low and undetectable in wild-type tissues. The second reason is that to demonstrate such an activity, one has to be sure that there are no agonists to contaminate the preparation. Finally, constitutive activity can only be demonstrated in native tissues if inverse agonists are available, which is only the case for some receptors. However, the list of GPCRs for which an inverse agonist is available is getting longer.

Inverse agonist effects have been observed in different cell lines without any need for overexpression of GPCRs (H.E.L. 92.1.7 cells endogenously expressing the human $\alpha 2-\mathrm{AR}$, RIN5AH cells expressing $\alpha 2-\mathrm{D}$ receptors and, as already discussed, NG108-15 cells expressing $\delta$-opioid GPCR) (see de Ligt et al., 2000). In native tissues, there is convincing evidence that in myocytes, forskolin-stimulated $\mathrm{Ca}^{2+}$ currents can be inhibited by the $\beta$ - 
adrenergic atenolol in the absence of agonists. Similarly, atropine seems to be able to block basal $\mathrm{Ca}^{2+}$ channel activity. Bradykinin antagonists also seem to be able to decrease basal phospholipase $\mathrm{C}$ activity in rat myometrial cells expressing endogenous receptors (see (de Ligt et al., 2000) for references). The overall demonstration of the existence of constitutively active GPCRs in native tissues is weak. However, Morisset et al. recently found that native histamine $\mathrm{H} 3$ receptors, which inhibit histamine release, are constitutively active. Physiologically, histamine H3 inverse agonists stimulated histamine release (Morisset et al., 2000).

The idea that naturally existing "inverse agonists" can be found in some organisms, is becoming more and more popular (see de Ligt et al., 2000). The agouti protein has been proposed to be an inverse agonist of melanocortin GPCRs and exendin, a peptide isolated from the lizard, has been proposed to be an inverse agonist of glucagon-like peptide GPCRs. We have already discussed the existence of constitutively active GPCR encoded within the genome of viruses such as Kaposi's sarcoma-associated herpes virus, poxvirus and cytomegalovirus. The herpes virus GPCR shows homology with vertebrate $\mathrm{C}-\mathrm{X}-\mathrm{C}$ receptors and is also referred to as ORF-74. An interferon- $\gamma$-inducible protein (IP10), agonist on C-X-C receptors, acts as an inverse agonist on ORF-74 (Geras-Raaka et al., 1998). Other chemokines, such as growth-related oncogenes are agonists, whereas stromal cell-derived Factor1a (SDF1a) and viral macrophage inflammatory protein II (vMIP-II) are also inverse agonists of ORF-74 (Rosenkilde et al., 1999). vMIP-II is also an antagonist of human chemokine GPCRs (Kledal et al., 1997).

D. Effects of long-term treatment with inverse agonists The possibility of categorizing GPCR antagonists into two categories: neutral antagonists and inverse agonists, is not without consequences. Indeed, there is data showing that chronic 
treatment with antagonists and inverse agonists do not have similar long-term consequences. The classical effect of long-term treatment with inverse agonists is an up-regulation of receptors which could be more pronounced than the up-regulation observed with antagonists (MacEwan et al., 1996; MacEwan and Milligan, 1996a; MacEwan and Milligan, 1996b). In both cases, stabilization of the occupied receptor occurs. Interestingly, long-term treatment with the 5-HT $2 \mathrm{C}$ inverse agonist, SB206553, sensitized the PLC pathway both to 5-HT, but also to ATP (Berg et al., 1999). An up-regulation of Gaq/11 partially accounts for these observations. Similarly, Bouaboula et al. (Bouaboula et al., 1999) also observed that treatment with a cannabinoid receptor (CB2) inverse agonist (SR 144528) also inhibits the lysophosphatidic acid (LPA) receptor-mediated pathway, an effect attributed to the trapping of Goi on CB2 occupied by SR 144528 (Bouaboula et al., 1999).

\section{Diseases caused by GPCR mutations}

In view of the physiological importance of GPCRs, it is not so surprising that a series of pathologies have been found to be related to mutations of GPCRs (Spiegel, 1996). Most of these pathologies are related to obvious clinical manifestations such as blindness, diabetes insipidus, hypo- or hyper-thyroidism, etc. Some mutations, as yet undiscovered, providing non-obvious phenotypes, are also likely to be responsible for pathologies such as psychiatric or neurological disorders. Some germline mutations may never be detected because they are incompatible with life. Both germline (inherited) and somatic (post-zygotic) mutations have been found to be responsible for loss or gain of functions. 
A. Loss of function mutations

These mutations are generally inherited disorders. Among them, the most common ones are certainly those that affect the gene coding for rhodopsin and vasopressin V2 receptors which are responsible for retinitis pigmentosa (RP) (Dryja and Li, 1995) and nephrogenic diabetes insipidus (NDI), respectively (Arthus et al., 2000) (see the web site:

www.medcon.mcgill.ca/nephros). Approximately 100 and 117 mutant alleles have been identified as being causal agents in RP (autosomal dominant except for three recessive alleles) and NDI (X-linked and autosomal recessive) pathologies, respectively. In both cases several types of receptor abnormalities have been found.

A minority of RP exhibit no difference from wild-type receptors when studied in heterologous cells (Edwards et al., 2000). In contrast, in photoreceptor cells, some of them (for example those affecting the last five residues of the C-terminal - truncation or point mutation), appear to have a mislocalization in the photoreceptor cell (Edwards et al., 2000). They remain in the cell body, rather than in the membrane sacs within the rods (Dryja and Li, 1995). Indeed, as we will discuss in section XI, the C-terminus of rhodopsin interacts with TcTex-1, a dynein light chain subunit (Tai et al., 1999) allowing the transport of post-Golgi rhodopsincontaining vesicles along the microtubules towards the outer segment. The majority of mutations (most are missense mutations) lead to non-functional rhodopsin acting as dominant negatives. Indeed, haplo-insufficiency is unlikely to be the problem since carriers of at least one apparent null allele are phenotypically normal (Rosenfeld et al., 1992). In most cases, the protein is certainly misfolded and retained in the endoplasmic reticulum, causing photoreceptor degeneration.

In the majority of NDI mutants, the problem is the abnormal intracellular retention of the synthesized protein. The receptor is most probably misfolded. Interestingly, permeant but not impermeant V2 vasopressin receptor antagonists have been found to dramatically increase 
cell-surface expression and rescue function of eight mutant vasopressin receptors, thus acting as pharmacological chaperones (Morello et al., 2000). This opens new therapeutic avenues for NDI and also for other GPCR-related pathologies due to misfolding of the protein. Another therapeutic possibility has been proposed following the observation that co-transfection of mutated receptors (nonsense, frame-shift, deletion or missense mutations in the third intracellular loop or the last two TMs) with a C-terminus V2-R peptide spanning the sequence where the various mutations occur, rescues functional receptors (Schoneberg et al., 1997; Schoneberg et al., 1996).

The diseases caused by loss of function of mutant GPCRs also include:

- color blindness (cone opsins) (Nathans, 1999);

- familial ACTH resistance (ACTH-R) (Clark et al., 1993; Naville et al., 1996; Tsigos et al., 1993);

- male pseudo-hermaphrodites under-virilization, or female amenorrhea with low estrogen production (LH-R) (Misrahi et al., 1998; Themmen et al., 1997);

- male defect in spermatogenesis and female insensitivity to FSH with ovarian dysfunction and infertility (FSH-R) (Misrahi et al., 1998; Themmen et al., 1997);

- familial or sporadic hypothyroidism (TSH-R) with phenotypes ranging from resistance to TSH to true hypothyroidism (Duprez et al., 1999);

- familial hypocalciuric hypercalcaemia/neonatal severe primary hyper-parathyroidism (CASR) (Brown, 1999);

- congenital bleeding (Thromboxane A2-R) (Hirata et al., 1994);

- Hirschprung's disease (endothelin-R) (Puffenberger et al., 1994);

- Laron-type dwarfism (GH-R) (Godowski et al., 1989; Okimura and Norton, 1998; Sanchez et al., 1998; Wojcik et al., 1998); 
- familial GH deficiency (GHRH-R) (Maheshwari et al., 1998; Salvatori et al., 1999; Wajnrajch et al., 1996);

- hypo-gonadism (GNRH-R), (Caron et al., 1999; de Roux et al., 1999a; de Roux et al., 1999b);

- Blomstrand's chondrodysplasia (PTH/PTHr-R) (Zhang et al., 1998);

- non-insulin-dependent diabetes mellitus (Glucagon-R) (Hager et al., 1995);

- obesity (melanocortin 4-R) (Hinney et al., 1999; Vaisse et al., 1998; Yeo et al., 1998); narcolepsy in Doberman dogs (orexin-R) (Lin et al., 1999).

\section{B. Gain of function mutations}

Site-directed mutagenesis of adrenergic receptors of the C-III loop by Lefkowitz's group leads to the key notion that a mutated receptor can adopt an active $\mathrm{R}^{*}$ conformation in the absence of the ligand (Cotecchia et al., 1992; Kjelsberg et al., 1992). Constitutively active mutated receptors responsible for diseases were described very rapidly after this discovery. One of them was the TSH receptor for which a wide series of somatic mutations have been described in many patients suffering from autonomous thyroid adenomas (Duprez et al., 1999; Parma et al., 1993; Parma et al., 1995). The first described mutations were localized within the C-III loop and subsequent data indicate that a cluster of mutations is localized at the amino-terminal portion of TM-VI. However, other mutations are dispersed along the receptor in: the extracellular domain, the extracellular loops, and TM-II, III, V, VI and VII (Duprez et al., 1999). Hereditary, as well as sporadic toxic thyroid hyperplasia with growing goiter and absence of auto-immunity, characterizing Graves disease, have been associated with mutations of TSH-R (Duprez et al., 1999). Familial gestational hyperthyroidism can be observed in the absence of auto-immunity and normal levels of hCG. A mutation affecting the extracellular domain of the TSH-R has been described. This mutation displaying an increased 
sensitivity to stimulation by hCG, keeps the same response to TSH (Rodien et al., 1998). The second receptor for which a constitutive activation has been described is the LH-R which causes familial male precocious puberty (Shenker et al., 1993; Themmen et al., 1997). Interestingly, there are no clinical manifestations in female carriers of the mutated gene. Spontaneous LH-R activation is sufficient to stimulate testosterone production and spermatogenesis, but inefficient in triggering puberty in females without concomitant FSH function.

The diseases caused by gain of functions of mutant GPCRs also include:

- congenital night blindness (rhodopsin) (Robinson et al., 1992). In the Lys ${ }^{296}$-Met mutant in rhodopsin cannot bind 11-cis-retinal, the receptor is constitutively active and this leads to retinal degeneration (Robinson et al., 1992). This is supposed to be equivalent to constant light exposure which is known to cause photoreceptor cell death;

- hypoparathyroidism (CASR) (Brown and Hebert, 1997);

- Jansen metaphyseal chondrodysplasia (PTH/PTHrP) (Schipani et al., 1995; Schipani et al., 1996);

- pigmentation (somber and tobacco darkening) defect in mice (MSH-R) (Robbins et al., 1993);

Genetic polymorphism of GPCRs frequently occurs (in contrast to rarer occurring mutations) and most probably underlies inter-individual variability in both pharmacological responses and propensity to diseases:

- a polymorphism in $\beta 2$-adrenergic-R ( $\mathrm{Arg}^{16}$-Gly) occurs more frequently in patients with nocturnal asthma, but its occurrence in hyper-tensive subjects is controversial (Buscher et al., 1999; Strosberg, 1997);

- a polymorphism ( $\operatorname{Trp}^{64}$-Arg) of $\beta 3$-AR may be associated with earlier onset of non-insulindependent diabetes and morbid obesity; 
- the dopamine D4-R contains an unusual polymorphism constituted of a 16-residue repeat region in the C-III loop. There are some pharmacological differences between the 4- and the 7-repeat receptors. A group of subjects with the 7 repeat allele exhibit significantly elevated Novelty Seeking scores in comparison to subjects lacking the 7 repeat allele (Ebstein et al., 1996). However, no link has been found between the 7 repeat allele and the deficit / hyperactivity disorder (Swanson et al., 2000).

\section{Allosteric antagonists and agonists of GPCRs}

We will call allosteric ligands those which do not bind to the binding site of the natural ligands.

A long series of non-peptidic antagonists for peptide GPCRs have been discovered, thanks to high throughput screening. They generally bind to the central core, composed of the 7 TMs. Non-peptidic antagonists for angiotensin (AT1 and AT2), bombesin, bradykinin, endothelin, opiates, vasopressin, oxytocin, neurotensin, substance $\mathrm{P}$ and $\mathrm{CRF}$, are now available (Betancur et al., 1997). As opposed to peptidic antagonists, they have the advantage of crossing the blood brain barrier. In fact, one may recall that for opiate GPCRs, allosteric agonists (morphine and heroin) and allosteric antagonists (naloxone) have been known for a long time. Non-peptidic antagonists do not have the same binding site as peptidic agonists. For example, CP96345 inhibits the NK1 substance P receptor with a Ki of 14 nM. However, mutations localized in the extracellular regions of TM-V and TM-VI, suppress CP96345 binding without modifying the binding of substance $\mathrm{P}$ (Gether et al., 1993). The structural modifications of these regions are indeed crucial for receptor activation. Introducing histidines into these regions, followed by $\mathrm{Zn}^{++}$treatment, inhibits receptor activation, but not substance P binding (Elling et al., 1995). Steroid hormones may also possibly bind to the core domain of GPCRs acting as allosteric antagonists. This has been shown in the case of 
oxytocin-R which is blocked by progesterone (Grazzini et al., 1998). Aspirin and sodium salicylate allosterically inhibit endothelin receptors (Talbodec et al., 2000). Interestingly, small and possibly allosteric antagonists of chemokine receptors, like bicyclam derivatives for CXCR4 or UCB35625 for CXCR3, are likely to be future compounds used to block HIV infection (De Clercq, 2000; Sabroe et al., 2000). Allosteric compounds acting on muscarinic receptors have also been described (see Lazareno et al., 2000).

In the case of family 3 , high affinity competitive antagonists have been particularly difficult to find. This is probably due to the difficulty of modifying the structure of natural ligands, while maintaining their affinity. Recently, novel, subtype-selective group I mGluR non-competitive antagonists have been discovered which bind within the core 7TM domain (which has not been involved in binding glutamate so far). CPCCOEt and BAY 36-7620 are specific mGluR1 non-competitive antagonists, whereas MPEP is a mGluR5 non-competitive antagonist (Carroll et al., 2001; Litschig et al., 1998; Pagano et al., 2000). Synthetic molecules like NPS467 and NPS568 have been shown to potentiate the action of $\mathrm{Ca}^{2+}$ on CASR (Hammerland et al., 1999; Nemeth et al., 1998). Alone, neither compound has agonist effects, but both induce a shift to the left of the $\mathrm{Ca}^{2+}$ concentration response curves, indicating that they act as allosteric modulators. $\mathrm{Ca}^{2+}$ alone may be a positive allosteric ligand acting at a site close to the binding site of glutamate in mGluRs (Kubo et al., 1998), and GABA in $\mathrm{GABA}_{\mathrm{B}}$ receptors (Galvez et al., 2000b).

\section{Post-trancriptional and post-translational modifications of GPCRs: role in activation and desensitization}

We have seen in section V that GPCR - G-protein interactions are complex and diverse. In addition to splicing with insertions localized mainly at the C-III loop and the C-terminal 
domains, GPCR domains implicated in G-protein interactions are susceptible to fine tuning via post-transcriptional and post-translational modifications.

A. RNA editing

Transcripts encoding the 5- $\mathrm{HT}_{2 \mathrm{C}}$ receptor, a PLC- and phospholipase A2-coupled receptor, undergo RNA editing events in which the genomically-encoded adenosine residues are converted to inosines by double-stranded RNA adenosine deaminase(s). Seven major 5-HT2 $\mathrm{C}^{-}$ $\mathrm{R}$ isoforms are predicted, encoded by 11 distinct RNA species, differing in their second intracellular loops. These modifications lead to changes in the efficacy of coupling to Gproteins. Agonist stimulation of the non-edited human receptor $\left(5-\mathrm{HT}_{2 \mathrm{C}}-\mathrm{INI}\right)$ and the edited 5$\mathrm{HT}_{2 \mathrm{C}^{-}} \mathrm{VSV}$ and 5-HT $2 \mathrm{C}^{-} \mathrm{VGV}$ receptor variants stably expressed in NIH-3T3 fibroblasts, demonstrate that serotoninergic agonists were less potent at the edited receptors (Burns et al., 1997). This reduced G-protein coupling for the edited isoforms is primarily due to silencing of the constitutive activity of the non-edited $5-\mathrm{HT}_{2 \mathrm{C}}-\mathrm{R}$.

B. Phosphorylation associated with desensitization Several mechanisms regulate the length and strength of GPCR signals. For a series of recent reviews see (Bohm et al., 1997; Bunemann and Hosey, 1999; Bunemann et al., 1999; Pitcher et al., 1998; Tsao and Zastrow, 2000). Generally, desensitization refers to a progressive loss of the physiological response and the effector activity, despite the continued presence of the signaling ligand. Two types of desensitization have been described. Homologous desensitization refers to the situation whereby only the activated GPCRs desensitize, while heterologous desensitization refers to the situation whereby activation of one GPCR leads to the desensitization of responses initiated by another, heterologous GPCR. There are multiple mechanisms of receptor desensitization, but they are not all understood. The most rapid phase 
of desensitization (minutes) involves agonist-induced phosphorylation either by classical second messenger activated kinases (mainly in heterologous desensitization) or by GPCRactivated kinases (GRK), followed by binding to adapter proteins such as arrestins.

Sequestration or internalization is a second event that commonly occurs with a slightly slower time-course. The receptor can be recycled at the cell surface, or destroyed in lysosomes (down-regulation).

In heterologous desensitization, classical second messenger-activated protein kinases are implicated. $\beta 2$-ARs are excellent substrates for cAMP protein kinase (PKA) and their phosphorylation, on the C-III loop, leads to an uncoupling from Gs. Recent reports suggest that PKA-mediated phosphorylation can increase $\beta 2$-adrenergic receptor coupling to $\mathrm{Gi}$ and promote MAP-kinase cascade activation (Daaka et al., 1997; Luttrell et al., 1999). However, this may not be a general mechanism (Luttrell et al., 1999; Tsao and Zastrow, 2000). PKCmediated heterologous desensitization has also been reported (Bunemann et al., 1999). A complex between the A-kinase-anchoring protein, AKAP79/150, PKA and PKC, facilitates receptor phosphorylation.

Homologous desensitization appears to involve phosphorylation by a unique family of GRKs (Pitcher et al., 1998). Six GRKs have been identified: GRK1 (rhodopsin-kinase localized in the retina), GRK2, 3 ( $\beta$-adrenergic receptor-kinases, $\beta$-ARK1, 2), GRK4, 5, 6. GRK4 is localized in testis, the others have a wide distribution.

The mechanisms of association of GRKs to the plasma membrane are diverse. GRK1 is isoprenylated, whereas GRK4 and 6 are palmitoylated. GRK2 and 3 are translocated to the membrane when $\beta \gamma$ is released from G-proteins upon activation by the phospholipid environment. Phosphorylation by GRKs occurs either in the C-terminus domain [( $\beta 2-\mathrm{AR}$, rhodopsin, somatostatin (SSTR3)), or in the C-III loop ( $\alpha 2-\mathrm{AR}$, muscarinic-R (m2)]. GRKs 
are subject to regulation by PKA, PKC and GRK themselves and $\mathrm{Ca}^{2+}$ binding proteins such as recoverin (for GRK1), calmodulin or others (Pitcher et al., 1998).

Phosphorylation does not necessarily mean uncoupling. After GRK-induced phosphorylation of rhodopsin and $\beta 2-\mathrm{AR}$, uncoupling occurs when arrestins (4 arrestins have been identified, arrestin-1 being found only in the retina) bind to the phosphorylated receptors. Other uncoupling or adapter proteins may exist. The most classical pathway for $\beta 2-\mathrm{AR}$ endocytosis involves its targeting to coated pits, although it can also be targeted, as some other GPCRs, to caveolae (Tsao and Zastrow, 2000). The targeting to coated pits is associated with the binding of several proteins to arrestin, such as the AP-2 adapter, NSF (N-ethylmaleimide-sensitive fusion protein), clathrin and Src (Laporte et al., 2000; Laporte et al., 1999; McDonald et al., 1999; Tsao and Zastrow, 2000). For some, but not all muscarinic receptors, dynamin, a GTPase that forms the necks of the vesicles, is required both in coated pits and caveolaemediated endocytosis (see for example Ahn et al., 1999; Bunemann et al., 1999). Internalization of Src via GPCR-induced endocytosis has been proposed to be the mechanism by which these receptors activate the MAP-kinase cascade. This hypothesis is questioned by other studies.

After being internalized in endosomes, the receptors can be recycled following dephosphorylation by a specific member of phosphatase $2 \mathrm{~A}$ and $2 \mathrm{~B}$ families. Recycling of $\beta 2$ AR requires interaction of its $\mathrm{PDZ} \mathrm{C}$-terminus ligand binding domain with the $\mathrm{EBP}_{50} / \mathrm{NEHRF}$ erzin-actin complex (see section X) (Cao et al., 1999). Alternatively, the receptor (vasopressin V2) can be sequestered for a long time in an unknown intracellular compartment (Innamorati et al., 1999; Oakley et al., 1999), or degraded in lysosomes (down-regulation) or in nonlysosomal compartments (Tsao and Zastrow, 2000). Whether the pathways involved in endocytosis and down-regulation are always similar or not, remains to be clarified. Downregulation of $\beta 2-\mathrm{AR}$ also involves a decrease in receptor synthesis and destabilization of 
mRNA (Bohm et al., 1997). Divergent residues located at the C-terminus of thrombin and substance $\mathrm{P}$ receptors specify differences in trafficking between lysosomal and recycling pathways.

The role of GRKs has also been studied in vivo using transgenic mice. GRK2 knock-out mice were found to be lethal to the embryo at the age of 15 days. They had severe defects in cardiac development and most likely died of cardiac failure. Mice over-expressing GRK2 showed an increased cardiac function (Pitcher et al., 1998). GRK3 ( $\beta$-arrestin2) determines morphine tolerance, but not dependence (Bohn et al., 2000).

\section{GPCRs are unfaithful to G-proteins}

It will come as no surprise to the reader to realize that GPCRs interact with many other proteins, in addition to G-proteins (Hall et al., 1999). This has already been discussed in the section on desensitization, where GPCRs have also been shown to interact with arrestins. This is a consequence of receptor activation via G-proteins and will not be discussed further here. What is more surprising is that GPCRs also directly interact with a wide variety of proteins which are important for some of their functions (clustering, anchoring, optimization of transduction, transduction not mediated through G-proteins...) and which do not implicate Gproteins.

A. Association with PDZ domain-containing proteins Various proteins have been recognized to contain PDZ domains; 90-residue domains first recognized in PSD-95/SAP90, its Drosophila homologue. Three groups of PDZ ligands have been recognized: Group I PDZ binds to C-terminal peptides with the consensus E-(S/T)-X- $\Phi$; in most cases, $\Phi$ is V or I) group II binds peptides with the $\Phi$-X- $\Phi$ triplet and group III binds 
peptides with a less defined consensus sequence such as $\varphi \varphi \Phi$, as exemplified in $\beta$-neurexine YYV ( $\Phi$ being a hydrophobic residue and $\varphi$ being an aromatic residue) (Daniels et al., 1998; Maximov et al., 1999; Sudol, 1998a). However, some variations on this theme are likely. Many ionic channels, receptor channels, enzymes, and synaptic protein C-termini, contain a PDZ binding sequence which interacts with the PDZ of multi-domain proteins. They form vast complexes in the synapse (Ehlers et al., 1998; O'Brien et al., 1998).

Many GPCR C-termini also contain PDZ binding ligand (figures 6 and 7):

- $\beta 2$-AR associates via a C-terminal PDZ binding domain with the $\mathrm{Na}^{+} / \mathrm{H}^{+}$exchanger regulator factor (NEHRF) and its homologue, the erzin-radixin-moesin binding phosphoprotein-50 (EBP-50) (figure 6A) (Cao et al., 1999; Hall et al., 1998a; Hall et al., 1998b). This protein contains two PDZ, the first one interacts with the DSLL C-terminus sequence of $\beta 2-\mathrm{AR}$. The interaction of $\beta 2-\mathrm{AR}$ and NEHRF has solved a mystery in the $\beta 2$ AR signaling pathway involved in the regulation of the $\mathrm{Na}^{+} / \mathrm{H}^{+}$transporter. Indeed, for a long time, $\beta 2$-AR were thought to be only coupled to Gs and that the only second messenger implied was cAMP. However, deletion of parts of the C-III intracellular loop of $\beta 2-\mathrm{AR}$ suppressed the Gs coupling as expected, but kept the activation of the $\mathrm{Na}^{+} / \mathrm{H}^{+}$exchange by B2-AR agonists (Barber et al., 1992). This was a clear indication as to the existence of another signaling pathway not requiring Gs and the C-III loop. Hall et al. using a $\beta 2$-AR tailGST protein fished out NEHRF (Hall et al., 1998a). In the absence of $\beta 2-A R$ agonists, NEHRF binds to the $\mathrm{Na}^{+} / \mathrm{H}^{+}$exchanger and inhibits its activity (figure 6A). NEHRF associated to activated $\beta 2-\mathrm{AR}$, suppresses the inhibition of NEHRF, leading to stimulation of the $\mathrm{Na}^{+} / \mathrm{H}^{+}$exchanger (figure $6 \mathrm{~A}$ ). Mutation experiments indicate that the PDZ binding domain of $\beta 2-A R$ is involved. P2Y1-R and the cystic fibrosis TM regulator also interact via their PDZ binding domains with the NEHRF protein (Hall et al., 1998b). In addition to the regulation of the $\mathrm{Na}^{+} / \mathrm{H}^{+}$exchange, the $\beta 2$-AR- EBP-50 erzin-actin complex controls the 
recycling of the receptor after endocytosis. Phosphorylation of the serine $\left(\mathrm{Ser}^{411}\right)$ of the DSLL binding domain by GRK-5, inhibits the association of $\beta 2-\mathrm{AR}$ with $\mathrm{EBP}_{50} / \mathrm{NEHRF}$ and receptor recycling (Cao et al., 1999).

- Somatostatin acts through five different GPCRs (SSTR1-R5). The SSTR2 has been shown to interact via its QTLI -PDZ binding domain, with two related proteins, cortactin-binding protein 1 (CortBP1) and SSTRIP (figure 6B) (Zitzer et al., 1999a; Zitzer et al., 1999b). In fact, CortBP1 and SSTRIP multi-domain proteins originate from the same family. CortBP1 is also called Shank2 and is homologous to ProSAP1, whereas SSTRIP is homologous to Shank1, Spank1, as well as synamon (see figure 7). These proteins contain various domains such as an ankyrine domain at the N-terminus, an SH3 domain, a PDZ domain, a prolinerich domain to which cortactin binds and a sterile a-motif (SAM domain) at its C-terminus which is implicated in dimerization (figure 7). SSTR2 associated to CortBP1 is stimulated by somatostatin. SSTR2 associates with actin via cortactin, an interaction proposed to be implicated in its anchoring in nerve terminals, where it regulates neurotransmitter release via the inhibition of $\mathrm{N}$-terminal calcium channels.

- Using the two-hybrid screen, in which the C-terminus of the 5- $\mathrm{HT}_{2 \mathrm{C}}$ receptor was a bait, MUPP1 (multi-PDZ-domain protein), a 13-PDZ domain protein was isolated (Ullmer et al., 1998). Protein alignment of all PDZ domains from INADL (inactivating no after-potential D-like), C52A11.4 and MUPP1, revealed that all three proteins share extremely identical PDZ domains. Moreover, the most identical PDZ domains are arrayed in the same order resulting in the same organization. 5- $\mathrm{HT}_{2 \mathrm{C}}, 2 \mathrm{~B},{ }_{2 \mathrm{~A}}$ receptors interact with PDZ 10 (figure 6C) via their C-terminus SSV, SYV and SCV, respectively. The MUPP1-5-HT 2 interaction was demonstrated in transfected COS-cells, and also in choroid plexus. Co-clustering and change in the conformation of MUPP1 occurs during the interaction (Bécamel et al., 2001) MUPP1 also interacts with NG2 via PDZ1 and with c-Kit via its PDZ 10 (Barritt et al., 2000; 
Mancini et al., 2000). The discovery of additional proteins that interact with other PDZ domains of MUPP1 should reveal its real function.

Note that re-sensitization and coupling of $5-\mathrm{HT}_{2}-\mathrm{R}$ to NO-S have been reported to implicate the C-terminus PDZ ligand of 5- $\mathrm{HT}_{2}-\mathrm{R}$. For these 5-HT $-\mathrm{R}$-mediated transduction processes, the interacting PDZ protein has been identified (Backstrom et al., 2000; Manivet et al., 2000).

- The N-terminus PDZ domain of RGS12 has been shown to interact with a PDZ binding sequence of the A/S-T-X-(L/V) type domain. The search for the possible interacting proteins indicates that the C-terminus of the interleukine-8 receptor B (CXCR2) and that of the alternative 3' exon form of RGS12, are likely to be partners (Snow et al., 1998).

- mGluR7a receptors interact with the protein interacting C kinase (PICK1), a one PDZ binding protein, via their C-terminus (-LVI). A much larger C-terminal domain is needed for a tight binding. The PICK1 PDZ site also interacts with AMPA receptors, ephrin ligands and receptors, and class I ADP-ribosylation factors. Since PICK1 can dimerize, a clustering of these molecules is likely. PICK1 interacts with the C-terminal of PKC $\alpha(\mathrm{QSAV})$ and modulates the phosphorylation of mGluR7a by PKC $\alpha$ (Dev et al., 2000).

- The Drosophila photo-transduction cascade is not a cGMP phosphodiesterase-mediated pathway, but a PLC- $\beta$ pathway leading activation of store-operated $\mathrm{Ca}^{2+}$ entry channels (TRP) and their associated non-specific cationic conductance channel TRPL (light activated channels) (Montell, 1997). PLC- $\beta$ is activated by the rhodopsin-Gq complex (Tsunoda et al., 1997; Xu et al., 1998). A remarkable characteristic of this cascade is the fact that rhodopsin, Goq, PLC- $\beta$, TRP, TRPL and PKC all bind (directly or indirectly) with INAD (inactivating no after-potential D), a 5 PDZ domain containing protein) (Bahner et al., 2000; Montell, 1997). TRP and TRPL clearly interact via their C-terminal PDZ binding domains, however, the mode of interaction of other proteins in the cascade is not as obvious. If one notes that INAD forms homo-multimers, then a vast complex is clearly involved (transduciosomes). 
INAD also interacts with calmodulin and an unconventional myosin: NINAC (Montell, 1997).

B. Association with EVH1-domain containing proteins

A family of proteins which appear to function as a link between cell surface signals (including focal adhesion proteins, zyxin and vinculin, or the axon guidance receptors, SAX-3/Robo) and actin-based cytoskeleton has recently been described. These proteins include Drosophilaenabled (Ena termed Mena in mouse), yeast Bee1p, vasodilator-stimulated phospho-protein (VASP) and the Wiscott-Aldrich syndrome protein (WASp) and encode one EVH1 domain which binds the consensus proline-rich motif FPPPP (Prehoda et al., 1999).

The Homer protein family belongs to the VASP/WASp super-family, but contains another type of EVH1 domain with a slightly different structure. This domain that binds the consensus sequence (PPXXF) has already been described (Beneken et al., 2000). The first member, called Homer1a, Vesl-1S and Ania-3 (named respectively by the three groups involved in its discovery), was identified on the basis of the rapid up-regulation of its mRNA (immediate early gene) following seizures, long-term potentiation, cocaine- and dopaminergic D1stimulation (Berke et al., 1998; Brakeman et al., 1997; Kato et al., 1997). Homer1a can be considered as an immediate early gene (IEG). The N-terminus (110 residues) essentially contains the EVH1 domain which has been shown to interact with group I mGluRs, IP3 and ryanodine receptors as well as Shank (CortBP1/ProSAP1/spank/SSTRIP) proteins (figure 7) (Naisbitt et al., 1999; Tu et al., 1999; Tu et al., 1998; Xiao et al., 1998). The other members of the Homer family contain an additional C-terminus with a predicted coiled-coil (CC) structure, including leucine zippers which allow them to dimerize or multimerize. These members comprise: 1) two other Homer1 splice variants, differing by 12 residues [Homer1b, and Homer1c (= PSD-Zip45, = Vesl-1L)]; 2) two Homer2 splice variants, differing by 11 
residues $[$ Homer2a $(=$ cupidin, $=$ Vesl-2D11 and Homer2b (=Vesl-2)]; 3) one Homer3. One Drosophila Homer (D-Homer) has also been cloned, as well as other splice variants (Fagni et al., 2000; Kato et al., 1998; Shiraishi et al., 1999; Tadokoro et al., 1999; Xiao et al., 1998; Xiao et al., 2000).

The PPSPF domain of mGluR5, approximately 50 residues from the carboxyl terminus (figure 7) is essential for binding the EVH1 domain of Homers, whereas its C-terminus PDZ ligand may interact with the PDZ domain of Shank (Naisbitt et al., 1999; Xiao et al., 2000). If one also notes that NMDA receptors also interact with this Shank PDZ domain via the PSD-95 GKAP (guanylate kinase associated protein) heterodimer, and that Shank dimerizes and also interacts with Cortactin and therefore actin (figure 7), this constitutes a colossal post-synaptic complex. The Homer dimers, or multimers, may directly connect mGluR group I to IP3 and ryanodine receptors, shown to be engaged in their signaling pathways. Induction of Homer1a, which does not dimerize (because it does not contain the $\mathrm{CC}$ domain), following active neuronal activation, has been shown to modify the mGluR1-induced kinetic of intracellular $\mathrm{Ca}^{2+}$ release (Tu et al., 1998). A role of Homers in cellular trafficking has also been reported (Xiao et al., 2000). In cerebellar neurons, Homer1b and Homerla are required to address a stabilized mGluR5 to dendrites, as well as dendrites plus axons, respectively (Ango et al., 2000).

C. Association with enzymes and transcription factors Several GPCRs, and especially angiotensin AT1 and 5- $\mathrm{HT}_{2 \mathrm{~A}}$, have been shown to activate the Jak kinases, better known as the first element in the cytokine receptor signaling cascade. These two receptors have been shown to bind Jak kinase in an agonist-dependent manner (Guillet-Deniau et al., 1997; Marrero et al., 1995). In AT1 receptors, the critical binding motif (YIPP) is localized within the proximal part of the C-terminus (319-322) (Ali et al., 1997). 
Tyrosine phosphorylation of this motif by Src, is necessary for binding the $\mathrm{SH} 2$ domain of SHP-2 (tyrosine phosphatase), which then binds Jak/STAT. The same phosphorylated tyrosine is necessary for the binding of PLC- $\gamma 1$ on the same YIPP motif (Venema et al., 1998). An interaction of CXCR4 receptors and Jak2/Jak3 kinases has also been reported (Vila-Coro et al., 1999).

Another interesting case is the association of bradykinin B2 receptor with eNOS and nNOS (endothelium and neuronal nitric oxide synthases) (Golser et al., 2000; Ju et al., 1998). eNOS forms an inhibitory complex with bradykinin receptors, likely via the blockade of the flavin to heme electron transfer. The inhibitory complex is released in a ligand- and $\mathrm{Ca}^{2+}$-dependent manner, due to tyrosine phosphorylation of the eNOS interacting region of the receptor. A similar interaction of angiotensin AT1 and endothelin-1 ETB receptors with eNOS has been described (Marrero et al., 1999). In all three receptors, the receptor-interacting domain is localized within the C-IV region (Ju et al., 1998).

Interestingly, the C-termini of $\mathrm{GABA}_{\mathrm{B}} \mathrm{R} 1$ and $\mathrm{R} 2$, which contribute to their heterodimerization, (as seen in section IV), are engaged in an interaction with the leucine-zipper domain of ATF-4 (CREB2), a transcription factor of the CREB/ATF family. ATF-4 and $\mathrm{GABA}_{\mathrm{B}}$ receptors are co-localized within soma and dendrites of cultured hippocampal neurons. Nehring et al., as well as White et al., demonstrated that $\mathrm{GABA}_{\mathrm{B}}$ receptors activate ATF-4-translocation to the nucleus and gene transcription in heterologous systems (Nehring et al., 2000; White et al., 2000).

D. Association with arrestins and associated proteins

We have already discussed that arrestins bind to phosphorylated GPCRs. This event is the first step in endocytosis (see section X). Arrestins recruit several other proteins, such as c-Src, NSF, AP2 and clathrin. This complex and the Src induced phosphorylating dynamin, within 
the coated pits, lead to the formation of endocytotic vesicles. Endocytosis of Src, leading to the activation of the MAP kinase cascade mediated via GPCR, has been proposed (see section XII and figure 8).

\section{E. Miscellaneous}

Interestingly, the C-IV region is also a binding site for $\mathrm{Ca}^{2+} /$ calmodulin in mGluR7 (O'Connor et al., 1999). This binding appears to be competitive with G $\beta \gamma$ and is blocked following PKC phosphorylation of serine residues within the same region (Nakajima et al., 1999). O'Connor et al. proposed a mechanism by which $\mathrm{Ca}^{2+} /$ calmodulin is required to release $\mathrm{G} \beta \gamma$ from the $\mathrm{C}$ terminus of mGluR7 in order to obtain a G $\beta \gamma$-mediated $\mathrm{N}$-type $\mathrm{Ca}^{2+}$ channel (O'Connor et al., 1999). Similarly, two regions of mGluR5 (and mGluR1a but not mGluR1b,c) interact with $\mathrm{Ca}^{2+} /$ calmodulin (Minakami et al., 1997). These regions are localized within the C-terminus (842-869 and 922-950) in mGluR5.

A domain, 10 residues upstream from the last C-terminal domain (339-348) of the angiotensin AT1 receptor, interacts with another protein, ATRAP (AT1 receptor-associated protein) (Daviet et al., 1999). Functional studies suggest that this protein inhibits AT1 coupling to PLC.

The C-terminus of rhodopsin ( $\mathrm{Gln}^{344}$-VAPA) is highly conserved among vertebrates and is a hot spot for mutations that cause some forms of retinitis pigmentosa $(\mathrm{RP})$. Two of these $\mathrm{C}$ termini mutants $\left(\mathrm{Gln}^{344}\right.$-ter characterized by removing the last 5 residues and Pro $^{347}$-Leu), are characterized by a specific defect in the transport of rhodopsin (Sung et al., 1994; Tai et al., 1999). Mice that express $\mathrm{Gln}^{344}$-ter rhodopsin show abnormal rhodopsin accumulation in the plasma membrane (instead of outer segment discs) and cell body where it is synthesized (Sung et al., 1994). This shows that the C-terminus is required for efficient transportation to, or retention in, the outer segment. Recently, the C-terminus has been shown to interact with 
TcTex-1, a dynein light chain subunit (Tai et al., 1999). This allows the transport of postGolgi rhodopsin containing vesicles along the microtubules up to the outer segment. $\beta 2-\mathrm{AR}$ can be endocytosed following insulin or IGF-1 phosphorylation on $\mathrm{Tyr}^{350}$. This creates a SH2 binding site for Grb2 which, via its SH3 domains, recruits PI3-kinase and dynamin. Induced $\beta 2-\mathrm{AR}$ internalization by insulin requires the presence of this $\operatorname{Tyr}^{350}$ (Karoor et al., 1998).

We can also recall that the C-terminus of dopamine D5, but not D1 receptors interacts directly with the $\gamma 2$ subunit of $\mathrm{GABA}_{\mathrm{A}}$ receptors (Liu et al., 2000).

\section{F. Proteins interacting with the C-III loop}

As we have seen, the C-III intracellular loop is very important for coupling to G-proteins. Proteins have been shown to interact directly to C-III of GPCRs. Spinophilin interacts with CIII of D2-dopaminergic receptors (Smith et al., 1999), the $\xi$ isoform of 14-3-3 proteins with $\alpha 2-A R$ (Prézeau et al., 1999) and endophilins with $\beta 1$-AR. Spinophilin is a protein containing an N-terminus actin binding domain, a central PDZ domain and a coiled-coil C-terminus domain. The C-III of D2-dopaminergic receptors interacts with the domain of spinophilin localized between the actin binding domain and the PDZ domain which also binds protein phosphatase-1. It is interesting to note that two isoforms of D2 receptors are generated by alternative splicing. They differ by the presence (D2L) or absence (D2S) of 29 amino acids. It has recently been shown that D2L acts mainly at post-synaptic sites (Usiello et al., 2000). Endophilins 1/2/3, an SH3 domain-containing family, interact with a C-III polyproline domain of $\beta 1-A R$ not present in $\beta 2-A R$. This interaction may be involved in internalization and desensitization of $\beta 1-A R$. The roles of these proteins remain to be elucidated. 
G. Proteins interacting with TM domains

There is much evidence for regulation of small G-proteins by heterotrimeric G-proteins, such as Ras, Rab, Rho, and ARF, but this generally occurs via a signaling cascade localized downstream of GPCRs. However, Rho and ARF have been shown to be immuno-precipitated in an agonist-dependent manner in association with $\mathrm{m} 3$ muscarinic receptors and AT1 angiotensin receptors. The common receptor sequence (NPxxY) required for the small Gprotein interaction is localized at the end of the TM-VII and is also required to activate phospholipase D via these receptors. Direct interaction is likely but remains to be demonstrated (Mitchell et al., 1998).

We have already discussed the interactions of the TM domains with other GPCRs in an homomeric or heterotrimeric manner as well as with one TM protein (see section IV).

\section{Cross-talk between the GPCRs and the Tyrosine receptor kinase (TRK) and small G-proteins}

In association with TRKs or alone, GPCRs and heterotrimeric G-proteins have recently been recognized to control proliferation, differentiation and even transformation (Gudermann et al., 2000) (figure 8).

Two main signaling pathways are involved in these functions, the Ras and Rho pathways. TRKs are classically involved in activating the Ras pathway. The cascade includes autotyrosine phosphorylation of the receptors, tyrosine phosphorylation and association with proteins like Shc (SH2 domain-containing $\alpha 2$-collagen-related) and Grb2 (growth factorbound protein 2), and recruitment of exchange factors for Ras-like SOS. Ras-GTP engaged the ERK (extracellular signal-regulated kinase) subfamily of MAPKs (mitogen-activated protein kinases). This includes the association with Raf1 or B-Raf kinases. Raf kinases are 
serine/threonine kinases which phosphorylate MEK (ERK kinase), which subsequently phosphorylate ERKs. Translocation of ERKs into the nucleus controls the transcription of genes involved in division or differentiation. The kinetics of ERK activation, the concomitant activation of Rap1, another small G-protein and the absence or the presence of B-Raf, determine whether a TRK will induce proliferation (like EGF and PDGF) or differentiation (like NGF) (Gudermann et al., 2000).

GPCRs acting via the four main subfamilies of heterotrimeric G-proteins, Gs, Gi/Go, Gq/G11 and G12/G13 control the TRK-ERK kinase pathway.

\section{A. Gs coupled receptors}

We have already discussed the fact that cAMP in some cells induces cell proliferation, whereas in many others cAMP is inhibitory. In cells like thyroid epithelium and GH secreting cells, gain of function of Gs lead to adenoma formation. In fact, cAMP via PKA may either inhibit Raf1 and therefore ERK and cell proliferation, like in NIH-3T3 fibroblasts (Chen and Iyengar, 1994), or activate ERK via activation of Rap1 and B-Raf (Vossler et al., 1997). In neuronal cells B-Raf is the most important MEK activator and cAMP always activates ERK. cAMP seems to activate Rap1 without requiring the activation of PKA. Indeed, a cAMP Rap1 GEF (guanine nucleotide exchange factor) which is directly activated by cAMP, also named Epac (exchange protein directly activated by cAMP), has been described (de Rooij et al., 1998; Kawasaki et al., 1998). $\beta 2-A R$ activates ERK via Rap1 and B-Raf in HEK cells (Schmitt and Stork, 2000).

\section{B. Gi/Go coupled receptors}

The descriptions of tumors induced by constitutively active Gai are very limited and are described only in human ovarian sex cord stromal tumors and adrenal cortical tumors (for a 
review see (Gudermann et al., 2000). However, many GPCRs like LPA receptors, $\alpha 2-\mathrm{AR}$ and 5- $\mathrm{HT}_{1 \mathrm{~A}}$ receptors have been shown to activate the ERK pathway and cell division very efficiently via PTX-dependent Gi/Go (Gudermann et al., 2000; Varrault et al., 1992). In addition, the $\beta 2$-AR Gs-coupled GPCR has also been shown to activate the ERK pathway via Gi/Go after its agonist induced phosphorylation (Daaka et al., 1997). G $\beta \gamma$ is the active dimer after receptor activation. Several possible pathways are conceivable. We have already discussed the fact that G $\beta \gamma$ binds GRK leading to receptor phosphorylation, binding of arrestin and recruitment of Src and clathrin (see section XI). The endocytosis of the complex, via coated-pits, conveys Src in the cytoplasm. Src phosphorylates Sch which is a link to the Ras-ERK cascade (Luttrell et al., 1998). However, some Gi/Go coupled GPCRs, like GnRH, activate ERK probably without requiring arrestin. Using dominant negative dynamin mutants which block endocytosis, some, but not all authors report an inhibition of GPCR or EGFmediated ERK activation (see Tsao and Zastrow, 2000). Therefore, the requirement for endocytosis may not be a generalized mechanism of ERK activation by GPCRs. G $\beta \gamma$ which also activates PI3-kinase $\gamma$, may directly activate MEK via the PKC $\zeta$ (Takeda et al., 1999). GPCRs, like angiotensin AT1, LPA and thrombin receptors, can also transphosphorylate RTKs via Src and unknown kinases (Heeneman et al., 2000; Zwick et al., 1999). Goo/i may also activate the Rap1 pathway by sequestering Rap-GAP (Mochizuki et al., 1999). G $\beta \gamma$ also activates Cdc42 (Simon et al., 1995) and binds Rho and Rac (Harhammer et al., 1996) and Arf (ADP ribosylation factor) (Franco et al., 1995), involved in coat formation and vesicular trafficking.

\section{Gq/ G11 coupled receptors}

There are many pathways by which Gq/G11 activating GPCRs can activate the ERK pathway (Gudermann et al., 2000). RasCalDAG-GEFI, II, III Ras GEF (GEF = guanine nucleotide 
exchange factor also called GRF $=$ GDP releasing factor), predominantly expressed in the nervous system are activated by DAG and $\mathrm{Ca}^{2+}$ (Yamashita et al., 2000), whereas Ras GRF is a Ras GEF activated by $\mathrm{Ca}^{2+}$-calmodulin in neuronal cells (Mattingly and Macara, 1996). In addition, the CalDAG-GEFI, III are also Rap1 GEF (Yamashita et al., 2000). More directly, PKC has been shown to directly activate Raf-1 and the PYK2-Src interaction (Dikic et al., 1996).

\section{G12/G13 coupled receptors}

Human G12 has been clearly identified as an oncogenic protein in NIH-3T3 cells (Chan et al.,

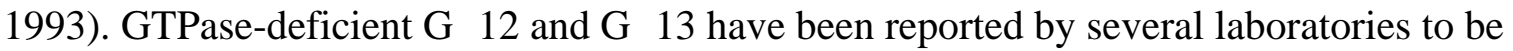
very efficient in transforming proteins. G $\alpha 12$ has been identified as a transforming oncogene

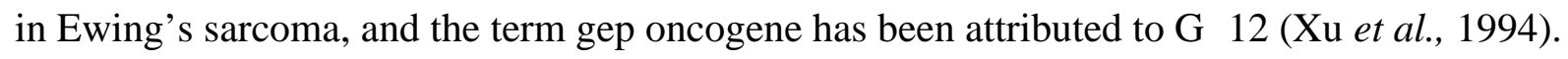
GPCR-mediated activation of G13 (and to a lesser extent G12) leads to p115RHoGEF, a RGS for these heterotrimeric G-proteins and a Rho GEF factor (Hart et al., 1998; Kozasa et al., 1998). Similarly, another G12/G13 RGS (PDZ-RhoGEF) is also a RhoGEF (Fukuhara et al., 1999). GPCR-induced Rho activation may induce cytoskeletal rearrangements. However, the mechanisms by which this activation of Rho control growth proliferation remain unclear. In some cases, such as LPA, bradykinin (B2) and serotonin (5- $\left.\mathrm{HT}_{2}\right)$ GPCRs, the involvement of EGF receptors is required to activate Rho. Rho regulates transcriptional events via serumresponsive element (SRE) and activates ROCK-I (Rho-associated coiled-coil forming kinase), two events which are likely to play a role in cell division (Gudermann et al., 2000). In addition, G12 interacts directly with PLCE, a novel PLC member which is a RasGEF (Lopez et al., 2001). 


\section{Concluding remarks}

The GPCR saga started 25 years ago with a very simple question : how do hormones act at the cellular level? Thus, the chapter on cellular signaling was opened. Landmarks of this saga were the discovery of cAMP, the discovery and purification of heterotrimeric G-proteins, the purification and cloning of GPCRs and finally the crystal structure of rhodopsin. Cellular signaling and cell-cell communication is now the central question in biology which will remain until physiological functions and regulations, in particular brain functions ("the" cellcell communication problem) and pathological diseases such as cancer, are fully understood.

\section{Acknowledgements}

F. Carroll, T. Galvez, V. Homburger, L. Joubert, M. Passama and Angie Turner-Madeuf for their help in preparing this chapter and for fruitful discussions. 


\section{Legends to figures}

Figure 1 - The "ménage à quatre" of GPCRs

A. GPCRs are transmembrane proteins (TM-I to TM-VII) with three extracellular loops (E-I to E-III) and three cytoplasmic loops (C-I to C-III), a fourth loop after TM-VII is present in rhodopsin (see figure 2D), and probably also in many family 1 GPCRs. GPCRs have been tinkered with by evolution to recognize ligands as different as photons, $\mathrm{Ca}^{2+}$, amino acids, proteins, lipids... (Bockaert and Pin, 1999).

B. Activation cycle of heterotrimeric $(\alpha \beta \gamma)$ G-proteins by GPCRs. The GTPase activity of Gos is activated by RGS (regulation of G-protein signaling). The different families of Gproteins and some of their effectors are listed.

Figure 2 - Structures of G-proteins and rhodopsin

A. Alignment of structural domains of the $\mathrm{G} \alpha$ subunit. The cylinders and the arrows represent the $\alpha$-helix ad the $\beta$-strands, respectively. Linkers are illustrated in black. The domains of interaction with $\beta \gamma$ and GPCRs are indicated. The ras domain and helical domain (green) are regionalised. SI, SII, and SIII are the "switch" domains which are structurally modified during the GDP $\rightarrow$ GTP exchange (see text).

B. Schematic representation of the structure of Gas.

C. Complex between a GPCR, G $\alpha$ and $\mathrm{G} \beta$ and G $\beta \gamma$. GPCR is a ribbon illustration of rhodopsin. The 3D model of the receptor and heterotrimeric G-proteins has been generated using the coordinate of bovine rhodopsin and a Gt $\alpha /$ Gi $\alpha$ chimera and $\beta \gamma$ (code pdb1F88 and 1GOT, respectively) with Swiss Pdb viewer (Glaxo) and POV-Ray

D. Ribbon illustrations of rhodopsin, parallel to the plane of the membrane. Reprinted by permission from Science (Palczewski et al. 289, 739-745) copyright (2000) published by the American Association for the Advancement of Science. 
E. A view into the membrane plane seen from the cytoplasmic side (extracellular side). Reprinted by permission from Science (Palczewski et al. 289, 739-745) copyright (2000) published by the American Association for the Advancement of Science.

\section{Figure 3 - The different GPCRs}

Protein sequences excluding $\mathrm{N}$-terminal and $\mathrm{C}$-terminal domains) were multi-aligned and a tree was calculated using ClustalW. A bootstrap analysis was performed on the tree construction; all branches with a bootstrap value lower than $80 \%$ were considered unreliable and were assigned a null length. The tree was drawn using TreeView (Page, 1996; Thompson et al., 1997).

The accession numbers of GPCRs used to construct this tree are:

Family 1: 5-HT 4 P97288; adrenergic ( $\beta 2$ ) Q28044; adenosine (A1) P47745; rhodopsin P35362; EDG-1 (receptor for sphingosine-1 phosphate) M31210; TSH P16473;

\section{LH-HCG P22888.}

Family 2: calcitonin-R P79222; CRF-R (corticotropin releasing factor 2) Q13324; secretin-R 47872; VIP-R (vasoactive intestinal peptide) P32241; glucagon-R P30082; EMR1 (cell surface glycoprotein F4/80) Q61549; $\alpha$-latrotoxin-R O88927; BAI-1 (brain specific angio-genesis inhibitor) O14514; GPR56 AF106858.

Family 3: mGluR1 Q13255; VR4 (vertebrate putative pheromone receptor) O35192; TR1, TR2 (vertebrate putative taste receptor) Q9Z0R8; Boss-Drome (bride of sevenless protein of Drosophila melanogaster) P22815; Boss-Drovi (Boss protein of Drosophila virilis) Q24738; GABA - R1 O08620; CASR P35384.

Family 4: VN1-3 (putative pheromone receptors) Q62850, Q62856, Q62852. 
Family 5: FZ-1 (vertebrate frizzled receptors) Q08463; FZD2, FZD3, 6 (Drosophila frizzled receptors) Q94916, O00144, O60353; MOM-5 (Caenorhabditis elegans frizzledlike receptor) O16147; LIN-17 (Caenorhabditis elegans frizzled-like receptor) U63557; SMO-Drome (Drosophila melanogaster smoothened receptor) P91682.

Family 6: CAR1,2,3,4 (cAMP receptor of Dictyostelium discoideum) P13773, P34907, P35352, Q9TX43.

Family 7: T2R1, 3, 4 (bitter taste receptor) AAF43902, AAF43903, AAF43904.

Family 8: DOR (Drosophila odorant receptor) P81909, P81910, P81914, P81915, P81921.

Extra family receptors:

Yeast pheromone receptors: STE2 P06842; STE3 P06783; Pheromone P Q00619.

Putative receptors from Arabidopsis thaliana: 004214

Mth: Methuselah putative GPCRs O97148.

Putative Drosophila gustative receptors: GR59D1 AC O86245; GR59D2 AC006245;

GR21D1 AC004420; GR22B1 AC003945.

Figure 4 - Crystal structure of mGluR1 fly-trap domains in liganded (glutamate) states.

A. The two protomers (in violet, left and red on the right), are shown from a position parallel to the membrane. The LB1 is on the top and LB2 at the bottom of the figure. Glutamate is made up of spheres. The 3D model has been generated using the coordinates of the mGluR1 extracellular domain (code pdb1EWK) with Swiss Pdb Viewer (Glaxo).

B. Illustration of the spatial arrangements of the two mGluR1 protomers. The two parts of LB1 (LB1a and LB1b) and LB2 (LB2a and LB2b) domains as well as the linkers (1,2,3) and the cysteine-rich region $(\mathrm{CR})$ are indicated. 
Figure 5 - The central core of family 1 GPCRs

A. Inactive family 1 GPCRs (view from the cytoplasm). The TM included in the N-and C-terminal part of C-I and C-III which are considered to be $\alpha$-helical structures (modified from Bourne, 1997b). The bars represent the structural constrains between the a-helical structures. The dotted line represents the structural constrains between TM-VII and TM-III provided by the retinal. For a further description of the other constrains, see section V. B. Activation of the central core of family 1 GPCRs (view from the cytoplasm). During activation, some of the constrains are released. TM-VII rotates clock-wise $\left(30^{\circ}\right)$. A cysteine introduced at position 285 goes from a hydrophobic domain to the hydrophilic cleft. The distance between TM-III and TM-VI increases. This opens a cleft in the central core in which the G-proteins can find their way. For a further description, see section V.

Figure 6 - GPCR interactions with PDZ proteins.

For further information, see section XI.

Figure 7 - The glutamate post-synaptic synapse.

For a complete description, see section XI.

Figure 8 - GPCR-receptor tyrosine kinase (RTK) dialog for activation of extracellular receptor kinases (ERKs) and cell division or differentiation.

For a complete description, see section XII. 


\section{References}

AbdAlla, S., Lother, H. and Quitterer, U. (2000). AT1-receptor heterodimers show enhanced G-protein activation and altered receptor sequestration. Nature 407, 94-98.

AbdAlla, S., Zaki, E., Lother, H. et al. (1999). Involvement of the amino terminus of the B(2) receptor in agonist-induced receptor dimerization. J. Biol. Chem. 274, 26079-26084.

Adler, E., Hoon, M. A., Mueller, K. L. et al. (2000). A novel family of mammalian taste receptors. Cell 100, 693-702.

Ahn, S., Maudsley, S., Luttrell, L. M. et al. (1999). Src-mediated tyrosine phosphorylation of dynamin is required for beta2-adrenergic receptor internalization and mitogen-activated protein kinase signaling. J. Biol. Chem. 274, 1185-1188.

Ali, M. S., Sayeski, P. P., Dirksen, L. B. et al. (1997). Dependence on the motif YIPP for the physical association of Jak2 kinase with the intracellular carboxyl tail of the angiotensin II AT1 receptor. J. Biol. Chem. 272, 23382-23388.

Ames, R. S., Sarau, H. M., Chambers, J. K. et al. (1999). Human urotensin-II is a potent vasoconstrictor and agonist for the orphan receptor GPR14 [published erratum appears in Nature 1999 Dec 23-30;402(6764):898]. Nature 401, 282-286.

Angers, S., Salahpour, A., Joly, E. et al. (2000). Detection of beta 2-adrenergic receptor dimerization in living cells using bioluminescence resonance energy transfer (BRET). Proc. Natl. Acad. Sci. USA 97, 3684-3689.

Ango, F., Pin, J. P., Tu, J. C. et al. (2000). Dendritic and axonal targeting of type 5 metabotropic glutamate receptor is regulated by Homer1 proteins and neuronal excitation. J. Neurosci. 20, 8710-8716.

Ango, F., Prézeau, L., Muller, T. et al. (2001). Agonist-independent activation of mGluRs by th intracellular protein, Homer. Nature submitted. 
Antonny, B., Otto-Bruc, A., Chabre, M. et al. (1993). GTP hydrolysis by purified alphasubunit of transducin and its complex with the cGMP phosphodiesterase inhibitor. Biochemistry, 8646-8653.

Armstrong, N., Sun, Y., Chen, G. Q. et al. (1998). Structure of a glutamate-receptor ligandbinding core in complex with kainate. Nature 395, 913-917.

Arnis, S., Fahmy, K., Hofmann, K. P. et al. (1994). A conserved carboxylic acid group mediates light-dependent proton uptake and signaling by rhodopsin. J. Biol. Chem. 269, 23879-23881.

Arshavsky, V. and Bownds, M. D. (1992). Regulation of deactivation of photoreceptor G protein by its target enzyme and cGMP. Nature 357, 416-417.

Arthus, M. F., Lonergan, M., Crumley, M. J. et al. (2000). Report of 33 novel AVPR2 mutations and analysis of 117 families with X-linked nephrogenic diabetes insipidus. $J$ Am Soc Nephrol 11, 1044-1054.

Backstrom, J. R., Price, R. D., Reasoner, D. T. et al. (2000). Deletion of the serotonin 5HT2C receptor PDZ recognition motif prevents receptor phosphorylation and delays resensitization of receptor responses. J. Biol. Chem. 275, 23620-23626.

Bahner, M., Sander, P., Paulsen, R. et al. (2000). The visual G protein of fly photoreceptors interacts with the PDZ domain assembled INAD signaling complex via direct binding of activated Galpha(q) to phospholipase cbeta. J. Biol. Chem. 275, 2901-2904.

Bai, M., Trivedi, S. and Brown, E. M. (1998). Dimerization of the extracellular calciumsensing receptor $(\mathrm{CaR})$ on cell surface of CaR-transfected HEK293 cells. J. Biol. Chem. 273, 23605-23610.

Bai, M., Trivedi, S., Kifor, O. et al. (1999). Intermolecular interactions between dimeric calcium-sensing receptor monomers are important for its normal function. Proc. Natl. Acad. Sci. USA 96, 2834-2839. 
Baker, E., Colley, N. and Zuker, C. (1994). The cyclophilin homolog NinaA functions as a chaperone, forming a stable complex in vivo with its protein target rhodopsin. EMBO J. 13, 4886-4895.

Baldwin, J. M. (1993). The probable arrangement of the helices in G protein-coupled receptors. EMBO J. 12, 1693-1703.

Ballesteros, J., Kitanovic, S., Guarnieri, F. et al. (1998). Functional microdomains in Gprotein-coupled receptors. The conserved arginine-cage motif in the gonadotropinreleasing hormone receptor. J. Biol. Chem. 273, 10445-10453.

Baranski, T. J., Herzmark, P., Lichtarge, O. et al. (1999). C5a receptor activation. Genetic identification of critical residues in four transmembrane helices. J. Biol. Chem. 274, $15757-15765$.

Barber, D. L., Ganz, M. B., Bongiorno, P. B. et al. (1992). Mutant constructs of the betaadrenergic receptor that are uncoupled from adenylyl cyclase retain functional activation of Na-H exchange. Mol. Pharmacol. 41, 1056-1060.

Bargmann, C. (1997). Olfactory receptors, vomeronasal receptors, and the organization of olfactory information. Cell 90, 585-587.

Bargmann, C. (1998). Neurobiology of the Caenorhabditis elegans genome. Science 282, 2028-2033.

Barritt, D. S., Pearn, M. T., Zisch, A. H. et al. (2000). The multi-PDZ domain protein MUPP1 is a cytoplasmic ligand for the membrane-spanning proteoglycan NG2. J. Cell Biochem. 79, 213-224.

Bécamel, C., Figge, A., Poliak, S. et al. (2001). Interaction of serotonin 5-HT2C receptors with PDZ10 of the multi PDZ protein MUPP1. J. Biol. Chem. in press.

Beneken, J., Tu, J. C., Xiao, B. et al. (2000). Structure of the Homer EVH1 domain-peptide complex reveals a new twist in polyproline recognition. Neuron 26, 143-154. 
Benkirane, M., Jin, D. Y., Chun, R. F. et al. (1997). Mechanism of transdominant inhibition of CCR5-mediated HIV-1 infection by ccr5delta32. J. Biol. Chem. 272, 30603-30606.

Benzing, T., Brandes, R., Sellin, L. et al. (1999). Upregulation of RGS7 may contribute to tumor necrosis factor-induced changes in central nervous function. Nat Med 5, 913-918.

Berg, K. A., Stout, B. D., Cropper, J. D. et al. (1999). Novel actions of inverse agonists on 5HT2C receptor systems. Mol. Pharmacol. 55, 863-872.

Berger, E. A., Murphy, P. M. and Farber, J. M. (1999). Chemokine receptors as HIV-1 coreceptors: roles in viral entry, tropism, and disease. Annu. Rev. Immunol. 17, 657-700.

Berke, J. D., Paletzki, R. F., Aronson, G. J. et al. (1998). A complex program of striatal gene expression induced by dopaminergic stimulation. J. Neurosci. 18, 5301-5310.

Berman, D. M., Wilkie, T. M. and Gilman, A. G. (1996). GAIP and RGS4 are GTPaseactivating proteins for the Gi subfamily of $\mathrm{G}$ protein alpha subunits. Cell $\mathbf{8 6}, 445-452$.

Berstein, G., Blank, J., Jhon, D.-Y. et al. (1992). Phospholipase C- $\beta 1$ is a GTPase-activating protein for $\mathrm{Gq} / 11$, its physiologic regulator. Cell 70, 411-418.

Bessis, A.-S., Bertrand, H. O., Galvez, T. et al. (2000). Three dimensional model of the extracellular domain of the type 4a metabotropic glutamate receptor: new insights into the activation process. Protein Sci. 9, 2200-2209.

Betancur, C., Azzi, M. and Rostène, W. (1997). Nonpeptide antagonists of neuropeptide receptors: tools for research and therapy. Trends Pharmacol. Sci 18, 372-385.

Bidot, S., Bidot, C., Spassky, N. et al. (2000). RGS14 is a novel Rap effector that preferentially regulates the GTPase activity of Galpha o. Biochem. J. 350, 19-29.

Birnbaumer, L. and Rodbell, M. (1969). Adenylyl cyclase in fat cells. II. Hormone receptors. J. Biol. Chem. 344, 3477-3482.

Birnbaumer, M. (1995). Mutations and diseases of G protein coupled receptors. J. Recept. Signal Transduct. Res. 15, 131-160. 
Blahos II, J., Fischer, T., Brabet, I. et al. (2001). Different sites on G-protein $\alpha$-subunits cooperate to control coupling to heptahelical receptors. J. Biol. Chem. in press.

Blahos, J., II, Mary, S., Perroy, J. et al. (1998). Extreme C terminus of G protein $\alpha$-subunits contains a site that discriminates between $\mathrm{G}_{\mathrm{i}}$-coupled metabotropic glutamate receptors. J. Biol. Chem. 273, 25765-25769.

Bockaert, J. and Pin, J.-P. (1998). Utiliser un récepteur couplé aux protéines G pour communiquer: un succès évolutif. C. R. Acad. Sci. Paris 321, 529-551.

Bockaert, J. and Pin, J. P. (1999). Molecular tinkering of G protein-coupled receptors: an evolutionary success. EMBO Journal 18, 1723-1729.

Boguski, M. S. and McCormick, F. (1993). Proteins regulating Ras and its relatives. Nature 366, 643-654.

Bohm, S. K., Grady, E. F. and Bunnett, N. W. (1997). Regulatory mechanisms that modulate signalling by G-protein-coupled receptors. Biochem. J. 322, 1-18.

Bohn, L., Gainetdinov, R., Lin, F.-T. et al. (2000). $\mu$-Opioid receptor desensitization by $\beta$ arrestin-2 determines morphine tolerance but not dependence. Nature 408, 720 - 723.

Bond, R. A., Leff, P., Johnson, T. D. et al. (1995). Physiological effects of inverse agonists in transgenic mice with myocardial overexpression of $\beta 2$-adrenoceptor. Nature 374, 272 276.

Borhan, B., Souto, M. L., Imai, H. et al. (2000). Movement of retinal along the visual transduction path. Science 288, 2209-2212.

Bouaboula, M., Desnoyer, N., Carayon, P. et al. (1999). Gi protein modulation induced by a selective inverse agonist for the peripheral cannabinoid receptor CB2: implication for intracellular signalization cross-regulation. Mol. Pharmacol. 55, 473-480.

Bourne, H. (1997a). The arginine finger strikes again. Nature 389, 673-674. 
Bourne, H. (1997b). How receptors talk to trimeric G proteins. Curr. Opin. Cell. Biol. 9, 134142.

Bourne, H. R. and Meng, E. C. (2000). Structure. Rhodopsin sees the light. Science 289, 733734.

Brabet, P., Pantaloni, C., Bockaert, J. et al. (1991). Metabolism of two Go $\alpha$ isoforms in neuronal cells during differentiation. J. Biol. Chem. 266, 12825-12828.

Braestrup, C., Schmiechen, R., Neef, G. et al. (1982). Interaction of convulsive ligands with benzodiazepine receptors. Science 216, 1241-1243.

Brakeman, P. R., Lanahan, A. A., O'Brien, R. et al. (1997). Homer: a protein that selectively binds metabotropic glutamate receptors. Nature 386, 284-288.

Brauner-Osborne, H. and Krogsgaard-Larsen, P. (2000). Sequence and expression pattern of a novel human orphan G-protein-coupled receptor, GPRC5B, a family C receptor with a short amino-terminal domain. Genomics 65, 121-128.

Brown, E. M. (1999). Physiology and pathophysiology of the extracellular calcium-sensing receptor. Am J Med 106, 238-253.

Brown, E. M. and Hebert, S. C. (1997). Calcium-receptor-regulated parathyroid and renal function. Bone 20, 303-309.

Bunemann, M. and Hosey, M. M. (1999). G-protein coupled receptor kinases as modulators of G-protein signalling. J. Physiol. (Lond.) 517, 5-23.

Bunemann, M., Lee, K. B., Pals-Rylaarsdam, R. et al. (1999). Desensitization of G-proteincoupled receptors in the cardiovascular system. Annu. Rev. Physiol. 61, 169-192.

Burns, C. M., Chu, H., Rueter, S. et al. (1997). Regulation of serotonin-2C receptor G-protein coupling by RNA editing. Nature 387, 303-308.

Buscher, R., Herrmann, V. and Insel, P. A. (1999). Human adrenoceptor polymorphisms: evolving recognition of clinical importance. Trends Pharmacol. Sci. 20, 94-99. 
Cao, T. T., Deacon, H. W., Reczek, D. et al. (1999). A kinase-regulated PDZ-domain interaction controls endocytic sorting of the $\beta 2$-adrenergic receptor. Nature 401, 286-290.

Caron, P., Chauvin, S., Christin-Maitre, S. et al. (1999). Resistance of hypogonadic patients with mutated GnRH receptor genes to pulsatile GnRH administration. J Clin Endocrinol Metab 84, 990-996.

Carroll, F., Stolle, A., Beart, P. et al. (2001). BAY 36-7620 is a new potent non-competitive mGlu1 receptor antagonists and the first inverse agonist on mGlu1a. Mol. Pharmacol. in press.

Chabre, M. and Deterre, P. (1989). Molecular mechanism of visual transduction. Eur. J. Biochem. 179, 255-256.

Chambers, J., Ames, R. S., Bergsma, D. et al. (1999). Melanin-concentrating hormone is the cognate ligand for the orphan G-protein-coupled receptor SLC-1. Nature 400, 261-265.

Chan, A. M., Fleming, T. P., McGovern, E. S. et al. (1993). Expression cDNA cloning of a transforming gene encoding the wild-type $\mathrm{G}$ alpha 12 gene product. Mol. Cell. Biol. 13, $762-768$.

Chandrashekar, J., Mueller, K. L., Hoon, M. A. et al. (2000). T2Rs function as bitter taste receptors. Cell 100, 703-711.

Changeux, J. and Edelstein, S. (1998). Allosteric receptors after 30 years. Neuron 21, 959980.

Chaudhari, N., Landin, A. M. and Roper, S. D. (2000). A metabotropic glutamate receptor variant functions as a taste receptor. Nature Neurosci. 3, 113-119.

Chemelli, R. M., Willie, J. T., Sinton, C. M. et al. (1999). Narcolepsy in orexin knockout mice: molecular genetics of sleep regulation. Cell 98, 437-451.

Chen, C. K., Burns, M. E., He, W. et al. (2000). Slowed recovery of rod photoresponse in mice lacking the GTPase accelerating protein RGS9-1. Nature 403, 557-560. 
Chen, J. and Iyengar, R. (1994). Suppression of Ras-induced transformation of NIH 3T3 cells by activated G alpha s. Science $\mathbf{2 6 3}, \mathbf{1 2 7 8 - 1 2 8 1 .}$

Chidiac, P., Hebert, T. E., Valiquette, M. et al. (1994). Inverse agonist activity of $\beta$ adrenergic antagonists. Mol. Pharmacol. 45, 490-499.

Cismowski, M. J., Ma, C., Ribas, C. et al. (2000). Activation of heterotrimeric G-protein signaling by a Ras-related protein. J. Biol.Chem. 275, 23421-23424.

Claeysen, S., Sebben, M., Becamel, C. et al. (1999). Novel brain-specific 5-HT4 receptor splice variants show marked constitutive activity: role of the C-terminal intracellular domain. Mol. Pharmacol. 55, 910-920.

Claeysen, S., Sebben, M., Bécamel, C. et al. (2000). Pharmacological properties of the 5Hydroxytryptamine4 receptor antagonists on constitutively active wild-type and mutated receptors. Mol. Pharmacol. 58, 136-144.

Claeysen, S., Sebben, M., Bécamel, C. et al. (2001). Constitutively active mutants of 5-HT4 receptors are they in unique active states? EMBO Reports 2, 61-67.

Clapham, D. E. and Neer, E. J. (1993). New roles for G-protein $\beta \gamma$-dimers in transmembrane signaling. Nature 365, 403-406.

Clark, A. J. (1933). The mode of action of drugs on cells. E. Arnold \& Co., London, U.K.

Clark, A. J., McLoughlin, L. and Grossman, A. (1993). Familial glucocorticoid deficiency associated with point mutation in the adrenocorticotropin receptor. Lancet 341, 461-462.

Clyne, P. J., Warr, C. G. and Carlson, J. R. (2000). Candidate taste receptors in Drosophila. Science 287, 1830-1834.

Clyne, P. J., Warr, C. G., Freeman, M. R. et al. (1999). A novel family of divergent seventransmembrane proteins: candidate odorant receptors in Drosophila. Neuron 22, 327-338.

Cohen, G. B., Yang, T., Robinson, P. R. et al. (1993). Constitutive activation of opsin: influence of charge at position 134 and size at position 296. Biochemistry 32, 6111-6115. 
Coleman, D. E., Berghuis, A. M., Lee, E. et al. (1994). Structures of active conformations of Gi $\alpha_{1}$ and the mechanism of GTP hydrolysis. Science 265, 1405-1412.

Conklin, B. R., Farfel, Z., Lustig, K. D. et al. (1993). Substitution of three amino acids

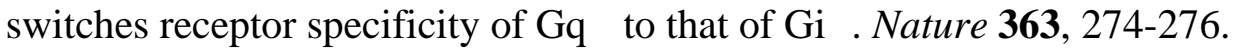

Costa, T. and Hertz, A. (1989). Antagonists with negative intrinsic activity at $\delta$ opioid receptors coupled to GTP-binding proteins. Proc. Natl. Acad. Sci. USA 86, 7321-7325.

Cotecchia, S., Exum, S., Caron, M. G. et al. (1990). Regions of the $\alpha 1$-adrenergic receptor involved in coupling to phosphatidylinositol hydrolysis and enhanced sensitivity of biological function. Proc. Natl. Acad. Sci. USA 87, 2896-2900.

Cotecchia, S., Ostrowski, J., Kjelsberg, J. et al. (1992). Discrete amino acid sequences of the alpha 1-adrenergic receptor determine the selectivity of coupling to phosphatidylinositol hydrolysis. J. Biol. Chem. 267, 1633-1639.

Coughlin, S. R. (1999). How the protease thrombin talks to cells. Proc. Natl. Acad. Sci. USA 96, 11023-11027.

Cvejic, S. and Devi, L. A. (1997). Dimerization of the delta opioid receptor: implication for a role in receptor internalization. J. Biol. Chem. 272, 26959-26964.

Daaka, Y., Luttrell, L. M. and Lefkowitz, R. J. (1997). Switching of the coupling of the $\beta_{2^{-}}$ adrenergic receptor to different G proteins by protein kinase A. Nature 390, 88-91.

Daniels, D. L., Cohen, A. R., Anderson, J. M. et al. (1998). Crystal structure of the hCASK PDZ domain reveals the structural basis of class II PDZ domain target recognition. Nat Struct Biol 5, 317-325.

Daviet, L., Lehtonen, J. Y., Tamura, K. et al. (1999). Cloning and characterization of ATRAP, a novel protein that interacts with the angiotensin II type 1 receptor. J. Biol. Chem. 274, 17058-17062. 
Davletov, B., Meunier, F., Ashton, A. et al. (1998). Vesicle exocytosis stimulated by alphalatrotoxin is mediated by latrophilin and requires both external and stored $\mathrm{Ca}^{2+} . E M B O J$. 17, 3909-3920.

De Clercq, E. (2000). Inhibition of HIV infection by bicyclams, highly potent and specific CXCR4 antagonists. Mol. Pharmacol. 57, 833-839.

De Lean, A., Stadel, J. M. and Lefkowitz, R. J. (1980). A ternary complex model explains the agonist-specific binding properies of the adenylate cyclase. J. Biol. Chem. 255, 71087117.

de Ligt, R. A. F., Kourounakis, A. P. and IJzerman, A. P. (2000). Inverse agonism at G protein-coupled receptors: (patho)physiological relevance and implications in drug discovery. Brit. J. Pharmacol. 130, 1-12.

de Rooij, J., Zwartkruis, F. J., Verheijen, M. H. et al. (1998). Epac is a Rap1 guaninenucleotide-exchange factor directly activated by cyclic AMP. Nature 396, 474-477. de Roux, N., Young, J., Brailly-Tabard, S. et al. (1999a). The same molecular defects of the gonadotropin-releasing hormone receptor determine a variable degree of hypogonadism in affected kindred. J Clin Endocrinol Metab 84, 567-572.

de Roux, N., Young, J., Misrahi, M. et al. (1999b). Loss of function mutations of the GnRH receptor: a new cause of hypogonadotropic hypogonadism. J Pediatr Endocrinol Metab 12 Suppl 1, 267-275.

De Vries, L., Mousli, M., Wurmser, A. et al. (1995). GAIP, a protein that specifically

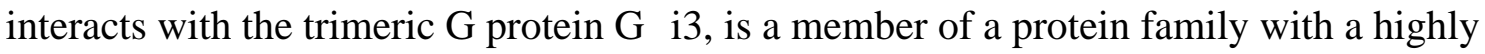
conserved core domain. Proc. Natl. Acad. Sci. USA 1995, 11916-11920.

de Vries, L., Zheng, B., Fischer, T. et al. (2000). The regulation of G protein signaling family. Annu.Rev.Pharmacol.Toxicol. 40, 235-271. 
Defer, N., Best-Belpomme, M. and Hanoune, J. (2000). Tissue specificity and physiological relevance of various isoforms of adenylyl cyclase. Am J Physiol Renal Physiol 279, F400-416.

Dev, K. K., Nakajima, Y., Kitano, J. et al. (2000). PICK1 interacts with and regulates PKC phosphorylation of mGluR7. J. Neurosci. 20, 7252-7257.

Devreotes, P. (1994). G protein-linked signaling pathways control the developmental program of Dictyostelium. Neuron 12, 235-241.

Dikic, I., Tokiwa, G., Lev, S. et al. (1996). A role for Pyk2 and Src in linking G-proteincoupled receptors with MAP kinase activation. Nature 383, 547-550.

Dohlman, H. G. and Thorner, J. (1997). RGS proteins and signaling by heterotrimeric G proteins. J. Biol. Chem. 272, 3871-3874.

Dohlman, H. G., Thorner, J., Caron, M. G. et al. (1991). Model systems for the study of seven-transmembrane-segment receptors. Ann. Rev. Biochem. 60, 653-688.

Doupnik, C., Davidson, N., Lester, H. A. et al. (1997). RGS proteins reconstitute the rapid gating kinetics of G $\beta \gamma$-activated inwardly rectifying $\mathrm{K}^{+}$channels. Proc. Natl. Acad. Sci. USA 94, 10461-10466.

Druey, K. M. and Kehrl, J. H. (1997). Inhibition of regulator of G protein signaling function by two mutant RGS4 proteins. Proc. Natl. Acad. Sci. USA 94, 12851-12856.

Dryja, T. P. and Li, T. (1995). Molecular genetics of retinitis pigmentosa. Hum. Mol. Genet. 4, 1739-1743.

Duprez, L., Parma, J., Van Sande, J. et al. (1999). Pathology of the TSH receptor. J Pediatr Endocrinol Metab 12 Suppl 1, 295-302.

Dwyer, N., Troemel, E., Sengupta, P. et al. (1998). Odorant receptor localization to olfactory cilia is mediated by ODR-4, a novel membrane-associated protein. Cell 93, 455-466. 
Ebstein, R. P., Novick, O., Umansky, R. et al. (1996). Dopamine D4 receptor (D4DR) exon III polymorphism associated with the human personality trait of Novelty Seeking. Nat Genet 12, 78-80.

Edwards, S. W., Tan, C. M. and Limbird, L. E. (2000). Localization of G-protein-coupled receptors in health and disease. Trends Pharmacol. Sci. 21, 304-308.

Ehlers, M. D., Fung, E. T., O'Brien, R. J. et al. (1998). Splice variant-specific interaction of the NMDA receptor subunit NR1 with neuronal intermediate filaments. J. Neurosci. 18, 720-730.

Elling, C. E., Moller Nielsen, S. and Schwartz, T. W. (1995). Conversion of antagonistbinding site to metal-ion site in tachykinin NK-1 receptor. Nature 374, 74-77.

Fagni, L., Chavis, P., Ango, F. et al. (2000). Complex interactions between mGluRs, intracellular Ca2+ stores and ion channels in neurons. Trends Neurosci $\mathbf{2 3}, 80-88$.

Farrens, D. L., Altenbach, C., Yang, K. et al. (1996). Requirement of rigid-body motion of transmembrane helices for light activation of rhodopsin. Science $\mathbf{2 7 4}$, 768-770.

Faure, S., Meyer, L., Costagliola, D. et al. (2000). Rapid progression to AIDS in HIV+ individuals with a structural variant of the chemokine receptor CX3CR1. Science 287, 2274-2277.

Ferreira, P., Nakayama, T., Pak, W. et al. (1996). Cyclophilin-related protein RanBP2 acts as chaperone for red/green opsin. Nature 383, 637-640.

Franco, M., Paris, S. and Chabre, M. (1995). The small G-protein ARF1GDP binds to the Gt beta gamma subunit of transducin, but not to Gt alpha GDP-Gt beta gamma. FEBS Lett 362, 286-290.

Fraser, C. M. and Venter, J. C. (1982). The size of the mammalian lung beta 2-adrenergic receptor as determined by target size analysis and immunoaffinity chromatography. Biochem. Biophys. Res. Commun. 109, 21-29. 
Fukuhara, S., Murga, C., Zohar, M. et al. (1999). A novel PDZ domain containing guanine nucleotide exchange factor links heterotrimeric G proteins to Rho. J. Biol. Chem. 274, $5868-5879$.

Galvez, T., Duthey, B., Kniazeff, J. et al. (2001). Complex allosteric cross-talk between subunits are required for $\mathrm{GABA}_{\mathrm{B}}$ receptor function. $E M B O J$. in press.

Galvez, T., Prézeau, L., Milioti, G. et al. (2000a). Mapping the agonist binding site of GABA B type 1 receptor: insights into the activation process of family 3 heptahelix receptors. $J$. Biol.Chem. in press.

Galvez, T., Urwyler, S., Prézeau, L. et al. (2000b). Ca(2+) requirement for high-affinity gamma-aminobutyric acid (GABA) binding at GABA(B) receptors: involvement of serine 269 of the GABA(B)R1 subunit. Mol. Pharmacol. 57, 419-426.

Gao, Q. and Chess, A. (1999). Identification of candidate Drosophila olfactory receptors from genomic DNA sequence. Genomics 60, 31-39.

George, S. R., Fan, T., Xie, Z. et al. (2000). Oligomerization of mu- and delta-opioid receptors. Generation of novel functional properties. J. Biol. Chem. 275, 26128-26135.

George, S. R., Lee, S. P., Varghese, G. et al. (1998). A transmembrane domain-derived peptide inhibits D1 dopamine receptor function without affecting receptor oligomerization. J. Biol. Chem. 273, 30244-30248.

Geras-Raaka, E., Varma, A., Ho, H. et al. (1998). Human interferon-gamma-inducible protein 10 (IP-10) inhibits constitutive signaling of Kaposi's sarcoma-associated herpesvirus G protein-coupled receptor. J Exp Med 188, 405-408.

Gether, U. (2000). Uncovering molecular mechanisms involved in activation of G proteincoupled receptors. Endocrinol. Rev. 21, 90-113. 
Gether, U., Ballesteros, J. A., Seifert, R. et al. (1997a). Structural instability of a constitutively active G protein-coupled receptor. Agonist-independent activation due to conformational flexibility. J. Biol. Chem. 272, 2587-2590.

Gether, U., Johansen, T. E., Snider, R. M. et al. (1993). Different binding epitopes on the NK1 receptor for substance P and a non-peptide antagonist. Nature 362, 345-348.

Gether, U., Lin, S., Ghanouni, P. et al. (1997b). Agonists induce conformational changes in transmembrane domains III and VI of the beta2 adrenoceptor. EMBO J. 16, 6737-6747.

Gilman, A. G. (1987). G proteins: transducers of receptor-generated signals. Annu. Rev. Biochem. 56, 615-649.

Godowski, P. J., Leung, D. W., Meacham, L. R. et al. (1989). Characterization of the human growth hormone receptor gene and demonstration of a partial gene deletion in two patients with Laron-type dwarfism. Proc. Natl. Acad. Sci. USA 86, 8083-8087.

Goldsmith, P. K., Fan, G. F., Ray, K. et al. (1999). Expression, purification, and biochemical characterization of the amino-terminal extracellular domain of the human calcium receptor. J. Biol. Chem. 274, 11303-11309.

Golser, R., Gorren, A. C., Leber, A. et al. (2000). Interaction of endothelial and neuronal nitric-oxide synthases with the bradykinin B2 receptor. Binding of an inhibitory peptide to the oxygenase domain blocks uncoupled NADPH oxidation [published erratum appears in J Biol Chem 2000 May 26; 275(21):16400]. J. Biol. Chem. 275, 5291-5296.

Gomeza, J., Joly, C., Kühn, R. et al. (1996a). The second intracellular loop of mGluR1 cooperates with the other intracellular domains to control coupling to G-protein. J. Biol. Chem. 271, 2199-2205.

Gomeza, J., Mary, S., Brabet, I. et al. (1996b). Coupling of metabotropic glutamate receptors 2 and 4 to $\mathrm{G} \alpha 15, \mathrm{G} \alpha 16$ and chimeric $\mathrm{G} \alpha \mathrm{q} / \mathrm{i}$ proteins: characterization of new antagonists. Mol. Pharmacol. 50, 923-930. 
Grazzini, E., Guillon, G., Mouillac, B. et al. (1998). Inhibition of oxytocin receptor function by direct binding of progesterone. Nature 392, 509-512.

Groblewski, T., Maigret, B., Larguier, R. et al. (1997). Mutation of Asn111 in the third transmembrane domain of the AT1A angiotensin II receptor induces its constitutive activation. J. Biol. Chem. 272, 1822-1826.

Gudermann, T., Grosse, R. and Schultz, G. (2000). Contribution of receptor/G protein signaling to cell growth and transformation. Naunyn Schmiedebergs Arch Pharmacol 361, 345-362.

Guillet-Deniau, I., Burnol, A. F. and Girard, J. (1997). Identification and localization of a skeletal muscle secrotonin 5-HT2A receptor coupled to the Jak/STAT pathway. J. Biol. Chem. 272, 14825-14829.

Hager, J., Hansen, L., Vaisse, C. et al. (1995). A missense mutation in the glucagon receptor gene is associated with non-insulin-dependent diabetes mellitus. Nat Genet 9, 299-304.

Hall, R., Premont, R., Chow, C. et al. (1998a). The beta 2 -adrenergic receptor interacts with the $\mathrm{Na}^{+} / \mathrm{H}^{+}$-exchanger regulatory factor to control $\mathrm{Na}^{+} / \mathrm{H}^{+}$exchange. Nature $392,626-$ 630.

Hall, R. A., Ostedgaard, L. S., Premont, R. T. et al. (1998b). A C-terminal motif found in the beta2-adrenergic receptor, $\mathrm{P} 2 \mathrm{Y} 1$ receptor and cystic fibrosis transmembrane conductance regulator determines binding to the $\mathrm{Na}+/ \mathrm{H}+$ exchanger regulatory factor family of PDZ proteins. Proc. Natl. Acad. Sci. USA 95, 8496-8501.

Hall, R. A., Premont, R. T. and Lefkowitz, R. J. (1999). Heptahelical receptor signaling: beyond the G protein paradigm. J Cell Biol 145, 927-932.

Hamm, H. (1998). The many faces of G protein signaling. J. Biol. Chem. 273, 669-672.

Hammerland, L. G., Krapcho, K. J., Garrett, J. E. et al. (1999). Domains determining ligand specificity for Ca2+ receptors. Mol. Pharmacol. 55, 642-648. 
Harhammer, R., Gohla, A. and Schultz, G. (1996). Interaction of G protein Gbetagamma dimers with small GTP-binding proteins of the Rho family. FEBS Lett 399, 211-214.

Hart, A. C., Kramer, H., Van Vactor, D. L., Jr. et al. (1990). Induction of cell fate in the Drosophila retina: the bride of sevenless protein is predicted to contain a large extracellular domain and seven transmembrane segments. Genes Dev 4, 1835-1847.

Hart, M. J., Jiang, X., Kozasa, T. et al. (1998). Direct stimulation of the guanine nucleotide exchange activity of p115 RhoGEF by Galpha13. Science 280, 2112-2114.

Hasegawa, H., Negishi, M. and Ichikawa, A. (1996). Two isoforms of the prostaglandin E receptor EP3 subtype different in agonist-independent constitutive activity. J. Biol. Chem. 271, $1857-1860$.

He, W., Cowan, C. W. and Wensel, T. G. (1998). RGS9, a GTPase accelerator for phototransduction. Neuron 20, 95-102.

Hebert, T. E., Moffett, S., Morello, J. P. et al. (1996). A peptide derived from a $\beta_{2} A R$ transmembrane domain inhibits both receptor dimerization and activation. J. Biol. Chem. 271, 16384-16392.

Heeneman, S., Haendeler, J., Saito, Y. et al. (2000). Angiotensin II induces transactivation of two different populations of the platelet-derived growth factor beta receptor. Key role for the p66 adaptor protein Shc. J. Biol. Chem. 275, 15926-15932.

Herbert, T. E., Moffett, S., Morello, J. P. et al. (1996). A peptide derived from a $\beta_{2}$-adrenergic receptor transmembrane domain inhibits both receptor dimerization and activation. $J$. Biol. Chem. 271, 16384-16392.

Hinney, A., Schmidt, A., Nottebom, K. et al. (1999). Several mutations in the melanocortin-4 receptor gene including a nonsense and a frameshift mutation associated with dominantly inherited obesity in humans. J Clin Endocrinol Metab 84, 1483-1486. 
Hinuma, S., Habata, Y., Fujii, R. et al. (1998). A prolactin-releasing peptide in the brain. [published erratum appears in Nature 1998 Jul 16;394(6690):302]. Nature 393, 272-276.

Hinuma, S., Onda, H. and Fujino, M. (1999). The quest for novel bioactive peptides utilizing orphan seven-transmembrane-domain receptors. Journal of Molecular Medicine 77, 495504.

Hirata, T., Kakizuka, A., Ushikubi, F. et al. (1994). Arg60 to Leu mutation of the human thromboxane A2 receptor in a dominantly inherited bleeding disorder. J Clin Invest 94, $1662-1667$

Hoon, M. A., Adler, E., Lindemeier, J. et al. (1999). Putative mammalian taste receptors: a class of taste-specific GPCRs with distinct topographic selectivity. Cell 96, 541-551.

Houssami, S., Findlay, D. M., Brady, C. L. et al. (1994). Isoforms of the rat calcitonin receptor: consequences for ligand binding and signal transduction. Endocrinology 135, 183-190.

Hsu, S. Y., Liang, S. G. and Hsueh, A. J. (1998). Characterization of two LGR genes homologous to gonadotropin and thyrotropin receptors with extracellular leucine-rich repeats and a G protein-coupled, seven-transmembrane region. Mol. Endocrinol. 12, $1830-1845$

Innamorati, G., Sadeghi, H. and Birnbaumer, M. (1999). Phosphorylation and recycling kinetics of G protein-coupled receptors. J. Recept. Signal Transduct. Res. 19, 315-326. Javitch, J. A., Fu, D., Liapakis, G. et al. (1997). Constitutive activation of the $\beta_{2}$-adrenergic receptor alters the orientation of its sixth membrane-spanning segment. J. Biol. Chem. 272, 18546-18549.

Joly, C., Gomeza, J., Brabet, I. et al. (1995). Molecular, functional and pharmacological characterization of the metabotropic glutamate receptor type 5 splice variants: comparison with mGluR1. J. Neurosci. 15., 3970-3981. 
Jones, K., Borowsky, B., Tamm, J. et al. (1998a). Cloning of GABA ${ }_{B}$ R2: Coexpression with $\mathrm{GABA}_{\mathrm{B}-} \mathrm{R} 1$ permits GIRK activation in oocytes and mammalian cells. Society Neurosci. Abstr. 24, 1991.

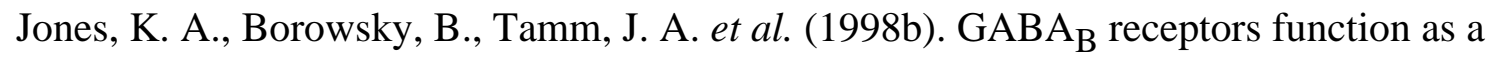
heteromeric assembly of the subunits $\mathrm{GABA}_{\mathrm{B}} \mathrm{R} 1$ and $\mathrm{GABA}_{\mathrm{B}} \mathrm{R} 2$. Nature 396, 674-679.

Jordan, B. A. and Devi, L. A. (1999). G-protein-coupled receptor heterodimerization modulates receptor function. Nature 399, 697-700.

Josefsson, L. G. (1999). Evidence for kinship between diverse G-protein coupled receptors. Gene 239, 333-340.

Josefsson, L. G. and Rask, L. (1997). Cloning of a putative G-protein-coupled receptor from Arabidopsis thaliana. Eur J Biochem 249, 415-20.

Ju, H., Venema, V. J., Marrero, M. B. et al. (1998). Inhibitory interactions of the bradykinin B2 receptor with endothelial nitric-oxide synthase. J. Biol. Chem. 273, 24025-24029.

Jung, H., Windhaber, R., Palm, D. et al. (1996). Conformation of a $\beta$-adrenoceptor-derived signal transducing peptide as inferred by circular dichroism and 1H NMR spectroscopy. Biochemistry 35, 6399-6405.

Kajava, A. V., Vassart, G. and Wodak, S. J. (1995). Modeling of the three-dimensional structure of proteins with the typical leucine-rich repeats. Structure 3, 867-877.

Kammerer, R. A., Frank, S., Schulthess, T. et al. (1999). Heterodimerization of a functional GABAB receptor is mediated by parallel coiled-coil alpha-helices. Biochemistry $\mathbf{3 8 ,}$ 13263-13269.

Karoor, V., Wang, L., Wang, H. Y. et al. (1998). Insulin stimulates sequestration of betaadrenergic receptors and enhanced association of beta-adrenergic receptors with Grb2 via tyrosine 350. J. Biol. Chem. 273, 33035-33041. 
Kato, A., Ozawa, F., Saitoh, Y. et al. (1998). Novel members of the Ves1/Homer family of the PDZ proteins that bind metabotropic glutamate receptors. J. Biol. Chem. 273, 2396923975.

Kato, A., Ozawa, F., Saitoh, Y. et al. (1997). vesl, a gene encoding VASP/Ena family related protein is upregulated during seizure, long-term potentiation and synaptogenesis. FEBS Lett. 412, 183-189.

Kaupmann, K., Huggel, H., Heid, J. et al. (1997). Expression cloning of GABA B receptors uncovers similarity to metabotropic glutamate receptors. Nature 386, 239-246.

Kaupmann, K., Malitschek, B., Schuler, V. et al. (1998). GABA B receptor subtypes assemble into functional heteromeric complexes. Nature 396, 683-687.

Kawabata, S., Tsutsumi, R., Kohara, A. et al. (1996). Control of calcium oscillation of metabotropic glutamate receptors. Nature 383, 89-92.

Kawasaki, H., Springett, G., Toki, S. et al. (1998). A rap guanine nucleotide exchange factor enriched highly in the basal ganglia. Proc. Natl. Acad. Sci. USA 95, 1378-13283.

Kenakin, T. and Weiss, J. (1996). The evolution of drug-receptor models: the cubic ternary complex model for seven transmembrane domain receptors. Biopharm. J 1, 3-14.

Kim, J. Y., Borleis, J. A. and Devreotes, P. N. (1998). Switching of chemoattractant receptors programs development and morphogenesis in Dictyostelium: receptor subtypes activate common responses at different agonist concentrations. Dev. Biol. 197, 117-128.

Kjelsberg, M. A., Cotecchia, S., Ostrowski, J. et al. (1992). Constitutive activation of the $\alpha_{1 B^{-}}$ adrenergic receptor by all amino acid substitutions at a single site. J. Biol. Chem. 267, $1430-1433$

Kledal, T. N., Rosenkilde, M. M., Coulin, F. et al. (1997). A broad-spectrum chemokine antagonist encoded by Kaposi's sarcoma-associated herpesvirus. Science 277, 1656-1659. 
Klein, P., Sun, T., Saxe, C., 3rd et al. (1988). A chemoattractant receptor controls development in Dictyostelium discoideum. Science 241, 1467-1472.

Kolakowski, L. F., Jr. (1994). GCRDb: a G-protein-coupled receptor database. Receptors Channels 2, 1-7.

Kornau, H., Seeburg, P. and Kennedy, M. (1997). Interaction of ion channels and receptors with PDZ domain proteins. Curr. Opin. Neurobiol. 7, 368-373.

Kostenis, E., Gomeza, J., Lerche, C. et al. (1997). Genetic analysis of receptor-Gaq coupling selectivity. J. Biol. Chem. 272, 23675-23681.

Kozasa, T., Jiang, X., Hart, M. J. et al. (1998). p115 RhoGEF, a GTPase activating protein for Galpha12 and Galpha13. Science 280, 2109-2111.

Krasnoperov, V. G., Bittner, M. A., Beavis, R. et al. (1997). $\alpha$-Latrotoxin stimulates exocytosis by the interaction with a neuronal G-protein-coupled receptor. Neuron $\mathbf{1 8}$, 925-937.

Kubo, Y., Miyashita, T. and Murata, Y. (1998). Structural basis for a Ca2+-sensing function of the metabotropic glutamate receptors. Science 279, 1722-1725.

Kuner, R., Kohr, G., Grunewald, S. et al. (1999). Role of heteromer formation in GABAB receptor function. Science $\mathbf{2 8 3}, \mathbf{7 4 - 7 7 .}$

Kunishima, N., Shimada, Y., Tsuji, Y. et al. (2000). Structural basis of glutamate recognition by a dimeric metabotropic glutamate receptor. Nature 407, 971-977.

Lambright, D. G., Noel, J. P., Hamm, H. E. et al. (1994). Structural determinants for activation of the $\alpha$-subunit of a heterotrimeric G protein. Nature 369, 621-628.

Lambright, D. G., Sondek, J., Bohn, A. et al. (1996). The 2.0A crystal structure of a heterotrimeric G protein. Nature 379, 311-319. 
Laporte, S. A., Oakley, R. H., Holt, J. A. et al. (2000). The interaction of beta-arrestin with the AP-2 adaptor is required for the clustering of beta 2-adrenergic receptor into clathrincoated pits. J. Biol. Chem. 275, 23120-23126.

Laporte, S. A., Oakley, R. H., Zhang, J. et al. (1999). The beta2-adrenergic receptor/betaarrestin complex recruits the clathrin adaptor AP-2 during endocytosis. Proc. Natl. Acad. Sci. USA 96, 3712-3717.

Lazareno, S., Popham, A. and Birdsall, N. J. (2000). Allosteric interactions of staurosporine and other indolocarbazoles with $\mathrm{N}-[$ methyl-(3)H] scopolamine and acetylcholine at muscarinic receptor subtypes: identification of a second allosteric site. Mol. Pharmacol. 58, 194-207.

Lee, C., Murakami, T. and Simonds, W. F. (1995). Identification of a discrete region of the G protein $\gamma$ subunit conferring selectivity in $\beta \gamma$ complex formation. J. Biol. Chem. 270, 8779-8784.

Lee, D., George, S., Evans, J. et al. (2001). Orphan G protein-coupled receptors in the central nervous system. Curr. Opin. Pharmacol. 1, 31-39.

Lefkowitz, R. J., Cotecchia, S., Samana, P. et al. (1993). Constitutive activity of receptors coupled to guanine nucleotide regulatory proteins. Trends Pharmacol. Sci. 14, 303-304.

Lezcano, N., Mrzljak, L., Eubanks, S. et al. (2000). Dual signaling regulated by calcyon, a D1 dopamine receptor interacting protein. Science 287, 1660-1664.

Libert, F., Cochaux, P., Beckman, G. et al. (1998). The deltaccr5 mutation conferring protection against HIV-1 in Caucasian populations has a single and recent origin in Northeastern Europe. Hum. Mol. Genet. 7, 399-406.

Lin, L., Faraco, J., Li, R. et al. (1999). The sleep disorder canine narcolepsy is caused by a mutation in the hypocretin (orexin) receptor 2 gene. Cell 98, 365-376. 
Lin, S. W. and Sakmar, T. P. (1996). Specific tryptophan UV-absorbance changes are probes of the transition of rhodopsin to its active state. Biochemistry 35, 11149-11159.

Lin, Y. J., Seroude, L. and Benzer, S. (1998). Extended life-span and stress resistance in the Drosophila mutant methuselah. Science 282, 943-946.

Litschig, S., Gasparini, F., Rueegg, D. et al. (1998). CPCCOEt, a non-competitive mGluR1 antagonist, inhibits receptor signaling without affecting glutamate binding. Mol. Pharmacol.. 55, 453-461.

Liu, F., Wan, Q., Pristupa, Z. B. et al. (2000). Direct protein-protein coupling enables crosstalk between dopamine D5 and gamma-aminobutyric acid A receptors. Nature 403, 274280.

Liu, J., Conklin, B., Blin, N. et al. (1995). Identification of a receptor/G protein contact site critical for signaling specificity and G protein activation. Proc. Natl. Acad. Sci. USA 92, 11642-11646.

Liu, J. and Wess, J. (1996). Different single receptor domains determine the distinct G protein coupling profiles of members of the vasopressin receptor family. J. Biol. Chem. 271, $8772-8778$.

Lopez, I., Mak, E. C., Ding, J. et al. (2001). A novel bifunctional phospholipase C that is regulated by $\mathrm{G}\{$ alpha $\} 12$ and stimulates the Ras/mitogen-activated protein kinase pathway. J. Biol. Chem. 276, 2758-2765.

Luttrell, L. M., Ferguson, S. S., Daaka, Y. et al. (1999). Beta-arrestin-dependent formation of beta2 adrenergic receptor-Src protein kinase complexes. Science 283, 655-661.

Luttrell, L. M., van Biesen, T., Hawes, B. E. et al. (1998). Regulation of mitogen-activated protein kinase pathways by catecholamine receptors. Adv Pharmacol 42, 466-470.

MacEwan, D. J., Kim, G. D. and Milligan, G. (1996). Agonist regulation of adenylate cyclase activity in neuroblastoma $\mathrm{x}$ glioma hybrid NG108-15 cells transfected to co-express 
adenylate cyclase type II and the beta 2-adrenoceptor. Evidence that adenylate cyclase is the limiting component for receptor-mediated stimulation of adenylate cyclase activity. Biochem. J. 318, 1033-1039.

MacEwan, D. J. and Milligan, G. (1996a). Inverse agonist-induced up-regulation of the human beta2-adrenoceptor in transfected neuroblastoma X glioma hybrid cells. Mol. Pharmacol. 50, 1479-1486.

MacEwan, D. J. and Milligan, G. (1996b). Up-regulation of a constitutively active form of the beta2-adrenoceptor by sustained treatment with inverse agonists but not antagonists. FEBS Lett 399, 108-112.

Maggio, R., Vogel, Z. and Wess, J. (1993). Coexpression studies with mutant muscarinic/adrenergic receptors provide evidence for intermolecular "cross-talk" between G-protein-linked receptors. Proc. Natl. Acad. Sci. USA 90, 3103-3107.

Maheshwari, H. G., Silverman, B. L., Dupuis, J. et al. (1998). Phenotype and genetic analysis of a syndrome caused by an inactivating mutation in the growth hormone-releasing hormone receptor: Dwarfism of Sindh. J Clin Endocrinol Metab 83, 4065-4074.

Malitschek, B., Schweizer, C., Keir, M. et al. (1999). The N-terminal domain of gammaaminobutyric Acid(B) receptors is sufficient to specify agonist and antagonist binding. Mol. Pharmacol. 56, 448-454.

Mancini, A., Koch, A., Stefan, M. et al. (2000). The direct association of the multiple PDZ domain containing proteins (MUPP-1) with the human c-Kit C-terminus is regulated by tyrosine kinase activity. FEBS Lett 482, 54-58.

Manivet, P., Mouillet-Richard, S., Callebert, J. et al. (2000). PDZ-dependent activation of nitric-oxide synthases by the serotonin 2B receptor. J. Biol. Chem. 275, 9324-9331. Margeta-Mitrovic, M., Jan, Y. N. and Jan, L. Y. (2000). A trafficking checkpoint controls GABA(B) receptor heterodimerization. Neuron 27, 97-106. 
Marrero, M. B., Schieffer, B., Paxton, W. G. et al. (1995). Direct stimulation of Jak/STAT pathway by the angiotensin II AT1 receptor. Nature 375, 247-250.

Marrero, M. B., Venema, V. J., Ju, H. et al. (1999). Endothelial nitric oxide synthase interactions with G-protein-coupled receptors. Biochem. J. 343 Pt 2, 335-340.

Mary, S., Gomeza, J., Prézeau, L. et al. (1998). A cluster of basic residues in the carboxylterminal tail of the short metabotropic glutamate receptor 1 variants impairs their coupling to phospholipase C. J. Biol. Chem. 273, 425-432.

Mattingly, R. R. and Macara, I. G. (1996). Phosphorylation-dependent activation of the RasGRF/CDC25Mm exchange factor by muscarinic receptors and G-protein beta gamma subunits. Nature 382, 268-272.

Matus-Leibovitch, N., Nussensveig, D. R., Gershengorn, M. C. et al. (1995). Truncation of the thyrotropin-releasing hormone receptor carboxyl tail causes constitutive activity and leads to impaired responsiveness in Xenopus oocytes and AtT20 cells. J. Biol. Chem. 270, 1041-1047.

Maximov, A., Sudhof, T. C. and Bezprozvanny, I. (1999). Association of neuronal calcium channels with modular adaptor proteins. J. Biol. Chem. 274, 24453-24456.

Mazzoni, M. R. and Hamm, H. E. (1996). Interaction of transducin with light-activated rhodopsin protects It from proteolytic digestion by trypsin. J. Biol. Chem. 271, 3003430040.

McDonald, P. H., Cote, N. L., Lin, F. T. et al. (1999). Identification of NSF as a betaarrestin1-binding protein. Implications for beta2-adrenergic receptor regulation. J. Biol. Chem. 274, 10677-10680.

Meunier, J. C., Mollereau, C., Toll, L. et al. (1995). Isolation and structure of the endogenous agonist of opioid receptor-like ORL1 receptor. Nature 377, 532-535. 
Milligan, G. (1993). Agonist regulation of cellular G protein levels and distribution: mechanisms and functional implications. Trends Pharmacol. Sci. 14, 413-418.

Minakami, R., Jinnai, N. and Sugiyama, H. (1997). Phosphorylation and calmodulin binding of the metabotropic glutamate receptor subtype 5 (mGluR5) are antagonistic in vitro. $J$. Biol. Chem. 272, 20291-20298.

Misrahi, M., Beau, I., Meduri, G. et al. (1998). Gonadotropin receptors and the control of gonadal steroidogenesis: physiology and pathology. Baillieres Clin Endocrinol Metab 12, $35-66$.

Mitchell, R., McCulloch, D., Lutz, E. et al. (1998). Rhodopsin-family receptors associate with small G proteins to activate phospholipase D. Nature 392, 411-414.

Mixon, M. B., Lee, E., Coleman, D. E. et al. (1995). Tertiary and quaternary structural changes in Gi 1 induced by GTP hydrolysis. Science 270, 954-960.

Mochizuki, N., Ohba, Y., Kiyokawa, E. et al. (1999). Activation of the ERK/MAPK pathway by an isoform of rap1GAP associated with G alpha(i). Nature 400, 891-894.

Monnot, C., Bihoreau, C., Conchon, C. et al. (1996). Polar residues in the transmembrane domains of the type 1 angiotensin II receptor are required for binding and coupling. $J$. Biol. Chem. 271, 1507-1513.

Monod, J., Wyman, J. and Changeux, J.-P. (1965). On the nature of allosteric transitions: a plausible model. J. Mol. Biol. 12, 88-118.

Montell, C. (1997). New light on TRP and TRPL. Mol. Pharmacol. 52, 755-763.

Morello, J. P., Salahpour, A., Laperriere, A. et al. (2000). Pharmacological chaperones rescue cell-surface expression and function of misfolded V2 vasopressin receptor mutants. $J$ Clin Invest 105, 887-895. 
Morin, D., Cotte, N., Balestre, M.-N. et al. (1998). The D136A mutation of the V2 vasopressin receptor induces a constitutive activity which permits discrimination between antagonists with partial agonist and inverse agonists activities. FEBS Lett. 441, 470-475.

Morisset, S., Traiffort, E., Arrang, J. M. et al. (2000). Changes in histamine H3 receptor responsiveness in mouse brain. Journal of Neurochemistry 74, 339-346.

Naisbitt, S., Kim, E., Tu, J. C. et al. (1999). Shank, a novel family of postsynaptic density proteins that binds to the NMDA receptor/PSD-95/GKAP complex and cortactin. Neuron 23, 569-582.

Nakajima, Y., Yamamoto, T., Nakayama, T. et al. (1999). A relationship between protein kinase $\mathrm{C}$ phosphorylation and calmodulin binding to the metabotropic glutamate receptor subtype 7. J. Biol. Chem. 274, 27573-27577.

Nathans, J. (1999). The evolution and physiology of human color vision: insights from molecular genetic studies of visual pigments. Neuron 24, 299-312.

Natochin, M., McEntaffer, R. L. and Artemyev, N. O. (1998). Mutational analysis of the Asn residue essential for RGS protein binding to G-proteins. J. Biol. Chem. 273, 6731-5.

Naville, D., Barjhoux, L., Jaillard, C. et al. (1996). [Mutations of ACTH receptor gene and familial syndrome of glucocorticoid deficiency]. Ann Endocrinol 57, 101-106.

Navon, S. E. and Fung, B. K. K. (1984). Characterization of transducin from bovine retinal rod outer segments: mechanism and effects of cholera toxin-catalysed ADP ribosylation. J. Biol. Chem. 259, 6686-6693.

Nehring, R. B., Horikawa, H. P., El Far, O. et al. (2000). The Metabotropic GABAB Receptor Directly Interacts with the Activating Transcription Factor 4 (ATF-4). J. Biol. Chem. 275, $35185-35191$. 
Nemeth, E. F., Steffey, M. E., Hammerland, L. G. et al. (1998). Calcimimetics with potent and selective activity on the parathyroid calcium receptor. Proc. Natl. Acad. Sci. USA 95, 4040-4045.

New, D. and Wong, J. (1998). The evidence for G-protein-coupled receptors and heterotrimeric G proteins in protozoa and ancestral metazoa. Biol. Signals Recept. 7, 98108.

Ng, G. Y., Clark, J., Coulombe, N. et al. (1999). Identification of a GABAB receptor subunit, gb2, required for functional GABAB receptor activity. J. Biol. Chem. 274, 7607-7610.

Ng, G. Y., O'Dowd, B. F., Lee, S. P. et al. (1996). Dopamine D2 receptor dimers and receptor-blocking peptides. Biochem. Biophys. Res. Commun. 227, 200-204.

Nicoletti, F., Wroblewski, J. T., Novelli, A. et al. (1986). The activation of inositol phospholipid metabolism as a signal-transduction system for excitatory amino acids in primary cultures of cerebellar granule cells. J. Neurosci. 6, 1905-1911.

Noel, J. P., Hamm, H. E. and Sigler, P. B. (1993). The $2.2 \AA$ crystal structure of transducin- $\alpha$ complexed with GTPYS. Nature 366, 654-663.

Northup, J. K., Smigel, M. D., Sternweis, P. C. et al. (1983). The subunits of the stimulatory regulatory component of adenylate cyclase. Resolution of the activated 45,000 Dalton (alpha) subunit. J. Biol. Chem. 258, 11369-11376.

O'Brien, R. J., Lau, L. F. and Huganir, R. L. (1998). Molecular mechanisms of glutamate receptor clustering at excitatory synapses. Curr. Opin. Neurobiol. 8, 364-369.

O'Connor, V., El Far, O., Bofill-Cardona, E. et al. (1999). Calmodulin dependence of presynaptic metabotropic glutamate receptor signaling. Science 286, 1180-1184.

O'Hara, P. J., Sheppard, P. O., Thogersen, H. et al. (1993). The ligand-binding domain in metabotropic glutamate receptors is related to bacterial periplasmic binding proteins. Neuron 11, 41-52. 
Oakley, R. H., Laporte, S. A., Holt, J. A. et al. (1999). Association of beta-arrestin with G protein-coupled receptors during clathrin-mediated endocytosis dictates the profile of receptor resensitization. J. Biol. Chem. 274, 32248-32257.

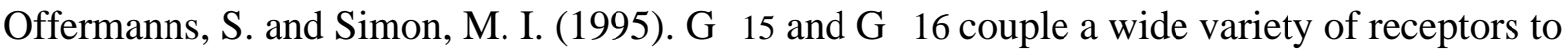
phospholipase C. J. Biol. Chem. 270, 15175-15180.

Okamoto, T., Sekiyama, N., Otsu, M. et al. (1998). Expression and purification of extracellular ligand binding region of metabotropic glutamate receptor subtype. J. Biol. Chem 273, 13089-13096.

Okimura, J. T. and Norton, S. A. (1998). Jealousy and mutilation: nose-biting as retribution for adultery. Lancet 352, 2010-2011.

Oliviera, L., Paiva, A. C. M., Sander, C. et al. (1994). A common step for signal transduction in G protein-coupled receptors. Trends Pharmacol. Sci. 15, 170-172.

Orly, J. and Schramm, M. (1976). Coupling of catecholamines receptor from one cell with adenylate cyclase from another cell by cell fusion. J. Biol.Chem. 73, 4410-4414.

Overton, M. C. and Blumer, K. J. (2000). G-protein-coupled receptors function as oligomers in vivo. Curr. Biol. 10, 341-344.

Pagano, A., Ruegg, D., Litschig, S. et al. (2000). The non-competitive antagonists 2-methyl6-(phenylethynyl)pyridine and 7-Hydroxyiminocyclopropan[b]chromen-1a-carboxylic acid ethyl ester interact with overlapping binding pockets in the transmembrane region of group I metabotropic glutamate receptors. J. Biol. Chem. 275, 33750-33758.

Page, R. D. (1996). TreeView: an application to display phylogenetic trees on personal computers. Computer Applications in the Biosciences 12, 357-358.

Palczewski, K., Kumasaka, T., Hori, T. et al. (2000). Crystal structure of rhodopsin: A G protein-coupled receptor. Science $\mathbf{2 8 9}$, 739-745. 
Pantaloni, C., Brabet, P., Bilanges, B. et al. (1996). Alternative splicing in the N-terminal domain of the PACAP receptor modulates receptor selectivity and relative potencies of PACAP-27 and -38 in phospholipase C activation. J. Biol. Chem. 271, 22146-22151.

Parker, E. M. and Ross, E. M. (1991). Truncation of the extended carboxyl-terminal domain increases the expression and regulatory activity of the avian $\beta$-adrenergic receptor. $J$. Biol. Chem. 266, 9987-9996.

Parma, J., Duprez, L., Van Sande, J. et al. (1993). Somatic mutations in the thyrotropin receptor gene cause hyperfunctioning thyroid adenoma. Nature $\mathbf{3 6 5}$, 649-651.

Parma, J., Van Sande, J., Swillens, S. et al. (1995). Somatic mutations causing constitutive activity of the thyrotropin receptor are the major cause of hyperfunctioning thyroid adenomas: identification of additional mutations activating both the cyclic adenosine 3',5'-monophosphate and inositol phosphate-Ca2+ cascades. Mol. Endocrinol. 9, 725-733.

Parmentier, M.-L., Joly, C., Restituito, S. et al. (1998). The G-protein coupling profile of the metabotropic glutamate receptors, as determined with exogenous proteins, is independent of their ligand recognition domain. Mol. Pharmacol. 53, 778-786.

Parmentier, M. L., Galvez, T., Acher, F. et al. (2000a). Conservation of the ligand recognition site of metabotropic glutamate receptors during evolution. Neuropharmacology 39, 11191131.

Parmentier, M. L., Pin, J. P., Bockaert, J. et al. (1996). Cloning and functional expression of a Drosophila metabotropic glutamate receptor expressed in the embryonic CNS. $J$. Neurosci. 16, 6687-6694.

Parmentier, M. L., Woods, D., Greig, S. et al. (2000b). Rapsynoid/Partner of Inscuteable controls asymmetric division of larval neuroblasts in Drosophila. J. Neuroscience 20, RC84 1. 
Patapoutian, A. and Reichardt, L. F. (2000). Roles of Wnt proteins in neural development and maintenance. Curr. Opin. Neurobiol. 10, 392-399.

Perrimon, N. (1996). Serpentine proteins slither into the wingless and hedgehog fields. Cell 86, 513-516.

Peyron, C., Faraco, J., Rogers, W. et al. (2000). A mutation in a case of early onset narcolepsy and a generalized absence of hypocretin peptides in human narcoleptic brains. Nature Med 6, 991-997.

Phang, T., Kundu, G., Hong, S. et al. (1998). The amino-terminal region of the luteinizing hormone/choriogonadotropin receptor contacts both subunits of human choriogonadotropin. II. Photoaffinity labeling. J. Biol. Chem. 273, 13841-13847.

Pin, J. P., De Colle, C., Bessis, A. S. et al. (1999). New perspectives for the development of selective metabotropic glutamate receptor ligands. Eur. J. Pharmacol. 375, 277-294.

Pin, J. P. and Duvoisin, R. (1995). The metabotropic glutamate receptors: structure and functions. Neuropharmacology 34, 1-26.

Pitcher, J. A., Freedman, N. J. and Lefkowitz, R. J. (1998). G protein-coupled receptor kinases. Annu. Rev. Biochem. 67, 653-692.

Plakidou-Dymock, S., Dymock, D. and Hooley, R. (1998). A higher plant seventransmembrane receptor that influences sensitivity to cytokinins. Curr. Biol. 8, 315-324.

Porter, J. E. and Perez, D. M. (1999). Characteristics for a salt-bridge switch mutation of the alpha(1b) adrenergic receptor. Altered pharmacology and rescue of constitutive activity. J. Biol. Chem. 274, 34535-34538.

Prehoda, K. E., Lee, D. J. and Lim, W. A. (1999). Structure of the enabled/VASP homology 1 domain-peptide complex: a key component in the spatial control of actin assembly. Cell 97, 471-480. 
Prézeau, L., Gomeza, J., Ahern, S. et al. (1996). Changes in the carboxyl-terminal domain of metabotropic glutamate receptor 1 by alternative splicing generate receptors with differing agonist-independent activity. Mol. Pharmacol. 49, 422-429.

Prézeau, L., Richman, J. G., Edwards, S. W. et al. (1999). The zeta isoform of 14-3-3 proteins interacts with the third intracellular loop of different alpha2-adrenergic receptor subtypes. J. Biol. Chem. 274, 13462-13469.

Puffenberger, E. G., Hosoda, K., Washington, S. S. et al. (1994). A missense mutation of the endothelin-B receptor gene in multigenic Hirschsprung's disease. Cell 79, 1257-1266.

Quitterer, U., Zaki, E. and AbdAlla, S. (1999). Investigation of the extracellular accessibility of the connecting loop between membrane domains I and II of the bradykinin B2 receptor. J. Biol. Chem. 274, 14773-14778.

Rasmussen, S. G., Jensen, A. D., Liapakis, G. et al. (1999). Mutation of a highly conserved aspartic acid in the beta2 adrenergic receptor: constitutive activation, structural instability, and conformational rearrangement of transmembrane segment 6. Molecular Pharmacology 56, 175-184.

Rath, P., DeCaluwe, L. L., Bovee-Geurts, P. H. et al. (1993). Fourier transform infrared difference spectroscopy of rhodopsin mutants: light activation of rhodopsin causes hydrogen-bonding change in residue aspartic acid-83 during meta II formation. Biochemistry 32, 10277-102782.

Reinscheid, R. K., Nothacker, H. P., Bourson, A. et al. (1995). Orphanin FQ: a neuropeptide that activates an opioid-like G protein-coupled receptor. Science 270, 792-794.

Robbins, L. S., Nadeau, J. H., Johnson, K. R. et al. (1993). Pigmentation phenotypes of variant extension locus alleles result from point mutations that alter MSH receptor function. Cell 72, 827-834. 
Robbins, M. J., Ciruela, F., Rhodes, A. et al. (1999). Characterization of the dimerization of metabotropic glutamate receptors using an N-terminal truncation of mGluR1alpha. $J$ Neurochem 72, 2539-2547.

Robinson, P. R., Cohen, G. B., Zhukovsky, E. A. et al. (1992). Constitutively active mutants of rhodopsin. Neuron 9, 719-725.

Rocheville, M., Lange, D. C., Kumar, U. et al. (2000a). Receptors for dopamine and somatostatin: formation of hetero-oligomers with enhanced functional activity. Science 288, 154-157.

Rocheville, M., Lange, D. C., Kumar, U. et al. (2000b). Subtypes of the somatostatin receptor assemble as functional homo- and heterodimers. J. Biol. Chem. 275, 7862-7869.

Rodbell, M. (1992). The role of GTP-binding proteins in signal transduction: from the sublimely simple to the conceptually complex. Curr. Top. Cell. Regul. 32, 1-47.

Rodbell, M. (1995). Nobel Lecture. Signal transduction: evolution of an idea. Biosci.Rep. 15, 117-133.

Rodbell, M., Birnbaumer, L., Pohl, S. L. et al. (1971). The glucagon-sensitive adenylyl cyclase system in plasma membranes of rat liver. V. An obligatory role of guanyl nucleotides in glucagon action. J. Biol. Chem. 246, 1877-1882.

Rodien, P., Bremont, C., Sanson, M. L. et al. (1998). Familial gestational hyperthyroidism caused by a mutant thyrotropin receptor hypersensitive to human chorionic gonadotropin. N Engl J Med 339, 1823-1826.

Romano, C., Yang, W.-L. and O'Malley, K. L. (1996). Metabotropic glutamate receptor 5 is a disulfide-linked dimer. J. Biol. Chem. 271, 28612-28616.

Rosenfeld, P. J., Cowley, G. S., McGee, T. L. et al. (1992). A null mutation in the rhodopsin gene causes rod photoreceptor dysfunction and autosomal recessive retinitis pigmentosa. Nat Genet 1, 209-213. 
Rosenkilde, M. M., Kledal, T. N., Brauner-Osborne, H. et al. (1999). Agonists and inverse agonists for the herpesvirus 8-encoded constitutively active seven-transmembrane oncogene product, ORF-74. J. Biol. Chem. 274, 956-961.

Roush, W. (1996). Regulating G protein signaling [news]. Science 271, 1056-1058.

Rubin, G. M., Yandell, M. D., Wortman, J. R. et al. (2000). Comparative genomics of the eukaryotes. Science 287, 2204-2215.

Ruiz i Altaba, R. (1997). Catching a Gli-mpse of hedgehog. Cell 90, 193-196.

Sabroe, I., Peck, M. J., Van Keulen, B. J. et al. (2000). A small molecule antagonist of chemokine receptors CCR1 and CCR3. Potent inhibition of eosinophil function and CCR3-mediated HIV-1 entry. J. Biol. Chem. 275, 25985-25992.

Saito, Y., Nothacker, H. P., Wang, Z. et al. (1999). Molecular characterization of the melaninconcentrating-hormone receptor. Nature 400, 265-269.

Sakurai, T., Amemiya, A., Ishii, M. et al. (1998). Orexins and orexin receptors: a family of hypothalamic neuropeptides and $\mathrm{G}$ protein-coupled receptors that regulate feeding behavior. Cell 92, 573-585.

Salahpour, A., Angers, S. and Bouvier, M. (2000). Functional Significance of Oligomerization of G-protein-coupled Receptors. Trends Endocrinol Metab 11, 163-168.

Salvatori, R., Hayashida, C. Y., Aguiar-Oliveira, M. H. et al. (1999). Familial dwarfism due to a novel mutation of the growth hormone-releasing hormone receptor gene. J Clin Endocrinol Metab 84, 917-923.

Samama, P., Cotecchia, S., Costa, T. et al. (1993). A mutation-induced activated state of the $\beta_{2}$-adrenergic receptor. Extending the ternary complex model. J. Biol. Chem. 268, 46254635 . 
Samson, M., Libert, F., Doranz, B. J. et al. (1996). Resistance to HIV-1 infection of Caucasian individuals bearing mutant alleles of the CCR5 chemokine receptor gene. Nature 382, 722-725.

Sanchez, J. E., Perera, E., Baumbach, L. et al. (1998). Growth hormone receptor mutations in children with idiopathic short stature. J Clin Endocrinol Metab 83, 4079-4083.

Scheer, A., Costa, T., Fanelli, F. et al. (2000). Mutational analysis of the highly conserved arginine within the Glu/Asp-Arg-Tyr motif of the alpha(1b)-adrenergic receptor: effects on receptor isomerization and activation. Molecular Pharmacology 57, 219-231.

Scheer, A., Fanelli, F., Costa, T. et al. (1996). Constitutively active mutants of the $\alpha_{1 B^{-}}$ adrenergic receptor: role of highly conserved polar amino acids in receptor activation. EMBO J. 15, 3566-3578.

Scheer, A., Fanelli, F., Costa, T. et al. (1997). The activation process of the alpha1Badrenergic receptor: potential role of protonation and hydrophobicity of a highly conserved aspartate. Proc. Natl. Acad. Sci. USA 94, 808-813.

Schiff, M. L., Siderovski, D. P., Jordan, J. D. et al. (2000). Tyrosine-kinase-dependent recruitment of RGS12 to the N-type calcium channel. Nature 408, 723-727.

Schipani, E., Kruse, K. and Juppner, H. (1995). A constitutively active mutant PTH-PTHrP receptor in Jansen-type metaphyseal chondrodysplasia. Science 268, 98-100.

Schipani, E., Langman, C. B., Parfitt, A. M. et al. (1996). Constitutively activated receptors for parathyroid hormone and parathyroid hormone-related peptide in Jansen's metaphyseal chondrodysplasia. $N$ Engl J Med 335, 708-714.

Schlegel, W., Kempner, E. S. and Rodbell, M. (1979). Activation of adenylate cyclase in hepatic membranes involves interactions of the catalytic unit with multimeric complexes of regulatory proteins. J. Biol. Chem. 254, 5168-5176. 
Schmitt, J. M. and Stork, P. J. (2000). beta 2-adrenergic receptor activates extracellular signal-regulated kinases (ERKs) via the small G protein rap1 and the serine/threonine kinase B-Raf. J. Biol. Chem. 275, 25342-25350.

Schoneberg, T., Sandig, V., Wess, J. et al. (1997). Reconstitution of mutant V2 vasopressin receptors by adenovirus-mediated gene transfer. Molecular basis and clinical implication. J Clin Invest 100, 1547-1556.

Schoneberg, T., Yun, J., Wenkert, D. et al. (1996). Functional rescue of mutant V2 vasopressin receptors causing nephrogenic diabetes insipidus by a co-expressed receptor polypeptide. EMBO J. 15, 1283-1291.

Schulz, A., Grosse, R., Schultz, G. et al. (2000). Structural implication for receptor oligomerization from functional reconstitution studies of mutant V2 vasopressin receptors. J. Biol. Chem. 275, 2381-2389.

Sheikh, S. P., Vilardarga, J. P., Baranski, T. J. et al. (1999). Similar structures and shared switch mechanisms of the beta2-adrenoceptor and the parathyroid hormone receptor. Zn(II) bridges between helices III and VI block activation. J. Biol. Chem. 274, 17033 17041.

Sheikh, S. P., Zvyaga, T. A., Lichtarge, O. et al. (1996). Rhodopsin activation blocked by metal-ion-binding sites linking transmembrane helices C and F. Nature 383, 347-350.

Shenker, A., Laue, L., Kosugi, S. et al. (1993). A constitutively activating mutation of the luteinizing hormone receptor in familial male precocious puberty. Nature 365, 652-654.

Shichida, Y. and Imai, H. (1998). Visual pigment: G-protein-coupled receptor for light signals. Cell Mol Life Sci 54, 1299-1315.

Shields, J. E., Dinovo, E. C., Henriksen, R. A. et al. (1967). The purification and amino acid composition of bovine rhodopsin. Biochimica et Biophysica Acta 147, 238-251. 
Shiraishi, Y., Mizutani, A., Bito, H. et al. (1999). Cupidin, an isoform of Homer/Vesl, interacts with the actin cytoskeleton and activated rho family small GTPases and is expressed in developing mouse cerebellar granule cells. J. Neurosci. 19, 8389-8400.

Shorr, R. G., Lefkowitz, R. J. and Caron, M. G. (1981). Purification of the beta-adrenergic receptor. Identification of the hormone binding subunit. J. Biol. Chem. 256, 5820-5826.

Siderovski, D. P., Diverse-Pierluissi, M. and De Vries, L. (1999). The GoLoco motif: a Galphai/o binding motif and potential guanine-nucleotide exchange factor. Trends Biochem Sci 24, 340-341.

Simon, M. N., De Virgilio, C., Souza, B. et al. (1995). Role for the Rho-family GTPase Cdc42 in yeast mating-pheromone signal pathway. Nature 376, 702-705.

Sladeczek, F., Pin, J.-P., Récasens, M. et al. (1985). Glutamate stimulates inositol phosphate formation in striatal neurones. Nature 317, 717-719.

Smith, F. D., Oxford, G. S. and Milgram, S. L. (1999). Association of the D2 dopamine receptor third cytoplasmic loop with spinophilin, a protein phosphatase-1-interacting protein. J. Biol. Chem. 274, 19894-19900.

Snow, B. E., Hall, R. A., Krumins, A. M. et al. (1998). GTPase activating specificity of RGS12 and binding specificity of an alternatively spliced PDZ (PSD-95/Dlg/ZO-1) domain. J. Biol. Chem. 273, 17749-17755.

Sondek, J., Lambright, D. G., Noel, J. P. et al. (1994). GTPase mechanism of G proteins from $1.7 \AA$ crystal structure of transducin $\alpha$-GDP.AIF4. Nature 372, 276-279.

Songyang, Z., Fanning, A. S., Fu, C. et al. (1997). Recognition of unique carboxyl-terminal motifs by distinct PDZ domains. Science 275, 73-77.

Speca, D. J., Lin, D. M., Sorensen, P. W. et al. (1999). Functional identification of a goldfish odorant receptor. Neuron $\mathbf{2 3}, 487-498$. 
Spengler, D., Waeber, C., Pantaloni, C. et al. (1993). Differential signal transduction by five splice variants of the PACAP receptor. Nature 365, 170-175.

Spiegel, A. M. (1996). Defects in G protein-coupled signal transduction in human disease. Annu. Rev. Physiol. 58, 143-170.

Spiegel, A. M., Weinstein, L. S. and Shenker, A. (1993). Abnormalities in G protein-coupled signal transduction pathways in human disease. J. Clin. Invest. 92, 1119-1125.

Sprang, S. R. (1997). G protein mechanisms: insights from structural analysis. Annu.Rev.Biochem. 66, 639-678.

Stacey, M., Lin, H. H., Gordon, S. et al. (2000). LNB-TM7, a group of seven-transmembrane proteins related to family-B G-protein-coupled receptors. Trends Biochem Sci 25, 284289.

Stadel, J. M., Wilson, S. and Bergsma, D. J. (1997). Orphan G protein-coupled receptors: a neglected opportunity for pioneer drug discovery. Trends Pharmacol. Sci. 18, 430-437.

Strosberg, A. D. (1997). Association of beta 3-adrenoceptor polymorphism with obesity and diabetes: current status. Trends Pharmacol. Sci. 18, 449-454.

Sudol, M. (1998a). From Scr homology domains to other signaling modules: proposal of the 'protein recognition code'. Oncogene 17, 1469-1474.

Sudol, M. (1998b). From Src Homology domains to other signaling modules: proposal of the 'protein recognition code'. Oncogene 17, 1469-1474.

Sunahara, R. K., Tesmer, J. J., Gilman, A. G. et al. (1997). Crystal structure of the adenylyl cyclase activator Gsalpha. Science 278, 1943-1947.

Sung, C. H., Makino, C., Baylor, D. et al. (1994). A rhodopsin gene mutation responsible for autosomal dominant retinitis pigmentosa results in a protein that is defective in localization to the photoreceptor outer segment. J. Neurosci. 14, 5818-5833. 
Sutherland, E. W. and Rall, T. W. (1958). Fractionation and characterization of a cyclic adenine ribonucleotide formed by tissue. J. Biol.Chem 232, 1077-1091.

Swanson, J., Oosterlaan, J., Murias, M. et al. (2000). Attention deficit/hyperactivity disorder children with a 7-repeat allele of the dopamine receptor D4 gene have extreme behavior but normal performance on critical neuropsychological tests of attention. Proc. Natl. Acad. Sci. USA 97, 4754-4759.

Tadokoro, S., Tachibana, T., Imanaka, T. et al. (1999). Involvement of unique leucine-zipper motif of PSD-Zip45 (Homer 1c/vesl-1L) in group 1 metabotropic glutamate receptor clustering. Proc. Natl. Acad. Sci. USA 96, 13801-13806.

Tai, A. W., Chuang, J. Z., Bode, C. et al. (1999). Rhodopsin's carboxy-terminal cytoplasmic tail acts as a membrane receptor for cytoplasmic dynein by binding to the dynein light chain Tctex-1. Cell 97, 877-887.

Takeda, H., Matozaki, T., Takada, T. et al. (1999). PI 3-kinase gamma and protein kinase Czeta mediate RAS-independent activation of MAP kinase by a Gi protein-coupled receptor. EMBO J. 18, 386-395.

Talbodec, A., Berkane, N., Blandin, V. et al. (2000). Aspirin and sodium salicylate inhibit endothelin ETA receptors by an allosteric type of mechanism. Mol. Pharmacol. 57, 797 804.

Tang, W. and A.G., G. (1991). Type-specific regulation of adenylyl cyclase by G protein $\beta \gamma$ subunits. Science 254, 1500-1503.

Tarasova, N. I., Rice, W. G. and Michejda, C. J. (1999). Inhibition of G-protein-coupled receptor function by disruption of transmembrane domain interactions. J. Biol. Chem. 274, 34911-34915. 
Tatemoto, K., Hosoya, M., Habata, Y. et al. (1998). Isolation and characterization of a novel endogenous peptide ligand for the human APJ receptor. Biochem. Biophys. Res. Commun. 251, 471-476.

Taylor, J. M., Jacob-Mosier, G. G., Lawton, R. et al. (1994). Binding of an $\alpha_{2}$ adrenergic

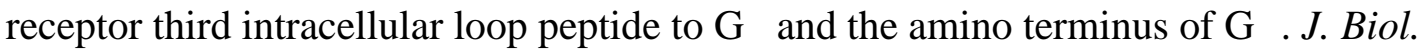
Chem. 269, 27618-27624.

Taylor, J. M., Jacob-Mosier, G. G., Lawton, R. et al. (1996). Receptor and membrane interaction sites on G $\beta$. A receptor-derived peptide binds to the carboxyl terminus. $J$. Biol. Chem. 271, 3336-3339.

Tesmer, J. G., Berman, D. M., Gilman, A. G. et al. (1997a). Structure of RGS4 bound to AlF4--activated Gio1: stabilization of the transition state for GTP hydrolysis. Cell 89, 251-261.

Tesmer, J. J. G., Sunahara, R. K., Gilman, A. G. et al. (1997b). Crystal structure of the catalytic domains of adenylyl cyclase in a complex with Gs $\alpha$ GTP $\gamma$ S. Science 278, 19071916.

Thannickal, T. C., Moore, R. Y., Nienhuis, R. et al. (2000). Reduced number of hypocretin neurons in human narcolepsy. Neuron 27, 469-474.

Themmen, A. P., Martens, J. W. and Brunner, H. G. (1997). Gonadotropin receptor mutations. J Endocrinol 153, 179-183.

Thompson, J. D., Gibson, T. J., Plewniak, F. et al. (1997). The CLUSTAL:X windows interface: flexible strategies for multiple sequence alignment aided by quality analysis tools. Nucleic Acids Research 25, 4876-4882.

Tota, M. R. and Strader, C. D. (1990). Characterization of the binding domain of $\beta$-adrenergic receptor with the fluorescent antagonist carazolol. Evidence for a buried ligand binding site. J. Biol. Chem. 26, 16891-16897. 
Tsang, S. H., Burns, M. E., Calvert, P. D. et al. (1998). Role for the target enzyme in deactivation of photoreceptor G protein in vivo. Science 282, 117-121.

Tsao, P. and Zastrow, M. (2000). Down-regulation of G protein-coupled receptors. Curr. Opin. Neurobiol. 10, 365-369.

Tsigos, C., Arai, K., Hung, W. et al. (1993). Hereditary isolated glucocorticoid deficiency is associated with abnormalities of the adrenocorticotropin receptor gene. J Clin Invest $\mathbf{9 2}$, $2458-2461$.

Tsuji, Y., Shimada, Y., Takeshita, T. et al. (2000). Cryptic dimer interface and domain organization of the extracellular region of metabotropic glutamate receptor subtype $1 . J$. Biol. Chem. 275, 28144-28151.

Tsunoda, S., Sierralta, J., Sun, Y. et al. (1997). A multivalent PDZ-domain protein assembles signalling complexes in a G-protein-coupled cascade. Nature 388, 243-249.

Tu, J. C., Xiao, B., Naisbitt, S. et al. (1999). Coupling of mGluR/Homer and PSD-95 complexes by the Shank family of postsynaptic density proteins. Neuron $\mathbf{2 3}, 583-592$.

Tu, J. C., Xiao, B., Yuan, J. P. et al. (1998). Homer binds a novel proline-rich motif and links group 1 metabotropic glutamate receptors with IP3 receptors. Neuron 21, 717-726.

Ullmer, C., Schmuck, K., Figge, A. et al. (1998). Cloning and characterization of MUPP1, a novel PDZ domain protein. FEBS Lett. 424, 63-68.

Umemori, H., Inoue, T., Kume, S. et al. (1997). Activation of the G protein Gq/11 through tyrosine phosphorylation of the alpha subunit. Science 276, 1878-1881.

Unger, V. M., Hargrave, P. M., Baldwin, J. M. et al. (1997). Arrangement of rhodopsin transmembrane alpha-helices. Nature 389, 203-206.

Usiello, A., Baik, J.-H., Rougé-Pont, F. et al. (2000). Distinct functions of the two isoforms of dopamine D2 receptors. Nature 408, 199-203. 
Vaisse, C., Clement, K., Guy-Grand, B. et al. (1998). A frameshift mutation in human MC4R is associated with a dominant form of obesity [letter]. Nat Genet 20, 113-114.

Van Sande, J., Parma, J., Tonacchera, M. et al. (1995). Somatic and germline mutations of the TSH receptor gene in thyroid diseases. J. Clin. Endocrinol. Metab. 80, 2577-2585.

Varrault, A., Bockaert, J. and Waeber, C. (1992). Activation of 5- $\mathrm{HT}_{1 \mathrm{~A}}$ receptors expressed in NIH-3T3 cells induces focus formation and potentiates EGF effect on DNA synthesis. Mol. Biol. Cell 3, 961-969.

Venema, R. C., Ju, H., Venema, V. J. et al. (1998). Angiotensin II-induced association of phospholipase Cgamma1 with the G-protein-coupled AT1 receptor. J. Biol. Chem. 273, 7703-7708.

Vernier, P., Cardinaud, B., Valdenaire, O. et al. (1995). An evolutionary view of drugreceptor interaction: the bioamine receptor family. Trends Pharmacol. Sci. 16, 375-381.

Vila-Coro, A. J., Mellado, M., Martin de Ana, A. et al. (2000). HIV-1 infection through the CCR5 receptor is blocked by receptor dimerization. Proc. Natl. Acad. Sci. USA 97, 33883393.

Vila-Coro, A. J., Rodriguez-Frade, J. M., Martin De Ana, A. et al. (1999). The chemokine SDF-1alpha triggers CXCR4 receptor dimerization and activates the JAK/STAT pathway. Faseb J 13, 1699-1710.

Vosshall, L. B., Amrein, H., Morozov, P. S. et al. (1999). A spatial map of olfactory receptor expression in the Drosophila antenna. Cell 96, 725-736.

Vossler, M. R., Yao, H., York, R. D. et al. (1997). cAMP activates MAP kinase and Elk-1 through a B-Raf-and Rap1-dependent pathway. Cell 89, 73-82.

Vuong, T. M. and Chabre, M. (1990). Subsecond deactivation of transducin by endogenous GTP hydrolysis. Nature 346, 71-74. 
Wajnrajch, M. P., Gertner, J. M., Harbison, M. D. et al. (1996). Nonsense mutation in the human growth hormone-releasing hormone receptor causes growth failure analogous to the little (lit) mouse. Nat Genet 12, 88-90.

Wall, M. A., Coleman, D. E., Lee, E. et al. (1995). The structure of the G protein heterotrimer. Cell 83, 1047-1058.

Wedegaertner, P. B. and Bourne, H. (1994). Activation and depalmitoylation of Gsa. Cell 77, 1063-1070.

Weiner, N. (1961). Cybernetics: or control and communication in the animal and the machine. MIT Press, Cambridge, Massachusetts, USA.

Weiss, E. R., Osawa, S., Shi, W. et al. (1994). Effects of carboxyl-terminal truncation on the stability and G protein-coupling activity of bovine rhodopsin. Biochemistry 33, 75877593.

Wells, T. N. and Schwartz, T. W. (1997). Plagiarism of the host immune system: lessons about chemokine immunology from viruses. Curr. Opin. Biotechnol. 8, 741-748.

Wess, J. (1997). G-protein-coupled receptors: molecular mechanisms involved in receptor activation and selectivity of G-protein recognition. FASEB J. 11, 346-354.

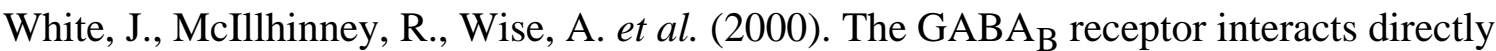
with the related transcription factors CREB2 and ATFx. Proc. Natl. Acad. Sci. USA 97, $13967-13972$.

White, J. H., Wise, A., Main, M. J. et al. (1998). Heterodimerization is required for the formation of a functional $\mathrm{GABA}_{\mathrm{B}}$ receptor. Nature 396, 679-682.

Wieland, T. and Chen, C. K. (1999). Regulators of G-protein signalling: a novel protein family involved in timely deactivation and desensitization of signalling via heterotrimeric G proteins. Naunyn Schmiedebergs Arch Pharmacol 360, 14-26. 
Wilson, S., Bergsma, D. J., Chambers, J. K. et al. (1998). Orphan G-protein-coupled receptors: the next generation of drug targets? Br J Pharmacol 125, 1387-1392.

Wojcik, J., Berg, M. A., Esposito, N. et al. (1998). Four contiguous amino acid substitutions, identified in patients with Laron syndrome, differently affect the binding affinity and intracellular trafficking of the growth hormone receptor. J Clin Endocrinol Metab 83, 4481-9.

Wreggett, K. A. and De Lean, A. (1984). The ternary complex model. Its properties and application to ligand interactions with the D2-dopamine receptor of the anterior pituitary gland. Mol. Pharmacol. 26, 214-27.

Xiao, B., Tu, J. C., Petralia, R. S. et al. (1998). Homer regulates the association of group 1 metabotropic receptors with multivalent complexes of Homer-related, synaptic proteins. Neuron 21, 701-716.

Xiao, B., Tu, J. C. and Worley, P. F. (2000). Homer: a link between neural activity and glutamate receptor function. Curr. Opin. Neurobiol. 10, 370-4.

Xu, N., Voyno-Yasenetskaya, T. and Gutkind, J. S. (1994). Potent transforming activity of the G13 alpha subunit defines a novel family of oncogenes. Biochem. Biophys. Res. Commun. 201, 603-9.

Xu, X. Z., Choudhury, A., Li, X. et al. (1998). Coordination of an array of signaling proteins through homo- and heteromeric interactions between PDZ domains and target proteins. $J$ Cell Biol 142, 545-55.

Xu, Y. K. and Nusse, R. (1998). The Frizzled CRD domain is conserved in diverse proteins including several receptor tyrosine kinases [letter]. Curr. Biol. 8, R405-6.

Yamashita, S., Mochizuki, N., Ohba, Y. et al. (2000). CalDAG-GEFIII activation of Ras, Rras, and Rap1. J. Biol. Chem. 275, 25488-93. 
Yeo, G. S., Farooqi, I. S., Aminian, S. et al. (1998). A frameshift mutation in MC4R associated with dominantly inherited human obesity [letter]. Nat Genet 20, 111-2.

Yokoyama, S., Zhang, H., Radlwimmer, F. B. et al. (1999). Adaptive evolution of color vision of the Comoran coelacanth (Latimeria chalumnae). Proc. Natl. Acad. Sci. USA 96, $6279-84$.

Zeng, F. Y. and Wess, J. (1999). Identification and molecular characterization of m3 muscarinic receptor dimers. J. Biol. Chem. 274, 19487-97.

Zhang, P., Jobert, A. S., Couvineau, A. et al. (1998). A homozygous inactivating mutation in the parathyroid hormone/parathyroid hormone-related peptide receptor causing Blomstrand chondrodysplasia. J Clin Endocrinol Metab 83, 3365-8.

Zhou, W., Flanagan, C., Ballesteros, J. A. et al. (1994). A reciprocal mutation supports helix 2 and helix 7 proximity in gonodotropin-releasing hormone receptor. Mol. Pharmacol. 45, 165-170.

Zhou, X.-M. and Fishman, P. H. (1991). Desensitization of the human $\beta_{1}$-adrenergic receptor. J. Biol. Chem. 266, 7462-7468.

Zhu, X. and Wess, J. (1998). Truncated V2 vasopressin receptors as negative regulators of wild-type V2 receptor function. Biochemistry 37, 15773-84.

Zitzer, H., Honck, H. H., Bachner, D. et al. (1999a). Somatostatin receptor interacting protein defines a novel family of multidomain proteins present in human and rodent brain. $J$. Biol. Chem. 274, 32997-3001.

Zitzer, H., Richter, D. and Kreienkamp, H. J. (1999b). Agonist-dependent interaction of the rat somatostatin receptor subtype 2 with cortactin-binding protein 1. J. Biol. Chem. 274, 18153-6.

Zwick, E., Hackel, P. O., Prenzel, N. et al. (1999). The EGF receptor as central transducer of heterologous signalling systems. Trends Pharmacol. Sci. 20, 408-12. 


\section{Abbreviations}

$\alpha$-AR: $\quad \alpha$-adrenergic receptor

AC: $\quad$ Adenylyl cyclase

ACTH: Adreno-corticotropin hormone

AGS: $\quad$ Activator of $\mathrm{G}$ protein signaling

AID: $\quad$ Acquired immuno-deficiency

AKAP: $\quad$ A-kinase anchoring protein

AlF4-: $\quad$ Fluoroaluminate

AP2: $\quad$ adaptin 2

APC: $\quad$ Adenomatous polyposis coli

ARF: $\quad$ ADP-ribosylation factor

AT: $\quad$ Angiotensin

ATP: $\quad$ Adenosine trisphosphate

BAI-1: Brain specific angio-genesis inhibitor

$\beta$-AR: $\quad \beta$-adrenergic receptor

$\beta$-ARK: $\quad \beta$-adrenergic receptor kinase

BRET: Bioluminescence resonance energy transfer

CASR: $\quad$ Calcium sensing receptor

CB2: $\quad$ Cannabinoid receptor 2

CCR4: $\quad$ Chemokine receptor 4

CortBP1: $\quad$ Cortactin binding protein 1

CRF: Corticotropin-releasing factor

CRLR: Calcitonin receptor-like receptor

DAG: Diacylglycerol 
DMCM: $\quad$ Methyl 6,7-dimethoxy-4-ethyl- $\beta$-carboline-e-carboxylate

EBP: $\quad$ Erzin-radixin-moesin binding protein-50

EGF: $\quad$ Epidermal growth factor

EMR1: $\quad$ Human cell specific surface glycoprotein F4/80

Ena: $\quad$ Drosophila enabled

eNOS: $\quad$ Endothelial-type NO-synthase

Epac: $\quad$ Exchange protein directly activated by cAMP

ERK: $\quad$ Extracellular regulated kinase

EST: $\quad$ Expressed sequence tags

EVH1: $\quad$ Ena/WASp homology domain 1

FRET: $\quad$ Fluorescence resonance energy transfer

FSH: $\quad$ Follicle-stimulating hormone

GABA: Gamma aminobutyric acid

GAIP: $\quad$ G $\alpha$-interacting protein

GAP: $\quad$ GTPase activating protein

Gat: $\quad$ Transducin

GEF: Guanine nucleotide exchange factor

GH: $\quad$ Growth hormone

GHRH: $\quad$ Growth hormone releasing hormone

GIRK: $\quad$ G-protein-coupled inward rectifying potassium channel

GKAP: $\quad$ Guanylate kinase-associated protein

GnRH: Gonadotropin releasing hormone

GPCR: $\quad$ G-protein coupled receptors

G protein: $\quad$ GTP binding protein

GR: $\quad$ Gustatory receptor 


$\begin{array}{ll}\text { GRF: } & \text { GDP releasing factor } \\ \text { GRK: } & \text { GPCR-activated kinases } \\ \text { GDP: } & \text { Guanosine diphosphate } \\ \text { GTP: } & \text { Guanosine triphosphate } \\ \text { hCG: } & \text { Human chorionic gonadotrophin } \\ \text { HEK: } & \text { Human embryonic kidney (cells) } \\ \text { HIV: } & \text { High performance liquid chromatography } \\ \text { HPLC: } & \text { Immediate early gene } \\ \text { IEG: } & \text { Inactivating no after-potential } \\ \text { INAD: } & \text { Inositol trisphosphate } \\ \text { IP3: } & \text { Interferon- } \gamma \text {-inducible protein } \\ \text { IP10: } & \text { Luteneizing hormone } \\ \text { LH: } & \text { Caenorhabditis elegans frizzled-like receptor } \\ \text { LIN-7: } & \end{array}$

LNB-TM-VII: Seven TM domains containing a long N-terminal extracellular region

LPA: $\quad$ Lyso-phosphatidic acid

LPS: $\quad$ Lipopolysaccharide

mGluR: $\quad$ Metabotropic glutamate receptor

MIP-1 $\alpha \quad$ Macrophage inflammatory protein- $1 \alpha$

MOM-5: $\quad$ Caenorhabditis elegans frizzled-like receptor

MUPP1: $\quad$ Multi-PDZ domain protein

NDI: $\quad$ Nephrogenic diabetes insipidus

NEHRF: $\quad \mathrm{Na}^{+} / \mathrm{H}^{+}$exchanger regulator factor

NGF: $\quad$ Nerve growth factor

NK1: $\quad$ Neurokinin 1 
nNOS: $\quad$ Neuronal-type NO synthase

NSF: $\quad$ N-ethylmaleimide-sensitive fusion protein

P2Y-h: Purinergic P2Y-receptor

PACAP: $\quad$ Pituitary adenylate cyclase activating polypeptide

PAR: $\quad$ Protease activated GPCRs

PDE: $\quad$ Phosphodiesterase

PDGF: $\quad$ Platelet-derived growth factor

PDZ: $\quad$ A domain present in $\underline{\mathbf{P} S D 95}$ and its Drosophila analog $\underline{\mathbf{D}}$ isc-large tumor suppressor gene and in tight junction protein $\underline{\mathbf{Z}} \mathrm{O}-1$

PICK: $\quad$ Protein interacting $\mathrm{C}$ kinase

PCK: Protein kinase C

PLC: $\quad$ Phospholipase C

PM: $\quad$ Plasma membrane

ProSAP: $\quad$ Proline-rich synapse-associated protein

PrP: $\quad$ Prion protein

PTH: $\quad$ Parathyroid hormone

R: $\quad$ Receptor under an inactive state

$\mathrm{R}^{*}: \quad$ Receptor under an active state

RAMP: $\quad$ Receptor activity-modifying protein

RANTES: $\quad$ Regulated upon activation, normal T-cell expressed and secreted

RGS: $\quad$ Regulator of G protein signaling

ROCK: $\quad$ Rho-activated coiled-coil forming kinase

RP: $\quad$ Retinitis pigmentosa

SDF-1: $\quad$ Stromal derived factor-1

SH3: $\quad$ Scr homology domain 3 
SST: $\quad$ Somatostatin

SST2: $\quad$ Somatostatin receptor 2

SSTRIP: $\quad$ Somatostatin interacting protein

TM: $\quad$ Transmembrane domain

TNF: $\quad$ Tumor necrosis factor

TRK: $\quad$ Tyrosine receptor kinase

TRP: $\quad$ Transient receptor potential calcium channel

TSH: $\quad$ Thyroid-stimulating hormone

VASP: $\quad$ Vasodilator-stimulated phospho-protein

VIP: $\quad$ Vasoactive intestinal peptide

WASp: $\quad$ Wiskott-Aldrich syndrome protein

WD repeat: Tryptophan-aspartate repeat 
Family 3

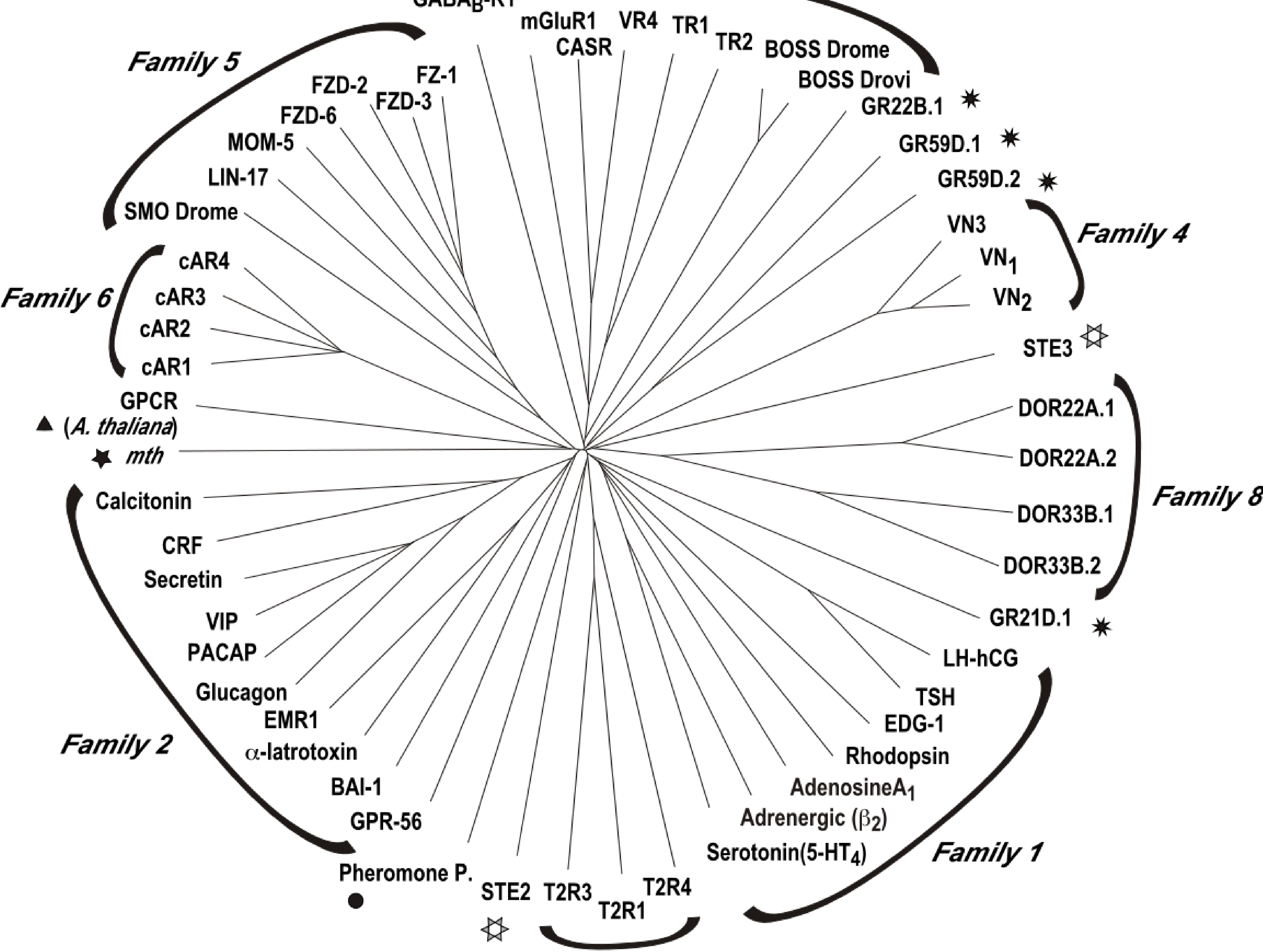

Family 7 

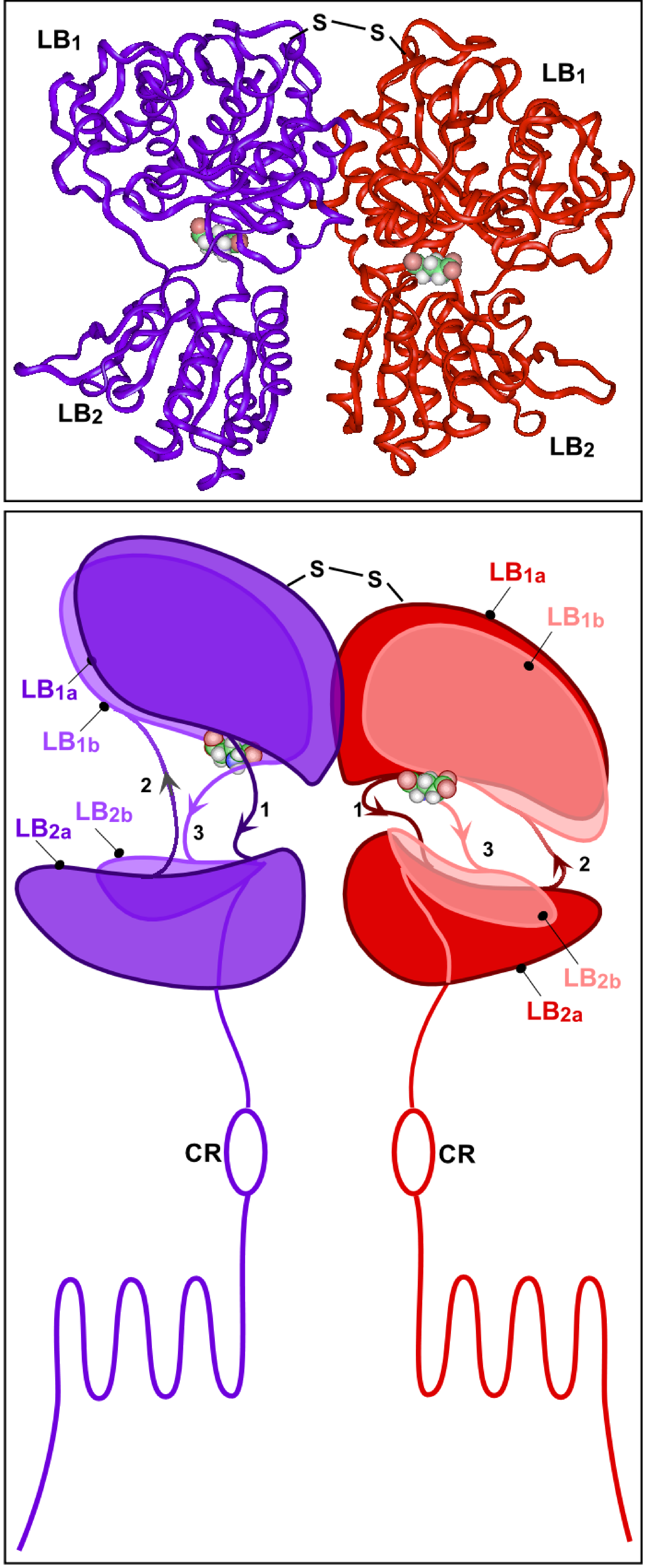

Figure 4 
$\downarrow$ EVH1-domain

Homer 1a

Q Homer 1b,2,3

Homer ligand

PDZ-ligand

- PDZ-domain

\& $\mathrm{SH}_{3}$-domain

* SAM-domain

$\square$ Guanylyl kinase domain

- Glutamate

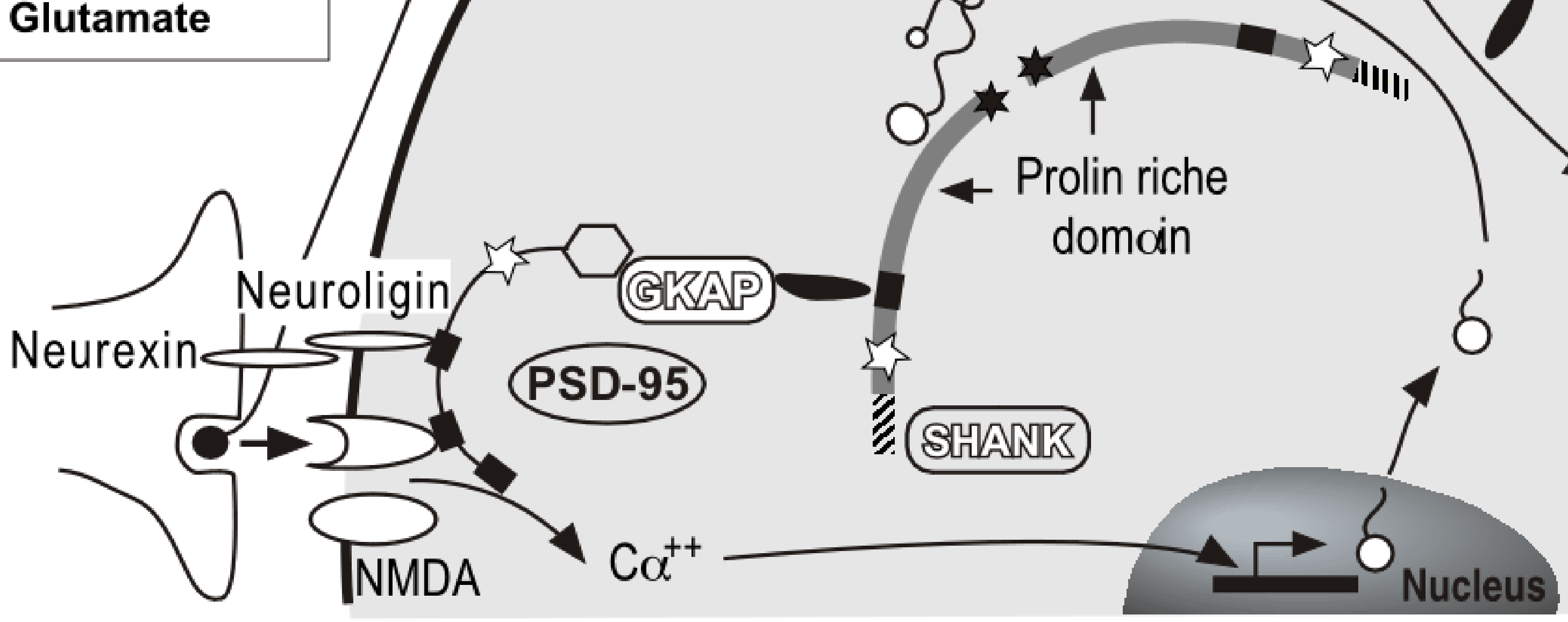


